\title{
A Phase Separation Study of Biological Polymers in Solid State Films
}

Jaclyn Nicole Kokx

West Virginia University

Follow this and additional works at: https://researchrepository.wvu.edu/etd

\section{Recommended Citation}

Kokx, Jaclyn Nicole, "A Phase Separation Study of Biological Polymers in Solid State Films" (2012). Graduate Theses, Dissertations, and Problem Reports. 3492.

https://researchrepository.wvu.edu/etd/3492

This Thesis is protected by copyright and/or related rights. It has been brought to you by the The Research Repository @ WVU with permission from the rights-holder(s). You are free to use this Thesis in any way that is permitted by the copyright and related rights legislation that applies to your use. For other uses you must obtain permission from the rights-holder(s) directly, unless additional rights are indicated by a Creative Commons license in the record and/ or on the work itself. This Thesis has been accepted for inclusion in WVU Graduate Theses, Dissertations, and Problem Reports collection by an authorized administrator of The Research Repository @ WVU. For more information, please contact researchrepository@mail.wvu.edu. 


\title{
A Phase Separation Study of Biological Polymers in Solid State Films
}

\author{
Jaclyn Nicole Kokx \\ Thesis submitted to the \\ College of Engineering and Mineral Resources \\ at West Virginia University \\ in partial fulfillment of the requirements \\ for the degree of \\ Master of Science \\ In \\ Mechanical Engineering
}

Robin S. Hissam, Ph.D., Chair

Edward Sabolsky, Ph.D., Co-Chair

Daneesh Simien, Ph.D.

Department of Mechanical Engineering

Morgantown, West Virginia

2012 


\section{Abstract \\ A Phase Separation Study of Biological Polymers in Solid State Films Jaclyn N. Kokx}

A growing need for nanoparticle-polymeric composite materials in the electronics and coatings industries has driven research to gain a better understanding of the mechanisms of self-assembled phase separation in polymer thin films and experiment with controlling the phase separation behavior of multicomponent polymer systems. This research proposed that biological polymers have the ability to phase separate into defined structures capable of organizing nanoparticles with unparallel control over the architecture of the molecule compared to synthetic polymers.

This study used recombinant DNA techniques and the expression host E. coli to accurately and repeatedly produce a peptide with a random coil secondary structure. The peptide was blended with synthetic polymers or other peptides, and dried into films on silicon wafers. The films were evaluated with SEM and tapping mode AFM to assess the organizational behavior of multicomponent macromolecular systems. Some films were also exposed to nickel nanoparticles to investigate whether preferential binding to the peptide could organize nanoparticles in a composite material.

Promising AFM phase images of a hybrid blend of PAA and (GAGPGP) ${ }_{12}$ peptide suggest phase separation, but when Ni nanoparticles were added, the nanoparticles only appeared to be welldispersed and not necessarily organized in one phase domain. A blend of the slightly hydrophobic (GAGPGP) ${ }_{12}$ peptide and a negatively charged peptide called VA2 also demonstrated signs of phase separation in the AFM phase images taken. However, when the film was exposed to a solution of $\mathrm{Ni}$ nanoparticles at high $\mathrm{pH}$ or the two peptides were coupled together, the film morphology changed drastically and no signs of phase separation were observed. The results of this research are significant because they suggest that biological polymers may phase separate in solid state films which is promising for various biomedical applications and is intriguing from a basic science point of view. 


\section{Acknowledgments}

I would like to take the time to thank all those that have helped make this research possible. First, I am sincerely grateful to my advisor, Dr. Robin Hissam for her support. Throughout the last two years she has encouraged, pushed, and guided my research efforts every step of the way. Truly, without her this research would not have been possible. I would also like to thank the members of my committee, Dr. Ed Sabolsky and Dr. Daneesh Simien for their consideration of my research, their advice throughout this work, and their feedback from my thesis. Although he was not officially on my committee, I would also like to thank Dr. Charter Stinespring for the opportunity to use his AFM instrument and for the time he always made for me when I had questions or needed advice about characterizing my films.

Without the help of a few very generous fellow graduate students I would not have gained all of the knowledge and data presented in characterization of my samples. I would like to thank Adrienne McGraw for imaging countless films with SEM and for always being willing to squeeze in my extra samples when she had a couple moments of free time. I am grateful to Srikanth Raghavan for taking the time to graciously teach me how to use the AFM instrument employed for characterizing many of the films mentioned in my thesis work. I thank Adam Finniss for his efforts in helping me obtain the DSC data, and Brian Train for the time he spent running the CD instrument that was essential in characterizing the secondary structure of my peptide. I am also grateful to Dr. Yogesh Kulkarni for taking time out of his own research to assistant me in the development of the Western Blot films presented in this work.

I would also like to thank my fellow lab members in Dr. Hissam's lab, especially Andrew Graves, McKenzie Mills, and A.J. Kosteleski for their help and their willingness to let me talk through new ideas and troublesome results with them. I thank Debbie Willis for navigating me through the process of graduating and for having the answers to all of my questions. I am also genuinely grateful to Jim Hall for all of his efforts to make sure our lab run as smoothly as possible. His help allowed me and many others to carry out our research without major setbacks.

Lastly, I want to convey my appreciation to my family and friends for their unwavering support and encouragement. I am grateful for the countless conversations about my research they endured and for their motivating words of wisdom. I am especially grateful to my parents for instilling in me the benefits of hard work and the appreciation for education. And to conclude, I would like to thank my husband, Tony Kokx for his support throughout this process and for his unwavering dedication to the life we have built together. 


\section{Table of Contents}

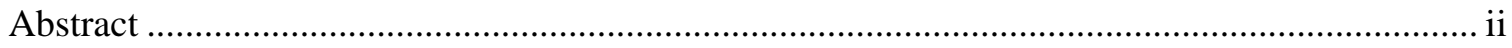

Acknowledgments ................................................................................................................. iii

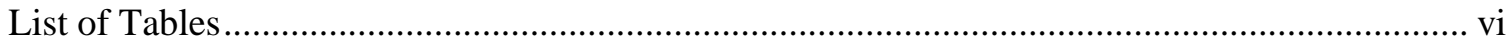

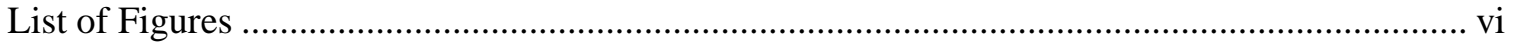

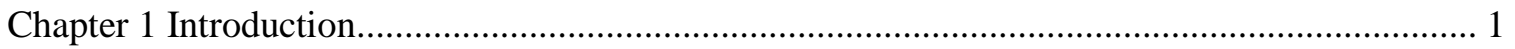

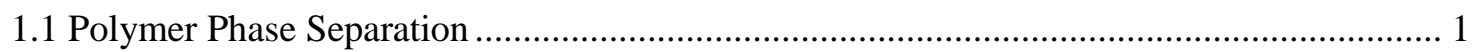

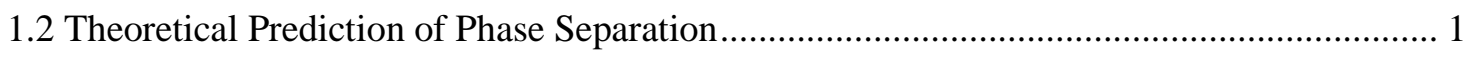

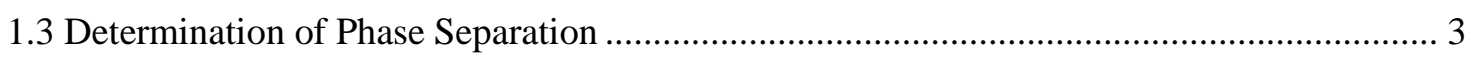

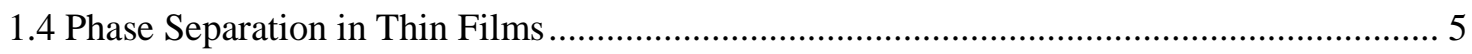

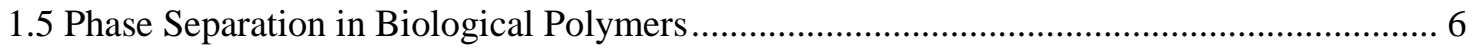

1.6 Phase Separation to Organize Nanoparticles..................................................................... 9

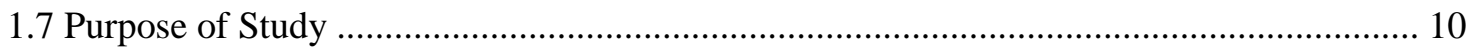

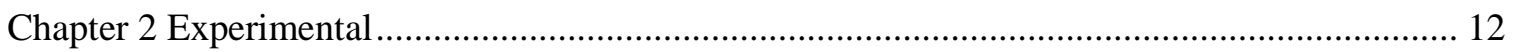

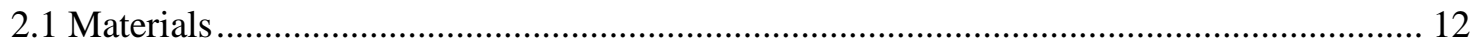

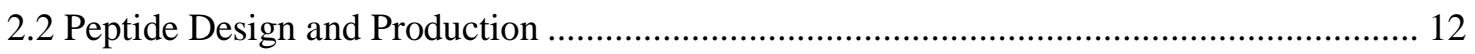

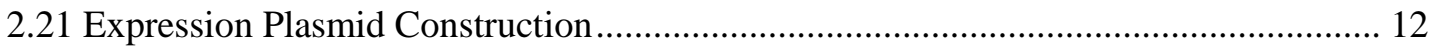

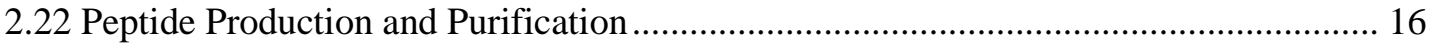

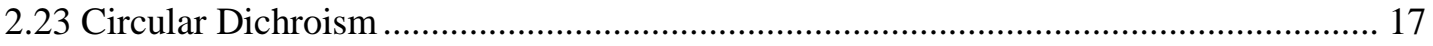

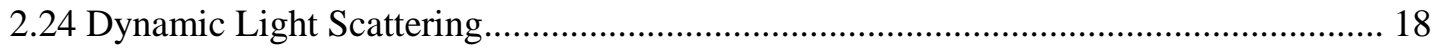

2.3 Hybrid Block Copolymer and Biological Block Copolymer Production............................ 18

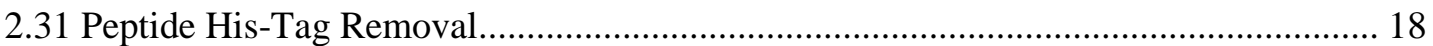

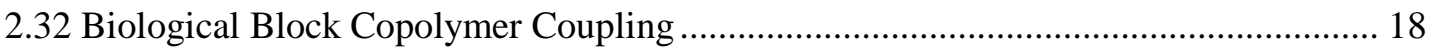

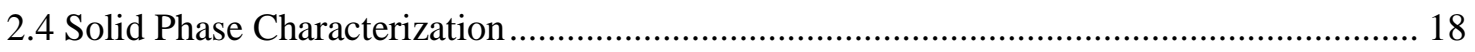

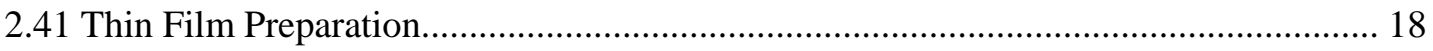

2.42 Nickel Nanoparticle Synthesis and Composite Preparation .......................................... 19

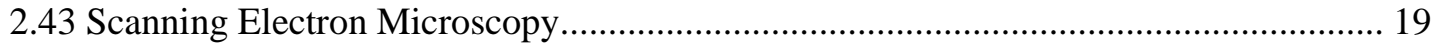

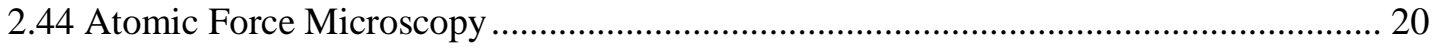

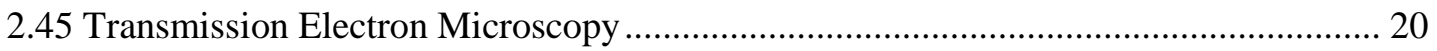

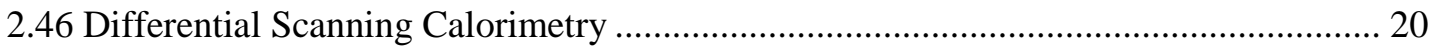

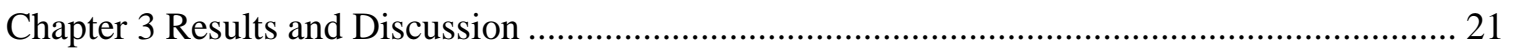

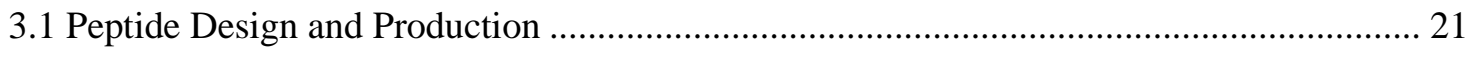

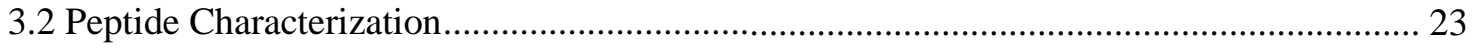


3.3 Hybrid Synthetic Biological Polymer Blends ............................................................... 31

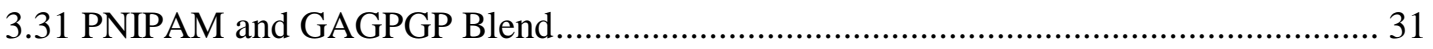

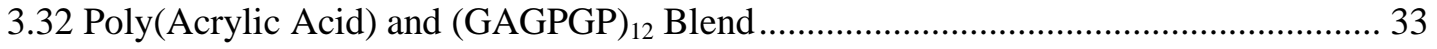

3.4 Peptide-Peptide Biological Polymer Blends and Block Copolymers .................................. 38

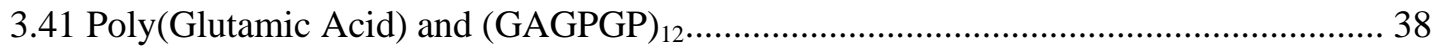

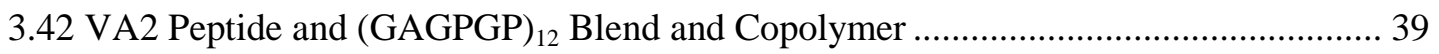

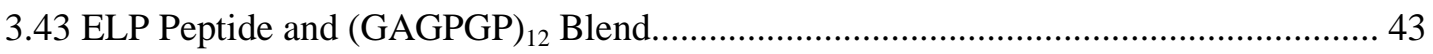

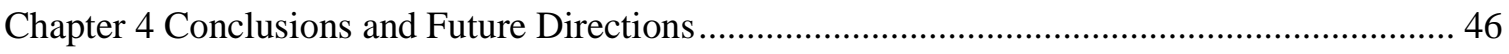

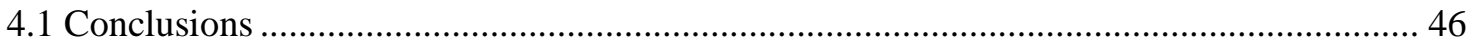

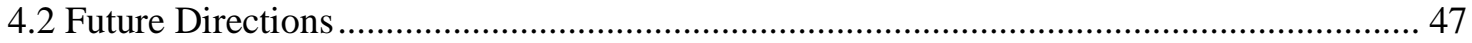

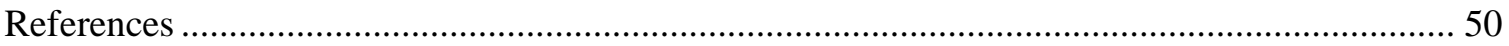

Appendix A: Nucleotide Analysis of the DNA coding for (GAGPGP) 12 .................................... 56

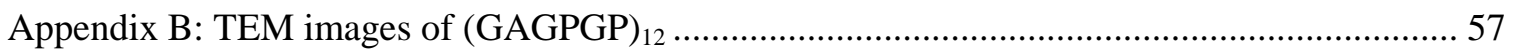

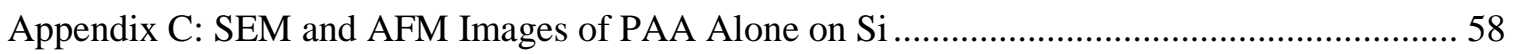

Appendix D: Spin-Coated and $90^{\circ} \mathrm{C}$ Drying Temperature PAA/(GAGPGP) ${ }_{12}$ Blend Samples ... 59

Appendix E: AFM analysis of a 9:1 wt\% PAA/(GAGPGP) ${ }_{12}$ Blend ............................................ 60

Appendix F: SEM Images of Ni Nanoparticles in (GAGPGP) ${ }_{12}$ Films ....................................... 61

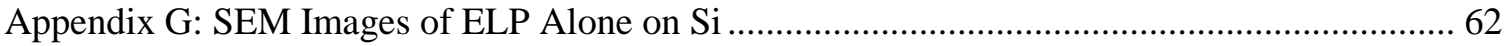

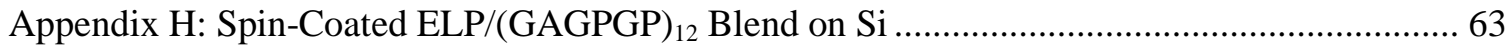

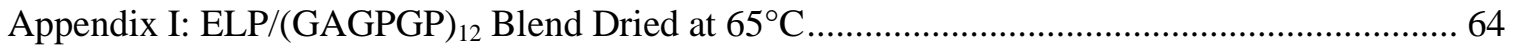

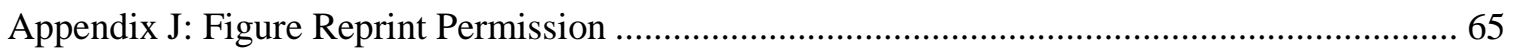




\section{List of Tables}

Table 1 Amino acid analysis results of the (GAGPGP) 12 peptide ................................................ 25

Table 2 DLS results of (GAGPGP) ${ }_{12}$ and the hybrid block copolymers in water ........................ 49

\section{List of Figures}

Figure 1. Two component polymer blend phase diagram. Reprinted with permission from Science 251, 898-905. Copyright 1991 AAAS $^{2}$ 3

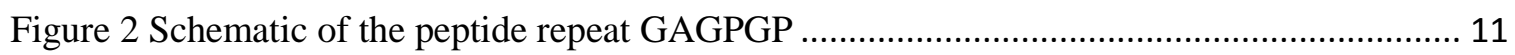

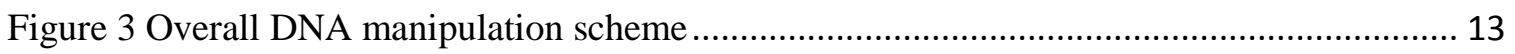

Figure 4 Vector map of a normal pET-19b expression plasmid ${ }^{65}$.............................................. 14

Figure 5 DNA sequence, amino acid translation, and restriction enzyme cleavage locations of A)

the G-over insert and B) the GAGP insert sequence used to construct the expression plasmid ... 15 Figure 6 A) Successful digestion of pET-19b with Bam HI and Nco I restriction enzymes, and B) Successful digestion of pJ201-G-over with Bam HI and Nco I restriction enzymes. 21

Figure 7 A) Successful Sap I digestion of pET-19b-G-over, and B) successful Sap I digestion of

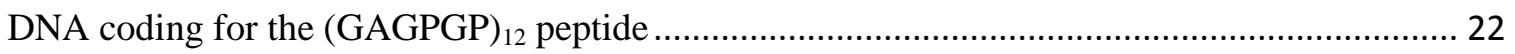

Figure 8 DNA coding for (GAGPGP) $)_{12}$ ligated into G-over/pET-19b ........................................ 23

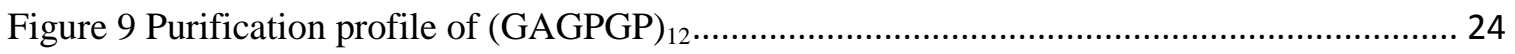

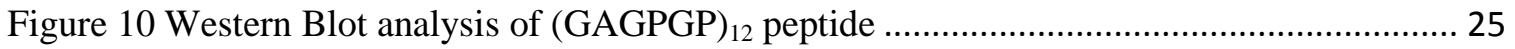

Figure $11 \mathrm{CD}$ evaluation of $0.5 \mathrm{mg} / \mathrm{mL}$ (GAGPGP) 12 in non-buffered water .............................. 26

Figure 12 SEM image of a $2 \mathrm{mg} / \mathrm{mL}$ solution of (GAGPGP) $)_{12}$ in water dried onto Si ................. 27

Figure 13 A) Detailed SEM image of (GAGPGP) ${ }_{12}$ taken at the edge of the sample and, B)

Detailed SEM image of (GAGPGP) $)_{12}$ taken at the center of the sample .................................... 27

Figure 14 AFM topology (left) and phase (right) analysis of (GAGPGP) ${ }_{12}$ dried at room temperature on $\mathrm{Si}$.

Figure 15 A) SEM image of spin coated (GAGPGP) $)_{12}$ on Si taken at the edge of the sample and,

B) SEM image of spin coated (GAGPGP) $)_{12}$ on Si in the center of the sample ............................. 29

Figure 16 DLS results of a $1 \mathrm{mg} / \mathrm{mL}$ solution of (GAGPGP) ${ }_{12}$ in water..................................... 30

Figure 17 AFM topography (left) and phase (right) images of PNIPAM/(GAGPGP) ${ }_{12}$ blend dried

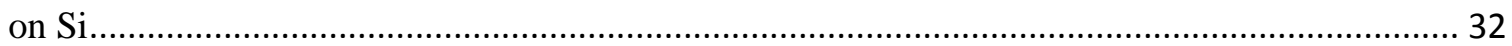

Figure 18 SEM image of dried solution of $2 \mathrm{mg} / \mathrm{mL}$ PAA/(GAGPGP) $)_{12}$ 1:1 wt ratio blend on Si33 Figure 19 AFM topography image (left) and phase image (right) of dried droplet of $2 \mathrm{mg} / \mathrm{mL}$

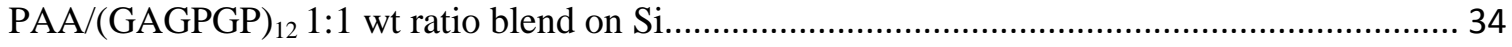

Figure 20 DSC results of (GAGPGP) $)_{12}$, PAA, drop cast PAA, and the PAA/(GAGPGP) ${ }_{12}$ blend36

Figure 21 SEM image of a PAA/(GAGPGP) $)_{12}$ blend film on Si with Ni nanoparticles ............... 37

Figure 22 AFM topography (left) and phase (right) images of polyE/(GAGPGP) $)_{12}$ blend........... 39

Figure 23 DNA and amino acid sequence of VA2 peptide ................................................... 40

Figure 24 AFM topography (left) and phase (right) image of VA2/(GAGPGP) $)_{12}$ blend.............. 40

Figure 25 SEM image of a VA2/(GAGPGP) $)_{12}$ blend film with Ni nanoparticles......................... 41 
Figure 26 AFM topography (left) and phase (right) image of VA2-(GAGPGP) ${ }_{12}$ block copolymer 42

Figure 27 A) SEM image of the overall network morphology within an ELP/(GAGPGP) ${ }_{12}$ blend film, and B) SEM image of the details of the network morphology in an ELP/(GAGPGP) $)_{12}$ blend

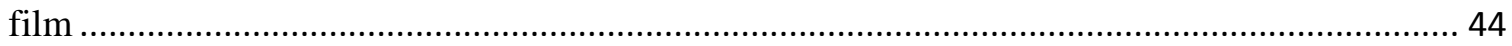

Figure 28 AFM topography (left) and phase (right) images of ELP/(GAGPGP) $)_{12}$ blend on Si.... 45 Figure 29 CD data comparing A) the peptide (GAGPGP) ${ }_{12}$ alone to the block copolymers: $\mathrm{B}$ ) PEG-(GAGPGP) $)_{12}$, C) $(\text { GAGPGP) })_{12}$-PEG, and D) PEG-(GAGPGP) $)_{12}$-PEG 48 


\section{Chapter 1 Introduction}

\subsection{Polymer Phase Separation}

Synthesis of new polymers for each arising application is not always feasible so material scientists and chemists have turned to combining two or more polymers to achieve the necessary enhanced material properties. ${ }^{1-6}$ The combination of multiple polymers has most often been characterized either as a simple mixture of two or more homopolymers referred to as a polymer blend, or as a block copolymer implying that two or more homopolymers have been covalently bonded together. ${ }^{2}$ In both multicomponent polymer systems, the phase separation is influenced by the molecular weight, composition, and concentration of each homopolymer. Additionally, for the block copolymer system, the molecular architecture of the macromolecule has an influence on phase behavior. Block copolymers can be fabricated into a considerable number of architectures including star block copolymers and branched block copolymers, but for the following sections examining the phase separation of polymer systems, this thesis focused on the simplest and most studied examples in each category, binary linear homopolymer blends and linear diblock copolymers. $^{2}$

Phase separation of a multicomponent polymer system occurs when high levels of interfacial energy exists between molecules of polymer type A and molecules of polymer type B favoring the reduction of surface area and leading to segregation of the homopolymers. ${ }^{2}$ In a blended system, the high interfacial energy drives macro-phase separation with coarse domains of homopolymer type A within the homopolymer type B. ${ }^{7}$ In a block copolymer system with high interfacial energy, the constraints of the covalent bond between polymer type A and polymer type B allow only microscopic phase separation on a scale comparable to the molecular dimensions of the of the block copolymer. ${ }^{2}$ Overall, phase separation in multicomponent polymer systems is both a useful phenomenon for applications like organizing nanoparticles in composite materials and interesting as a self-assembly process from a basic science point of view.

\subsection{Theoretical Prediction of Phase Separation}

According to Green et al. the interfacial energy and overall phase behavior of a multicomponent polymer system is determined by the summation of the translational entropy of the chains and the enthalpic interactions between polymer type A and polymer type B. ${ }^{8}$ In the Gibbs free energy equation of mixing, given in Equation (1), the relationship between entropy $\left(\Delta \mathrm{S}_{\text {mix }}\right)$ and enthalpy $\left(\Delta \mathrm{H}_{\text {mix }}\right)$ is clearly stated. ${ }^{9}$ 


$$
\Delta G_{\text {mix }}=\Delta H_{\text {mix }}-T \Delta S_{\text {mix }}
$$

One of the simplest models presented by D. R. Paul and J. W. Barlow in 1984 as an expansion on the original Flory-Huggins theory of polymer solutions specifies that the entropy of mixing can be approximated as

$$
\Delta S_{m i x}=-R\left(V_{A}-V_{B}\right)\left[\frac{\phi_{A} \ln \phi_{A}}{\tilde{V}_{A}}+\frac{\phi_{B} \ln \phi_{B}}{\tilde{V}_{B}}\right]
$$

where $R$ is the universal gas constant, $V_{A}$ is the volume component type $\mathrm{A}, V_{B}$ is the volume of component type $\mathrm{B}, \emptyset_{A}$ is the volume fraction of component type $\mathrm{A}, \emptyset_{B}$ is the volume fraction of component type B, $\tilde{V}_{A}$ is the molar volume of component type A, and $\tilde{V}_{B}$ is the molar volume of component type B. ${ }^{10}$ From Equation (2), the sign of the entropy equation always favors mixing of the two components; however, in multicomponent polymer systems, high molecular weights correspond to high values of $\tilde{V}_{A}$ and $\tilde{V}_{B}$ causing the size of the entropy value to shrink. ${ }^{10}$ Anastasiadis et al. further explains this decrease in entropy with increasing molecular weight as the result of increasing numbers of interfacial tensions experienced within the polymer complex. ${ }^{11}$ Examples of these interfacial tensions can be the formation of intermolecular and intramolecular hydrogen bonds and pi-stacking. ${ }^{10}$ On the other hand, the enthalpy component of the free energy system is described by Paul and Barlow as

$$
\Delta H_{\text {mix }}=\left(V_{A}+V_{B}\right) B \phi_{A} \phi_{B}
$$

where $B$ is a binary interaction energy density. Paul and Barlow use $B$ instead of the more often used $\chi$ parameter out of convenience of units. The binary interaction energy density relates to the more commonly used $\chi$ parameter by

$$
\frac{B}{R T}=\frac{\chi_{A}}{\tilde{V}_{A}}=\frac{\chi_{B}}{\tilde{V}_{B}}=\tilde{\chi}_{A B}
$$

and from this equation, it can be seen that $B$ is a function of both temperature and concentration of the polymer components. Overall, considering both the entropy and enthalpy terms, to achieve mixing with a small entropy value from the large molecular weights of polymers, there needs to be a negative interaction parameter to drive the Gibbs Free Energy Equation (1) to a negative value.

A value for the interaction parameter between the polymers can be determined experimentally by finding the bimodal and spinodal temperatures as a function of the composition of the polymer system (see Figure 1), or theoretically by calculating the functional group contributions., 2,11,12 


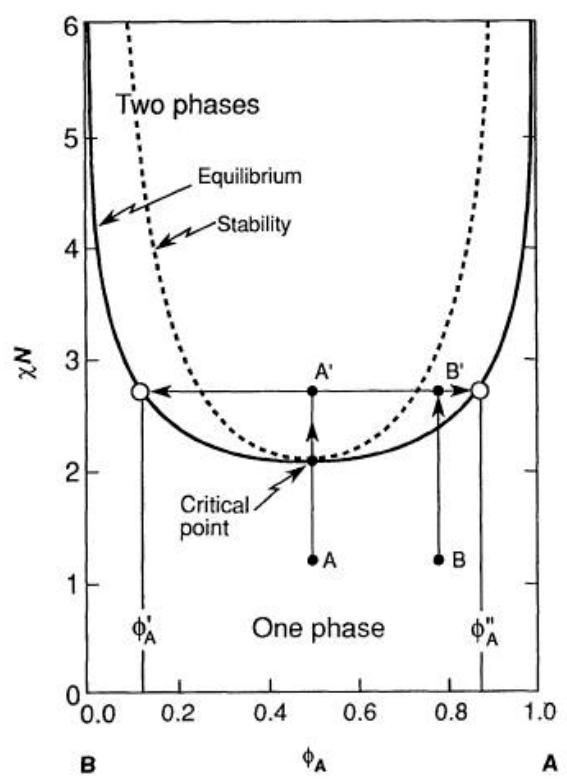

Figure 1. Two component polymer blend phase diagram. Reprinted with permission from Science 251, 898-905. Copyright 1991 AAAS $^{2}$

Coacervation temperatures determined by light scattering at varying compositions are regularly used to determine the bimodal curve of a polymer system, while the spinodal curve has been measured using light scattering, X-ray scattering, and neutron scattering. These techniques, however, do have limitations including the viscosity of polymer melt systems and the temperature range of the instruments. ${ }^{13}$ Furthermore, within the phase separated section of the phase diagram in Figure 1, a binary polymer blend or a linear diblock copolymer can assemble into various ordered phases depending on the volume fractions of each component.

Theoretically, the interaction parameter between two polymers, the temperature, and the volume fraction of each polymer can be tuned for each multicomponent polymer system to achieve the morphology needed for an application. Realistically, while the interaction parameter and model of the free energy of mixing can reasonably predict whether two polymers will phase separate, the theory fails to take into account specific interactions like hydrogen bonding, acid-base side chains, and charge transfer interactions. ${ }^{13}$ The incomplete free energy model, along with a lack of interaction data between many polymers leaves much to be determined and explained in the field of polymer phase separation. This is particularly true for protein-based polymers in which specific interactions play a pertinent role in polymer structure and assembly.

\subsection{Determination of Phase Separation}

The theoretical model described above can be used to predict if phase separation will occur in a multicomponent polymer system. To confirm immiscibility, Krause explains that phase 
separation is usually studied by direct observation of a thin section or film of the multicomponent polymer system. ${ }^{14}$ This can be accomplished with transmission electron microscopy (TEM) by using a selective heavy metal dye that will bind to only one of the polymers. Once under the microscope, one polymer can be differentiated from another polymer and phase separation can be confirmed. An example of this procedure was published recently by Kato et al. and involved using liquid nitrogen to freeze a polyketone/polyamide blend sample, an ultra-microtome then sliced the sample into thin sections about $200 \mathrm{~nm}$ thick, and phosphotungstic acid stain to visualize the phases. ${ }^{15}$

An alternative method of characterizing polymer phase separation is tapping mode atomic force microscopy (AFM). With AFM, one polymer can be distinguished from another through differences in phase angle felt by the probe due to tip-sample interaction. The change in phase angle has been related to the dissipation of energy between the tip and the sample, but how the energy dissipation relates to material properties and can be quantified is not well understood. ${ }^{16}$ Properties such as stiffness, work of adhesion, damping, and topography have all been recorded to impact the phase angle to different extents. ${ }^{17}$ Nonetheless, tapping mode AFM phase imaging is commonly used on thin sections of a bulk sample to qualitatively differentiate between two phases. Raghavan et al. published an example of using AFM to document phase separation in films of blended poly(methyl methacrylate) (PMMA) and polybutadiene (PB) ${ }^{16}$ With tapping mode AFM Raghaven et al. were able to determine that each blend contained PMMA-rich domains within a matrix of PB-rich areas.

Furthermore, a lack of change in the glass transition temperatures of a multicomponent polymer sample can indicate phase separation of a polymer sample. If phase separated, a system of two polymers should produce two separate glass transition temperatures $\left(\mathrm{T}_{\mathrm{g}}\right)$ easily observed using a differential scanning calorimeter (DSC). However, if the two polymers are miscible, one unified $\mathrm{T}_{\mathrm{g}}$ will appear. ${ }^{14}$ Meaurio et al. illustrated this technique by using DSC to investigate the phase behavior and specific interactions involved in their poly(L-Lactide) (PLLA) and poly(vinylphenol) (PVPh) blend samples. ${ }^{18}$ With calorimetry, they were able to discover miscibility at all compositions of the PLLA-PVPh blend when prepared by solution precipitation, but when solvent casting was used to prepare the PLLA-PVPh blends, phase separation was evident. Meaurio et al. attributed the difference in phase behavior between the differently prepared samples to favorable solvent-polymer interactions in the solvent cast samples causing one polymer to be excluded from growing phase domains as the solvent evaporates. 


\subsection{Phase Separation in Thin Films}

Most studies in phase separation involve mixing multiple polymers in bulk and analyzing the phase behavior in the main body of the material., ${ }^{2,10,19,20}$ However, the growing importance of polymer thin films in the electronics and coatings industries has driven research into the more complicated realm of polymer thin films. ${ }^{5,21}$ Traditional modeling of polymer phase behavior of bulk samples has been discussed above, but a thin film polymer system is more complex due to the presence of a substrate and the presence of the solid/gas interface. These factors influence phase behavior in addition to the entropic and enthalpic forces described above. ${ }^{22}$ In the thickness range of thin films, specific attraction or repulsion interactions between the polymer chains and substrate and the requirement of lowering surface-free energy dictate the pattern formed by the polymer phases. ${ }^{23}$ Generally, to achieve a thin film of a multicomponent polymer system, a sample is spin coated onto a substrate. The spin coating procedure creates a non-equilibrium state of the polymer system from the fast rate of solvent evaporation and the applied centrifugal forces. ${ }^{23}$ The free energy of the system is lowered through obtaining microphase separation and/or dewetting when the sample is annealed above its $T_{g}$ or melting temperature $\left(T_{m}\right){ }^{23}$

A recent example of producing a multicomponent thin film was published in December 2011 by Cozzens et al. and involved comparing commercially available thermoplastic polyurethanes (TPUs) to novel polyisobutylene(PIB)-poly(tetramethylene oxide) (PTMO) TPUs for coating blood-contacting medical devices. ${ }^{24}$ Nine different block copolymers were diluted in toluene, $\mathrm{N}, \mathrm{N}$-dimethylformamide, or 1-methyl-2-pyrrolidone at a concentration of approximately $0.5 \mathrm{wt} \%$ and spin coated onto the top of an electrode. The resulting films were approximately $30-60 \mathrm{~nm}$ thick and phase separation was investigated using tapping mode. Cozzens et al. determined there was phase separation within the thin films and that the domain sizes increased with an increase in the PTMO content of the polymer system. In another study, Meier et al. investigated phase separation as a function of film thickness in the polymer blend system of poly[(1-methoxy)-4-(2ethylhexyloxy)-p-phenylenevinylene] (MEH-PPV) and poly(Nvinylcarbazole) (PVK). ${ }^{25}$ The polymer blends were spin-coated onto silicon wafers and the films analyzed with grazing incidence ultrasmall-angle X-ray scattering (GIUSAXS) and AFM. They found that there was a strong linear dependence of phase separation on increasing thickness of the MEH-PPV-PVK blend films. It was concluded that this dependence resulted from adhesion to silicon substrate and viscosity changes in the last stage of spin coating. The samples transitioned from cylindrical geometries to a random phase separation configuration with increasing film thickness. Meier et al. believe that the decreasing phase domains and therefore increasing interfacial areas with 
decreasing thickness illustrates an interesting approach for achieving high efficiency organic electric devices.

In the field of organic photovoltaic devices, Hou and colleagues demonstrated control over the nanostructures produced from the phase separation of a blend of poly[2,3-bis-(3-octyloxyphenyl) quinoxaline-5,8-diyl-alt-thiophene-2,5-diyl] (TQ1) and [6,6]-phenyl- $\mathrm{C}_{71}$-butyric acid methyl ester $\left(\mathrm{PC}_{71} \mathrm{BM}\right){ }^{26}$ The phase separation of these two polymers provides an electron donor/acceptor interface for charge generation and permeating domains to favor charge transport for organic photovoltaic devices. Hou et al. stated that a rapid rate of solvent removal from the films produced a finer nanostructure and significantly improved charge separation. Similarly, in 2003, Peumans et al. from Princeton University showed that annealing phase separated organic photovoltaic thin films within a confined geometry results in a power conversion efficiency $50 \%$ higher than the best values reported for comparable bilayer devices. ${ }^{27}$

\subsection{Phase Separation in Biological Polymers}

The phenomenon of phase separation is well-studied in synthetic multicomponent polymer systems, but there are far fewer examples in hybrid synthetic biological polymer systems, and in purely biological polymer systems phase separation has only been documented in solution. ${ }^{28-30}$ To molecular biologists, a peptide is usually considered a smaller section of a protein, but to materials scientists peptides are naturally produced biological polymers. Molecularly, these biological polymers are composed of a very precise sequence of amino acids that constitute a chain with a carbon-based backbone and varying side chain functional groups. ${ }^{31,32}$ Macroscopically, biological polymers can function as materials with impressive properties including great mechanical strength of spider silk, incredible elasticity of elastin, and energy conversion capabilities within reaction center protein complexes. ${ }^{29,33,34}$ Some of these properties are the result of the highly specific molecular interactions such as hydrogen bonding, hydrophobic and electrostatic interactions, and restricted peptide backbone rotation. ${ }^{30}$ Biological polymers can be produced through chemical reactions using a technique called solid-phase peptide synthesis introduced by R. B. Merrifield in $1962 .{ }^{35}$ This technique involves covalently binding an amino acid to a solid synthetic polymer support and adding subsequent amino acids in a step-wise method to produce the peptide sequence. Once the peptide is fully assembled, the peptide is cleaved from the synthetic polymer. Alternatively, peptides can be produced biologically using DNA and a suitable expression host like Escherichia coli (E. coli). ${ }^{36}$ Genetic and protein engineering has allowed researchers to utilize the protein manufacturing machinery within a cell to produce biological polymers with very precise polymer chain length, composition, 
sequence, topology, and stereochemistry. ${ }^{37}$ Also, in comparison with synthetic polymers that are usually random coiled chains, the increased number of intermolecular hydrogen bonding offer more opportunities to direct nanoscale structure formation through secondary structures like $\alpha$ helical coil and $\beta$-sheet. ${ }^{38,39}$ In addition to near absolute control of the sequence of biological polymers and an increased amount of hierarchical structure obtainable, most synthetic polymers are produced and manipulated in hazardous organic solvents while peptides can be synthesized and handled in aqueous solutions at ambient conditions. ${ }^{40}$

To capitalize on the conveniences and benefits of both synthetic and biological polymers, many hybrid biological-synthetic polymeric materials have been produced and investigated. ${ }^{41,31,42}$ Most commonly, biological-synthetic hybrid block copolymers are used to assess structural and functional properties of solid state hybrid materials. One of the first noted studies in phase separation of a solid state hybrid material was by B. Perly, A. Douy, and B. Gallot in 1976. Perly et al. reported that a polybutadiene-b-poly( $\gamma$-benzyl-L-glutamate) (PB-PBLG) hybrid diblock copolymer and a PB-b-poly $\left(\mathrm{N}^{5}\right.$-hydroxylpropyl-L-glutamate) (PB-PHPG) hybrid diblock copolymer both formed well-ordered lamellar structure confirmed by X-ray scattering and TEM with $\mathrm{OsO}_{4}$ staining. ${ }^{43}$ More recently, Rathore and Sogah from Cornell University demonstrated microphase separated morphology in a poly(ethylene oxide) (PEO) and glycine-alanine-glycinealanine peptide multiblock copolymer. ${ }^{44}$ DSC, AFM, and TEM analysis were performed on the hybrid biological-synthetic polymer samples to confirm 20-50 nm peptide domains within a continuous PEO phase in solid state. Lastly, in 2006 Vandermeulen et al. found that in solid state both block and graft hybrid copolymers of the peptide sequence glycine-alanine-glycine-alanine and polyferrocenylsilane (PFS) showed signs of phase separation. ${ }^{45}$ The DSC thermograms showed two thermal transitions for both of the hybrid polymers suggesting phase separation between the peptide and PFS domains of the polymer system. The authors attributed this selfassembly to the antiparallel $\beta$-sheets formed by the peptide portion of the biological-synthetic hybrid polymer.

In the case of pure biological polymer, most studies have investigated the self-assembly behavior of block copolypeptides in solution. For example, Wiradharma et al. studied the effect of a hydrophobic block in six different triblock oligopeptide amphiphiles on the self-assembly of micelles in solution and drug load capacities. ${ }^{46}$ The macromolecules consisted of a hydrophobic end composed of alanine, phenylalanine, and/or leucine; a histidine block; and a hydrophilic cationic end of lysine. In aqueous solution the molecules assembled into micelles with hydrophobic cores and hydrophilic shells. Using dynamic light scattering (DLS) and fluorescence 
microscopy, Wiradharma et al. found that the propensity to form micelles, the size of the micelles, and the drug load capacity of the oligopeptide assemblies could be adjusted by tuning only the hydrophobic block of the molecule. In 2006, Chécot et al. studied the self-assembly behavior of a poly(L-glutamic acid)-b-poly(L-lysine) polypeptide diblock copolymer with static light scattering (SLS), DLS, small angle neutron scattering (SANS), and TEM. ${ }^{47}$ In both basic and acidic aqueous conditions, reversible vesicles were formed with hydrodynamic radii of 175 $\mathrm{nm}$ and $110 \mathrm{~nm}$, respectively. The group concluded that in acidic conditions the poly(L-lysine) block formed a shell around a ring of poly(L-glutamic acid), while in basic conditions the poly(glutamic acid) block formed a shell around a ring of poly(L-lysine). Another study conducted by Rabotyagova et al. examined the phase behavior of spider silk-like block copolypeptides composed of polyalanine (A) and glycine-rich (B) blocks in aqueous solution or 2-propanol. ${ }^{48}$ Attenuated Total Reflectance-Fourier Transform Infrared Spectroscopy (ATRFTIR) was used to determine the secondary structures of the molecules and SEM was used to observe any structures that remained after drying on a silicon wafer. Rabotyagova et al. found that increasing the number of hydrophobic blocks in the macromolecule lead to a transition from thin films to micelles. Within the thin films no organized structures or phase separation was detected. Additionally, they found that changing the solvent to 2-propanol caused nanofibers and large compound micelles to form.

After a thorough literature search only one study has reported phase separation in solid films of biological polymers. Toshihiko Niwa et al. reported a pattern of stripes in a solid state Langmuir Blodgett (LB) film produced from a poly( $\gamma$-benzyl-L-glutamate) (PBLG) and poly(L-lysine) (PLLys) triblock biopolymer. ${ }^{49}$ The authors conducted circular dichroic spectroscopy (CD) on the biological polymer to confirm an overall $\alpha$-helical secondary structure and AFM to image the solid state LB film prepared on a mica substrate. The AFM imaging revealed a stripe interval of about $28 \mathrm{~nm}$. Thin films of biological polymers without apparent phase separation have been achieved by multiple groups of researchers including Krishnaji et al. in 2011. Krishnaji and colleagues published AFM topography and phase images of 2-3 nm thick monolayers of a spidersilk like block copolymer. ${ }^{29}$ The group was able to show evidence of loose circular domains within a dried LB film, and observed a correlation between the structural organization of the film and the number of hydrophobic repeats within the peptide. Additionally, liquid crystalline order has been reported in the literature as in the case of PBLG systems published by Minich et al., but liquid crystalline organization is beyond the scope of this research. ${ }^{50}$ 


\subsection{Phase Separation to Organize Nanoparticles}

An important application of phase separated multicomponent polymer thin films is to act as an ordering template for uniform dispersion of nanoparticles. ${ }^{51}$ To exploit the properties of nanoparticles in polymeric composite material, highly controllable and ordered arrays of the nanoparticles are required. However, during fabrication of polymer nanocomposites, nanoparticles tend to separate from the polymer and aggregate into unpredictable and inconsistent areas of the material which negates the benefits of their nanosized dimension. ${ }^{52}$ To prevent this aggregation, in 2009 Rosset et al. tried combining nanoparticles within polymers by using lowenergy metal ion implantation by filtered cathodic vacuum arc into polydimethylsiloxane (PDMS). ${ }^{53}$ A gold-PDMS composite material was found to form a conducting network even when stretched to twice the original length. ${ }^{53}$ With this technique, micro-scale control over the electrode dimensions was achieved by using a shadow mask for patterning the nanoparticles. Moreover, in attempts at one-step fabrication, researchers have tried combining nanoparticles with the multicomponent polymer systems in solution prior to casting a film. ${ }^{54,55}$ With this process, the nanoparticles were found to alter the morphology and microdomains of the block copolymers. Theoretical and computational modeling showed that because the nanoparticles are solids, the polymeric chains need to stretch around the rigid volume, causing a loss in the conformations of the polymer. Larger-sized nanoparticles can even be expelled from the film. In 2006, Kim et al. showed that density of attached thiol end functional polystyrene homopolymers (PS-SH) to gold nanoparticles determined the location of the nanoparticles within a phase separated poly(styrene-b-2-vinylpyridine) (PS-b-P2VP) diblock copolymer template. ${ }^{56}$ If the density of PS-SH was high enough to completely cover the nanoparticle, then the nanoparticles segregated to the center of the PS regions. But, if a lower density of PS-SH was used and the nanoparticles were only partially coated with PS-SH, the nanoparticles agglomerate at the interfaces between the PS and P2VP blocks.

In the literature, biological polymers have also been used as a template for nanoparticles. In 2002, R. Andrew McMillan and associates were able to form two-dimensional ordered gold and quantum dot nanoparticle arrays using hollow ring-structured crystallized proteins called chaperonins. ${ }^{57}$ The chaperonins were modified to have either $3 \mathrm{~nm}$ or $9 \mathrm{~nm}$ size pores and were arranged onto a substrate. The crystalline protein templates were then able to size-selectively bind and organize the gold (5 and $10 \mathrm{~nm}$ ) or CdSe-ZnS semiconductor (4.5 nm) quantum dots into arrays. Similarly, in 2010 Matthew Shindel et al. demonstrated two-dimensional organization of gold nanoparticles by utilizing electrostatic interactions between the nanoparticles and 
streptavidin crystals. ${ }^{58}$ They found that the negatively charged particles preferred binding to the areas between protein molecules. Though, both groups were able to achieve nanoparticle organization with chaperonins and streptavidin, crystallizing proteins is a well-known difficult task which makes this technique difficult to apply to biological polymers. Cui et al. published an example of using peptides bound to the surface of graphene to bind and arrange gold nanoparticles. ${ }^{59}$ Nanostrips of graphene were fabricated using photolithography and etching, and then biological triblock copolymer macromolecules consisting of a graphene binding end, a glycine linker, and a gold nanoparticle binding end were immobilized onto to graphene nanostrips. A solution of gold nanoparticles was added to peptide graphene substrate and selective binding of the nanoparticles to the peptide was demonstrated and documented using AFM and SEM.

\subsection{Purpose of Study}

A growing need for control over the organization of nanoparticles within a polymeric composite has developed in the electronics and coatings industries. ${ }^{5,21}$ This need has thus far been addressed with phase separated synthetic polymer thin films, but production and manipulation of synthetic polymers involves hazardous chemicals and most often results in polydispersity indices capable of disrupting phase separation prediction models. ${ }^{14,60}$ Instead of synthetic polymers, biological polymers have been proposed recently to address both the issue of hazardous chemicals in production and the polydispersity indices. ${ }^{37,39}$ Biological polymers can be produced under ambient conditions without harsh chemicals while maintaining outstanding control over polymer sequence by using a biological expression host. ${ }^{61}$

Drawing from lessons composite materials in nature, this work aimed to develop a thin film composed entirely of micro-phase separated biological polymers. Nickel nanoparticles were then incorporated into the films to produce a biological polymer nanoparticle composite material. Specifically, this research used recombinant DNA techniques and an E. coli expression host to produce blocks of polypeptides with specific functional groups. A peptide with the repeating sequence of glycine-alanine-glycine-proline-glycine-proline (GAGPGP) was designed to have a random coil secondary structure and lacking any charged functional groups to limit the number of specific interactions like hydrogen bonding, acid-base side chains, and charge transfer interactions (see Figure 2). 


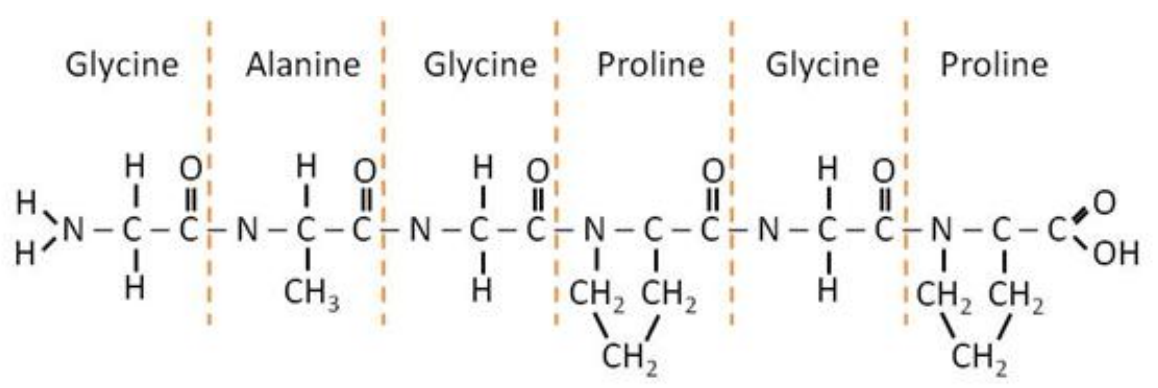

Figure 2 Schematic of the peptide repeat GAGPGP

This biological polymer was thought to be a good contender for phase separation because the random coil secondary structure of the molecule would allow peptide chain flexibility close to that of synthetic polymers, and previous studies had reported the ability to produce continuous solid films from similar peptide sequences. ${ }^{29,30,62,63}$ Blends and block copolymers of this GAGPGP biological polymer with other peptides and/or synthetic polymers were produced to investigate the organizational behavior of the multicomponent polymer systems in the solid state. Tapping mode AFM was used to assess the structure of the dried films on silicon. Then, to investigate the capability of a biological thin film to organize nanoparticles, a simple solution of nickel nanoparticles was deposited onto the biological polymeric film and SEM was used to observe the behavior of the composite material.

Although synthetic polymers have been the dominant player in nanoparticle polymer composite materials, this work demonstrates that there is a possibility of using biological polymers as thin film nanoparticle templates. Production of biological polymers by an expression host offers greater control over the molecular sequence of the polymer than the chemical production methods of producing synthetic polymers. The greater degree of control translates to a precise management of the overall organization of the material. If biological polymers can achieve a phase separated organization, the biological material may be able to arrange nanoparticles within a composite material. Nanoparticle composite materials composed of biological polymers have the potential to impact the field of coating, photovoltaics, and biosensors. 


\section{Chapter 2 Experimental}

\subsection{Materials}

A modified version of pET-19b plasmid developed by N. L. Goeden-Wood and J. D. Keasling was a gift of K. L. Kiick. ${ }^{36}$ The nucleotides coding for the amino acid sequence GAGPGP and an additional linker insert (G-over) containing a glycine overhang and histidine tag were both ordered from DNA2.0 (Menlo Park, CA) and was received in the production cloning plasmid pJ201. The restriction enzymes Bam HI, Nco I, Sap I, and Eco RI were obtained from Fermentas (Glen Burnie, MD). The T4 DNA Ligase was ordered from New England Biolabs (Ipswich, MA) and the nucleotide purification kits were obtained from Qiagen (Valencia, CA). Max efficiency DH5 $\alpha$ cells were purchased from Invitrogen (now Life Technologies in Grand Island, NY). For peptide production, chemically competent One Shot BL21 Star(DE3)pLysS E. coli cells were also obtained from Invitrogen. The chemical isopropyl- $\beta$-D-thiogalactopyranoside (IPTG) was from Fisher Scientific (Pittsburgh, PA). Spectra/Por Biotech Cellulose Ester Dialysis membranes with 100-500 Da molecular weight cut-off was purchased from Fisher Scientific. Silicon wafers of $<100>$ orientation were given to the lab by C. Stinespring in the Chemical Engineering Department at WVU. Carbon Type-A TEM grids were purchased from Ted Pella (Redding, CA). The 7.9 $\mathrm{kDa}$ peptide referred to as VA2 was expressed from cell stocks prepared by a former graduate student. ${ }^{64}$ The peptide ELP was a gift from K. A. Woodhouse at Queen's University. Formic acid and cyanogen bromide used in the His-tag cleavage were obtained from Fisher Scientific. All general reagents were obtained from Fisher Scientific.

\subsection{Peptide Design and Production}

\subsection{Expression Plasmid Construction}

Constructing the expression plasmid needed for producing a peptide with the sequence $(\text { GAGPGP })_{X}$ required multiple steps of genetic manipulation. Figure 3 shows the overall scheme of recombinant DNA techniques used for producing the novel peptide. This scheme was designed so that multiple inserts of DNA coding for the amino acid sequence GAGPGP could be incorporated into the expression plasmid. The sequence GAGPGP can be thought of as the biological monomer and through the DNA methods described below, the monomer was polymerized into varying length biological polymers. The expression plasmid was transformed into E. coli cells and with this technique varying lengths of the peptide could be accurately and precisely produced. Although, there was the capability to produce many different molecular 
weights of the (GAGPGP) $)_{\mathrm{X}}$ biological polymer or peptide, only one molecular weight peptide was chosen to characterize and to use in further thin film studies.

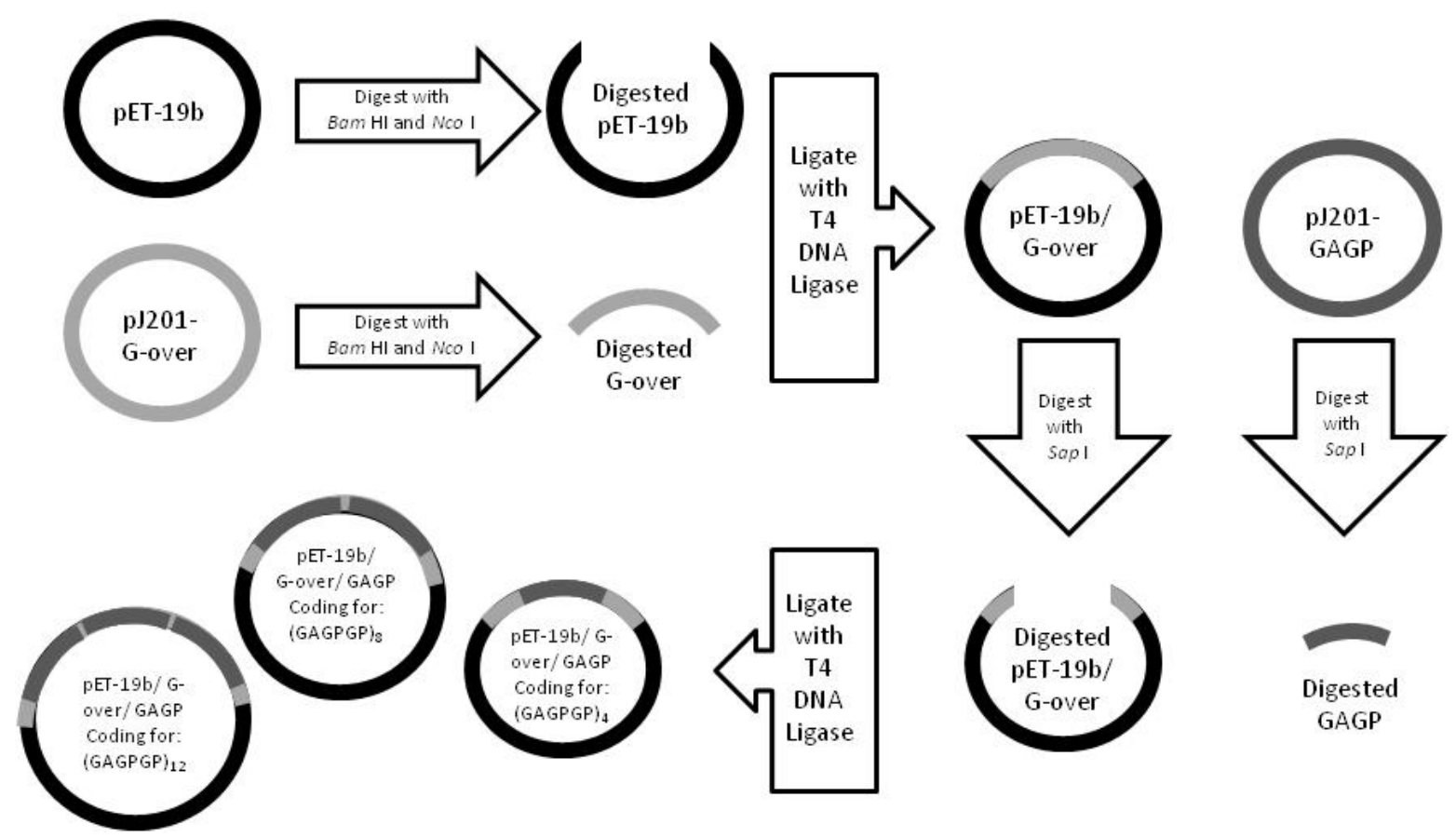

Figure 3 Overall DNA manipulation scheme

A modified version of pET-19b plasmid was chosen as the expression plasmid for this work because of a previous working knowledge of this plasmid, the compatibility of this plasmid with the BL21 Star(DE3)pLysS E. coli cell lines and the convenience of an eliminated Sap I digestion site. The vector map in Figure 4 shows the ampicillin antibiotic resistant gene and the digestion sites of a normal pET-19b plasmid including the Sap I site located at $3713 \mathrm{bp}$. The modified version of pET-19b used in this work was mutangenized to eliminate this Sap I site. ${ }^{36}$ It was advantageous to use a plasmid with no Sap I digestion sites because Sap I sites were added at specific locations into the gene sequences designed to be inserted into the plasmid. Consequently, when the restriction enzyme Sap I was used to digest the plasmid, cleavages occurred only at the designed sites within the added genes. From this point forward the modified pET-19b plasmid was referred to only as pET-19b. 


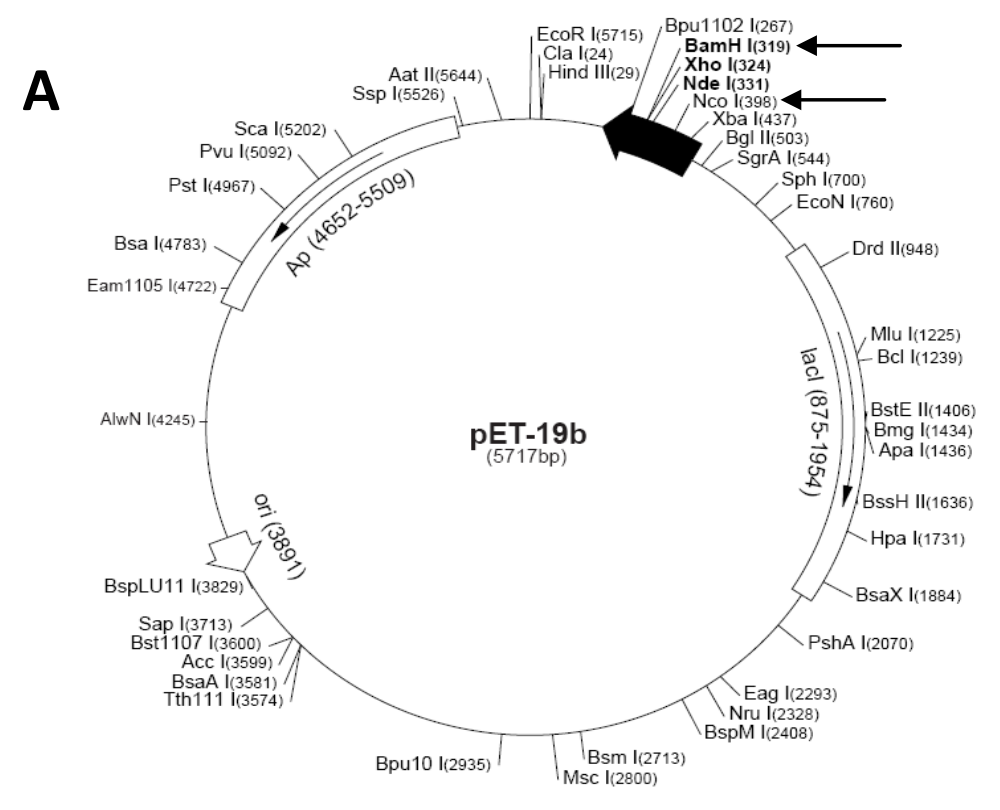

Figure 4 Vector map of a normal pET-19b expression plasmid ${ }^{65}$

To this expression plasmid, two novel gene inserts were added: G-over and GAGP. The G-over insert was flanked with an Nco I and a Bam HI digestion sites, and contained a sequence coding for ten histidine residues, also called a His-tag (see Figure 5a). The His-tag was needed for purifying the novel peptide away from natural occurring E. coli proteins after expression. Also included in the G-over insert are two internal Sap I digestion sites. These Sap I sites was used to insert multiple copies of the GAGP insert. The GAGP insert was flanked with Sap I digestion sites and contained the sequence coding for a (GAGPGP) $)_{4}$ peptide (see Figure 5b). The DNA for both inserts came from the manufacturer in the production plasmid pJ201.

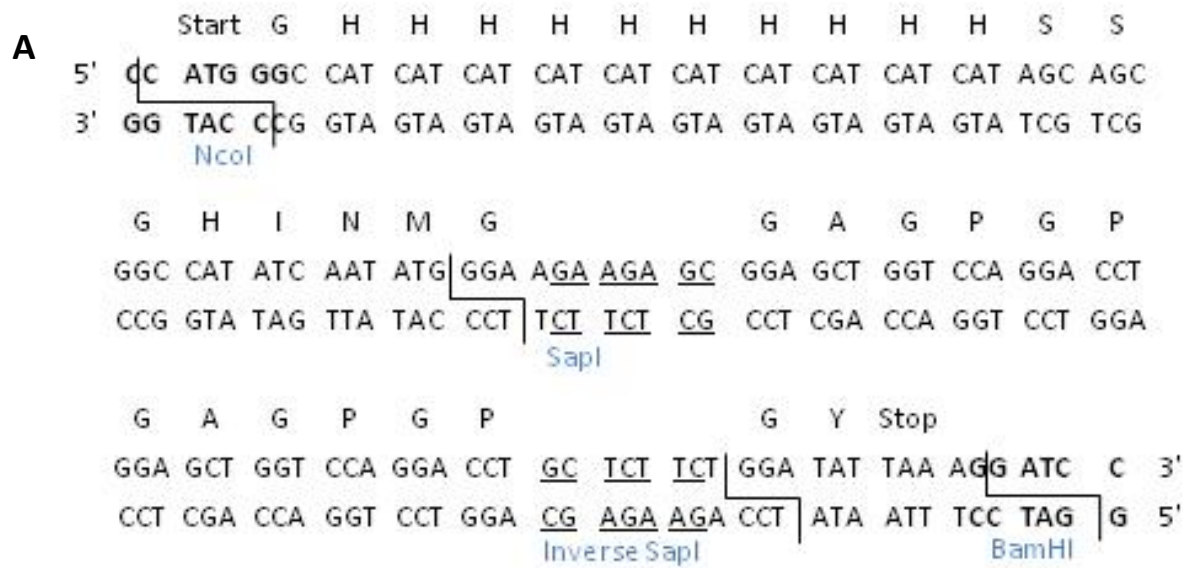




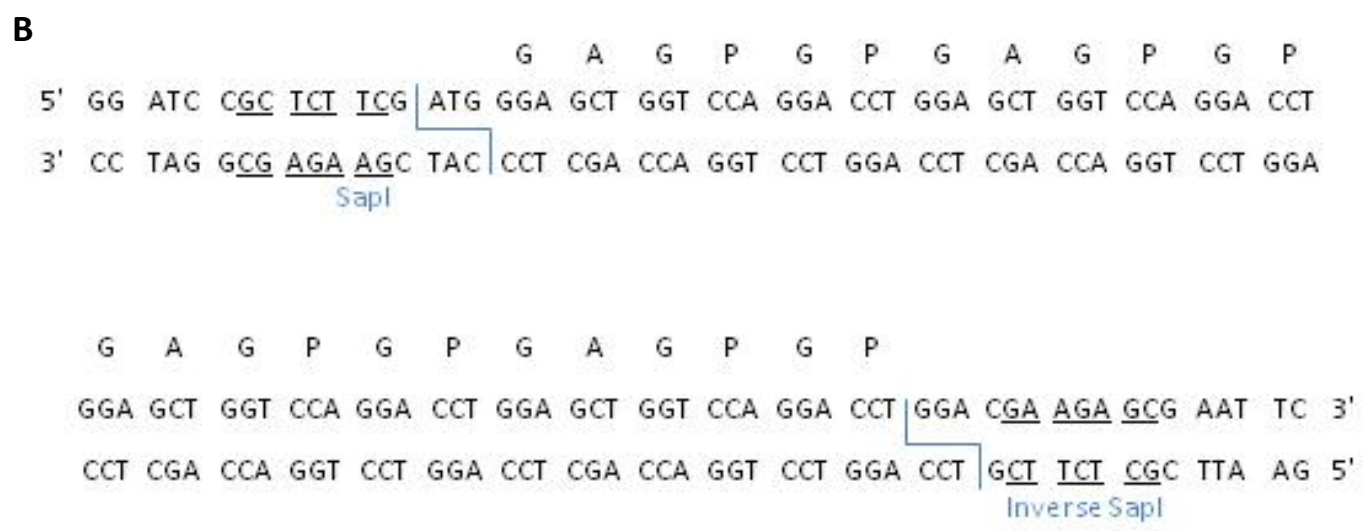

Figure 5 DNA sequence, amino acid translation, and restriction enzyme cleavage locations of A) the G-over insert and B) the GAGP insert sequence used to construct the expression plasmid

Construction of the expression plasmid coding for the GAGP peptide began with digesting both the pJ201-G-over and pET-19b plasmids with restriction enzymes Bam HI and Nco I. These enzymes recognized specific nucleotide sequences (in bold font in Figure 5a) and precisely cleaved the DNA between explicit nucleotides. The exact locations of cleavage can be seen in Figure 4 (arrows point the location within pET-19b) and Figure 5a. Figure 5a also shows the difference in distance along the 3' strand of DNA and the 5' strand of DNA that both Bam HI and Nco I cleave, leaving an overhang of nucleotides called sticky ends. Because the same restriction enzymes were used (Bam HI and Nco I) the sticky ends remaining after digesting the pET-19b plasmid perfectly match the sticky of the digested G-over insert. A typical digestion consisted of combining $20 \mu \mathrm{L}$ of DNA, $5 \mu \mathrm{L}$ of water, $3 \mu \mathrm{L}$ of 10X Digestion Buffer, $1 \mu \mathrm{L}$ of Bam HI, and $1 \mu \mathrm{L}$ of $\mathrm{Nco}$ I. This solution was gently mixed and incubated at $37^{\circ} \mathrm{C}$ for 30 minutes. To stop the digestion reaction $6 \mu \mathrm{L}$ of agarose gel tracking buffer was added to the solution and to confirm digestion the sample was run on a $1.5 \%$ agarose gel along with a 100 bp DNA ladder.

To insert G-over into pET-19b and connect the sticky ends of DNA an enzyme called T4 DNA Ligase was used to catalyze the formation of a covalent bond between the sugar-phosphate backbones. ${ }^{66}$ A typical ligation reaction consisted of combining $12 \mu \mathrm{L}$ of water, $4 \mu \mathrm{L}$ of $5 \mathrm{X}$ Ligation Buffer, $2 \mu \mathrm{L}$ of digested pET-19b, $1 \mu \mathrm{L}$ of digested G-over, and $1 \mu \mathrm{L}$ of T4 DNA Ligase. The sample was incubated at room temperature for 80 minutes, and incubated at $65^{\circ} \mathrm{C}$ for 20 minutes to stop the ligation reaction. To confirm ligation, the ligated samples of DNA were transformed into chemically competent DH5 $\alpha$ cloning E. coli cells and grown on agar plates overnight at $37^{\circ} \mathrm{C}$. The agar plates were prepared to contain the antibiotic ampicillin. Ampicillin readily kills normal DH5 $\alpha$. coli cells, but if the transformation of the plasmid into the E. coli 
cells was successful the cells will contain an ampicillin resistance gene that allows them to live in the presence of the antibiotic. Any colonies that grew on the plate were grown up further in $5 \mathrm{~mL}$ liquid media cultures overnight at $37^{\circ} \mathrm{C}$. The ligated DNA from the culture was purified from the E. coli cells using a Qiagen nucleotide removal kit. The ligated DNA and a pET-19b control were digested with the restriction enzymes Eco RI and Nco I, and run on a 2\% agarose gel with a 100 bp DNA Ladder.

After confirming the G-over insert was successfully inserted into the pET-19b plasmid (designated as pET-19b-G-over), both the pET-19b-G-over plasmid and the GAGP insert were digested with the restriction enzyme Sap I. The Sap I cleaved the internal digestion sites in the Gover insert leaving a specifically placed gap in the pET-19b-G-over plasmid (see Figure $5 \mathrm{a}$ for the location of the digestion sites and nucleotide sequences recognized underlined). In the GAGP insert, Sap I cleaved on either side of the insert, removing it from the manufacturer's plasmid pJ201 (location and sequences shown in Figure 5b). GAGP was ligated into the pET-19b-G-over plasmid using the T4 DNA Ligase enzyme again. Once the ligation reaction was complete, the DNA samples were transformed into E. coli and grown up overnight on agar plates. All colonies that formed were scrapped off of the agar plates and transferred into $5 \mathrm{~mL}$ cultures of liquid media and grown overnight again to increase the number of $E$. coli cells thereby amplifying the amount of DNA in the samples. Cell stocks of these samples were frozen and the DNA was removed from the cells with the previously mentioned Qiagen kit. The DNA was digested with the restriction enzymes Nco I and Eco RI, and run on a 2\% agarose gel. Additionally, to further analyze the results of the GAGP and pET-19b-G-over ligation nucleotide analysis was conducted at the Genomics Core Laboratory at WVU. Following the confirmation of DNA sequences from the nucleotide analysis, the ligated DNA sample coding for the peptide (GAGPGP) ${ }_{12}$ was chosen to work with for the remainder of the experiments and designated as pET-19b-G-over-GAGP 12

\subsection{Peptide Production and Purification}

To produce the (GAGPGP) $)_{12}$ peptide, the pET-19b-G-over-GAGP 12 plasmid was transformed into a strain of chemically competent E. coli cells designed to have high-level expression of the T7-regulated genes called BL21 Star(DE3)pLysS. Frozen cells stocks were made from successful transformations and stored at $-80^{\circ} \mathrm{C}$. A seed culture was started by scraping cells from the frozen cell stock and adding them to $100 \mathrm{~mL}$ of sterile $2 \mathrm{x}$ TY liquid media containing $200 \mu \mathrm{g} / \mathrm{mL}$ ampicillin and $30 \mu \mathrm{g} / \mathrm{mL}$ chloramphenicol. This seed stock was grown up overnight ( $\sim 16$ hours) shaking at $175 \mathrm{rpm}$ at $37^{\circ} \mathrm{C}$. The following morning $20 \mathrm{~mL}$ of this seed stock was used to inoculate flask containing $1 \mathrm{~L}$ volume of sterile $2 \mathrm{x}$ TY media with $200 \mu \mathrm{g} / \mathrm{mL}$ ampicillin and 
$30 \mu \mathrm{g} / \mathrm{mL}$ chloramphenicol. This culture was allowed to grow for about 2.5 hours at $250 \mathrm{rpm}$ or until an optical density of 0.6 at $600 \mathrm{~nm}$ was measured. At this point, IPTG was added to the culture for a final concentration of $1 \mathrm{mM}$ to induce peptide production within the E. coli cells. The flask of cells remained shaking for another two hours at $250 \mathrm{rpm}$ and $37^{\circ} \mathrm{C}$. After two hours the culture was centrifuged at 6,000 rpm to pellet the cells. The supernatant of excess media was discarded and the pellet of cells was resuspended in denaturing buffer containing $8 \mathrm{M}$ urea, $10 \mathrm{mM}$ Tris-Cl, and $100 \mathrm{mM} \mathrm{NaH}_{2} \mathrm{PO}_{4}$ at $\mathrm{pH} 8.0$ and frozen overnight at $-20^{\circ} \mathrm{C}$.

To purify the (GAGPGP) ${ }_{12}$ peptide from the other natural proteins and peptides that E. coli produces, affinity chromatography was used. The cells were lysed by sonication for approximately20 minutes or until the solution becomes translucent. The lysate was centrifuged at 10,000 rpm for 30 minutes to separate the water soluble peptides from the other cellular debris. After centrifugation, the supernatant containing the proteins and peptides was combined with NiNTA resin at a 1:4 volume ratio of resin to lysate. The mixture was mixed gently on a plate shaker for 60 minutes at room temperature. After an hour, the mixture was poured into empty gravity flow columns and allowed to pass through the column. The flow-through was collected and the resin was washed three times with a column volume of denaturing buffer at $\mathrm{pH}$ 6.3. Each wash was collected. The column was washed twice with denaturing buffer at $\mathrm{pH}$ 5.9, again collected each wash. The peptide was eluted twice with denaturing buffer at $\mathrm{pH} 4.5$, and both elutions were collected and dialyzed in distilled/deionized water with 100-500 Da molecular weight cut-off dialysis tubing. After dialysis, the eluted sample was frozen at $-80^{\circ} \mathrm{C}$ and lyophilized. The purification process of (GAGPGP) $)_{12}$ was monitored by sodium dodecyl sulfate polyacrylamide gel electrophoresis (SDS-PAGE) with Coomassie blue protein stain, and by Western Blot with His-tag antibodies.

\subsection{Circular Dichroism}

After producing and purifying the (GAGPGP) 12 peptide, characterization of the secondary structure of the peptide and the hybrid copolymers was investigated using circular dichroic spectroscopy (CD). The samples were analyzed on a Jasco J-810 spectropolarimeter in quartz cuvettes with a $1 \mathrm{~mm}$ path length by Brian Train in the School of Pharmacy at WVU. Background scans of the buffers (non-buffered water, $2 \mathrm{MNaCl}$, and methanol) were performed beforehand and the scan was set to automatically subtract the baseline in real-time during acquisition. A continuous scanning mode of $50 \mathrm{~nm} / \mathrm{min}$ was used to collect data with a pitch of $1 \mathrm{~nm}$ and a bandwidth of 2nm. Data was collected in triplicate from $190 \mathrm{~nm}$ to $300 \mathrm{~nm}$. The peptide and the copolymer samples were prepared at approximately $0.5 \mathrm{mg} / \mathrm{mL}$ in non-buffered water. 


\subsection{Dynamic Light Scattering}

Dynamic Light Scattering was also used to characterize the behavior of the (GAGPGP) $)_{12}$ peptide in aqueous solutions. The hydrodynamic diameter of each sample was evaluated on a Zetasizer NanoSeries Nano-ZS model ZEN-3600 by Malvern Instruments. The light source was a He-Ne laser with a wavelength of $633 \mathrm{~nm}$ and the detector at a $173^{\circ}$ scattering angle. The DTS Nano software was used in Size mode to perform size measurements of a $1 \mathrm{mg} / \mathrm{mL}$ solution $(\text { GAGPGP })_{12}$ in non-buffered water.

\subsection{Hybrid Block Copolymer and Biological Block Copolymer Production}

\subsection{Peptide His-Tag Removal}

To remove the His-tag from the VA2 peptide a protocol utilizing cyanogen bromide from Short Protocols in Molecular Biology was used to hydrolyze the peptide bond on the C-terminal side of the methionine residue (see Figure $5 \mathrm{a}$ for the location of the Met residue). ${ }^{67}$ Approximately $3 \mathrm{mg}$ of VA2 was reconstituted in $3 \mathrm{~mL}$ of a solution of $50 \mathrm{mg} / \mathrm{mL}$ cyanogen bromide in $70 \%$ formic acid and incubated at room temperature overnight. The reacted sample was dialyzed in nonbuffered water, froze, and lyophilized.

\subsection{Biological Block Copolymer Coupling}

The VA2 peptide was coupled to (GAGPGP $)_{12}$ through a condensation reaction using 2-(1HBenzotriazole-1-yl)-1,1,3,3-tetramethyluronium hexafluorophosphate (HBTU) and the activating agent N,N-Diisopropylethylamine (DIEA). A typical reaction involved dissolving about $8 \mathrm{mg}$ of VA2 in $1 \mathrm{~mL}$ of DMSO, adding $10 \mathrm{mg}$ of (GAGPGP) ${ }_{12}, 26.7 \mu \mathrm{mol}$ of HBTU, and $267 \mu \mathrm{mol}$ of DIEA. This reaction covalently bound available amine groups to available carboxylic acid groups between the peptides while in suspension.

\subsection{Solid Phase Characterization}

\subsection{Thin Film Preparation}

To investigate the properties of (GAGPGP) $)_{12}$, hybrid copolymers, and biopolymers in the solid state solutions of each were dried onto silicon wafers. Before use the silicon wafers were rinsed with both deionized/distilled water and ethanol. (GAGPGP) ${ }_{12}$ at a concentration of $0.15 \mathrm{mg} / \mathrm{mL}$ in water was spotted onto the wafer and allowed to dry overnight at $37^{\circ} \mathrm{C}$.

Spin coating was used to investigate the effect of solvent evaporation on the films with a P6700 Series Spincoated from Specialty Coatings Systems, Inc. A $0.15 \mathrm{mg} / \mathrm{mL}$ solution of (GAGPGP) $)_{12}$ 
in water was dropped onto a Si wafer and spun at 1200 rpms for 1 minute. The sample was then left to further dry overnight at $37^{\circ} \mathrm{C}$.

Hybrid copolymer blends were prepared by combining $10 \mu \mathrm{L}$ of $2 \mathrm{mg} / \mathrm{mL}$ (GAGPGP) ${ }_{12}$ in water and $10 \mu \mathrm{L}$ of $2 \mathrm{mg} / \mathrm{mL}$ PAA in water. The blended hybrid copolymer was spotted onto a wafer and allowed to dry overnight at room temperature. Samples containing varying ratios of $(\text { GAGPGP })_{12}$ to PAA in water were prepared with the same procedure.

The peptides polyE, ELP, and VA2 were each spotted onto silicon wafers at a concentration of $2 \mathrm{mg} / \mathrm{mL}$ and allowed to dry overnight at room temperature. Thin films of biopolymer blends were produced by combining $10 \mu \mathrm{L}$ of $2 \mathrm{mg} / \mathrm{mL}$ (GAGPGP) $)_{12}$ in water with $10 \mu \mathrm{L}$ of the respected peptide at $2 \mathrm{mg} / \mathrm{mL}$ and allowed to dry overnight at room temperature.

\subsection{Nickel Nanoparticle Synthesis and Composite Preparation}

Nickel nanoparticles were produced by implementing a metal reduction method published in 2009 by Sidhaye et al. in the Journal of Physical Chemistry $C^{68}{ }^{6}$ The reaction consisted of dissolving $0.1 \mathrm{mmol}$ of Nickel sulfate hexahydrate into $100 \mathrm{~mL}$ deionized/distilled water at room temperature. SDS was added to operate as a surfactant in the solution for a concentration of $10 \mathrm{mM}$ and $0.1 \mathrm{mM}$ of oleic acid was added to perform as a capping agent to the nanoparticles. While stirring, $25 \mathrm{mg}$ of sodium borohydride was added to the solution to reduce the nickel metal ions. The solution was left to stir at room temperature for 1 hour. To purify the nanoparticles away from the excess reagents and reaction products, the solution was centrifuged at $9000 \mathrm{rpm}$ for 20 minutes. The supernatant was removed from the pellet and the pellet was resuspended in approximately $8 \mathrm{~mL}$ of deionized/distilled water. The nanoparticle solution was centrifuged again and the pellet rinsed again under the same conditions for a total of four washes.

To observe the behavior of the Ni nanoparticles in a composite thin film with blended hybrid copolymer (GAGPGP) $)_{12}$-PAA, $10 \mu \mathrm{L}$ of $2 \mathrm{mg} / \mathrm{mL}$ (GAGPGP) 12 in $\mathrm{pH} 10$ aqueous solution was combined with $10 \mu \mathrm{L}$ of $2 \mathrm{mg} / \mathrm{mL}$ PAA in $\mathrm{pH} 10$ aqueous solution. A $5 \mu \mathrm{L}$ volume of the $\mathrm{Ni}$ nanoparticle solution was added to the blended solution of (GAGPGP) $)_{12}$-PAA and incubated at room temperature for 20 minutes. The mixture was spotted onto a silicon wafer and allowed to dry overnight at room temperature.

\subsection{Scanning Electron Microscopy}

The surface of dried samples of (GAGPGP) $)_{12}$ on silicon wafers was inspected with a Hitachi S4700 Scanning Electron Microscope (SEM) with a cold field emission electron source. Samples 
were analyzed without coating. The instrument was operated by the Chemical Engineering Department Research Assistant Adrienne McGraw.

\subsection{Atomic Force Microscopy}

Tapping mode atomic force microscopy (AFM) was also used as a tool to investigate the topography and phase behavior of the dried (GAGPGP) ${ }_{12}$ samples. The instrument used was an Agilent Technologies (Molecular Imaging) PicoScan 3000 with a mechanical and acoustical vibration isolation chamber. Analysis was performed under ambient conditions with a standard silicon NSC-316 tips that had nominal spring constants of $50 \mathrm{~N} / \mathrm{m}$ and resonance frequencies of approximately $170 \mathrm{kHz}$. The software used was PicoScan 5 and images were processed in flattened mode.

\subsection{Transmission Electron Microscopy}

The TEM used to image (GAGPGP) 12 was a JEOL TEM-2100. A volume of $5 \mu \mathrm{L}$ of $2 \mathrm{mg} / \mathrm{mL}$ $(\text { GAGPGP })_{12}$ was spotted onto a carbon Type-A TEM grid and allowed to dry overnight at room temperature. The sample was analyzed with the assistance of Dr. Marcela Redigolo.

\subsection{Differential Scanning Calorimetry}

Differential scanning calorimetry (DSC) thermographs were obtained on a TA Instruments DSC Q100 using TA Instrument Explorer software with the help of Adam Finniss. Universal Analysis 2000 software was also used to view and graph the thermographs. The (GAGPGP) ${ }_{12}$ sample was prepared by drop casting approximately $50 \mu \mathrm{L}$ of a $100 \mathrm{mg} / \mathrm{mL}$ (GAGPGP) ${ }_{12}$ sample in water into a pre-weighed DSC pan. After drying at room temperature overnight, the sample was left overnight in a vacuum oven at $60^{\circ} \mathrm{C}$ to remove any residual water from the sample. The DSC pan was weighed again and the mass of dried (GAGPGP) ${ }_{12}$ was determined to be $4.400 \mathrm{mg}$. The same method was used for the 1:1 wt ratio PAA/(GAGPGP) $)_{12}$ blend with a mass of $2.065 \mathrm{mg}$. PAA was directly taken from the manufacturer bottle and placed into a pre-weighed DSC pan. The sample was left in the vacuum oven at $60^{\circ} \mathrm{C}$ overnight. The final mass of PAA was $2.050 \mathrm{mg}$. Another PAA sample was prepared by reconstituting PAA in water a concentration of $100 \mathrm{mg} / \mathrm{mL}$ and drop casting about $50 \mu \mathrm{L}$ of the solution into a pre-weighed DSC pan. The final mass of the drop cast PAA sample was $5.080 \mathrm{mg}$. 


\section{Chapter 3 Results and Discussion}

\subsection{Peptide Design and Production}

DNA manipulation began with digesting both pET-19b and G-over insert with the restriction enzymes Bam HI and Nco I. A volume of $20 \mu \mathrm{L}$ of pET-19b plasmid purified from E. coli with a QIAprep Spin digested with Bam HI and Nco I for 30 minutes was run on a 1.5\% agarose gel along with $20 \mu \mathrm{L}$ of purified undigested pET-19b (see Figure 6a). Similarly, $36 \mu \mathrm{L}$ of digested pJ201-G-over was run on a 2.0\% agarose gel (see Figure 6b).
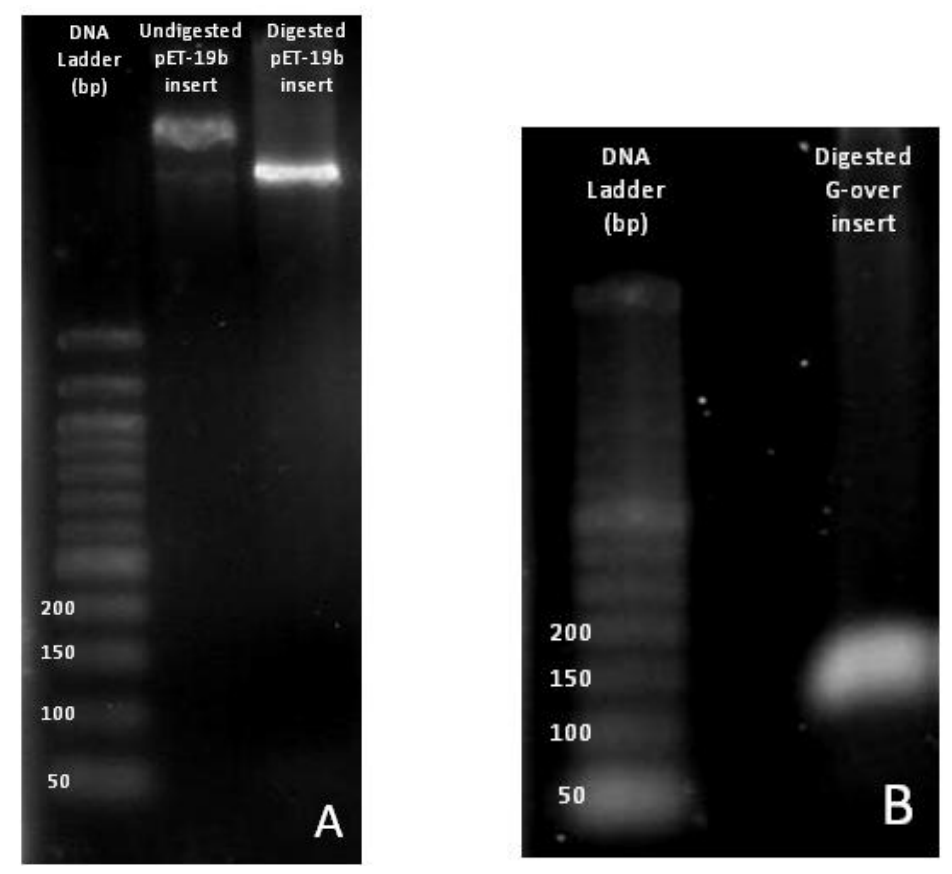

Figure 6 A) Successful digestion of pET-19b with Bam HI and Nco I restriction enzymes, and B) Successful digestion of pJ201-G-over with Bam HI and Nco I restriction enzymes

Theoretically, the digest should have resulted in a 79 bp segment and a 5638 bp segment of the plasmid. The difference in the height of both samples indicates that the digestion by restriction enzymes was effective. The G-over insert was expected to be $115 \mathrm{bp}$ and Figure $6 \mathrm{~b}$ clearly shows a band between $100 \mathrm{bp}$ and $150 \mathrm{bp}$ indicating an effective digestion. After successfully digesting the plasmid pET-19b and the G-over insert, the G-over insert was ligated into the pET-19b plasmid. Because the plasmid and the insert were digested with the same restriction enzymes, the sticky ends of the inserts and plasmid match, and therefore the insert can be ligated in the correct orientation within the plasmid. The ligated pET-19b-G-over DNA was digested with the restriction enzyme Sap I and $20 \mu \mathrm{L}$ of the digest was run on a 1.5 agarose gel (see Figure $7 \mathrm{a}$ ). The GAGP insert coding for the peptide with (GAGPGP) 12 sequence was digested from the 
manufacturer's plasmid (pJ201) with Sap I restriction enzyme and run on a 2.0\% agarose gel (see Figure $7 b)$.
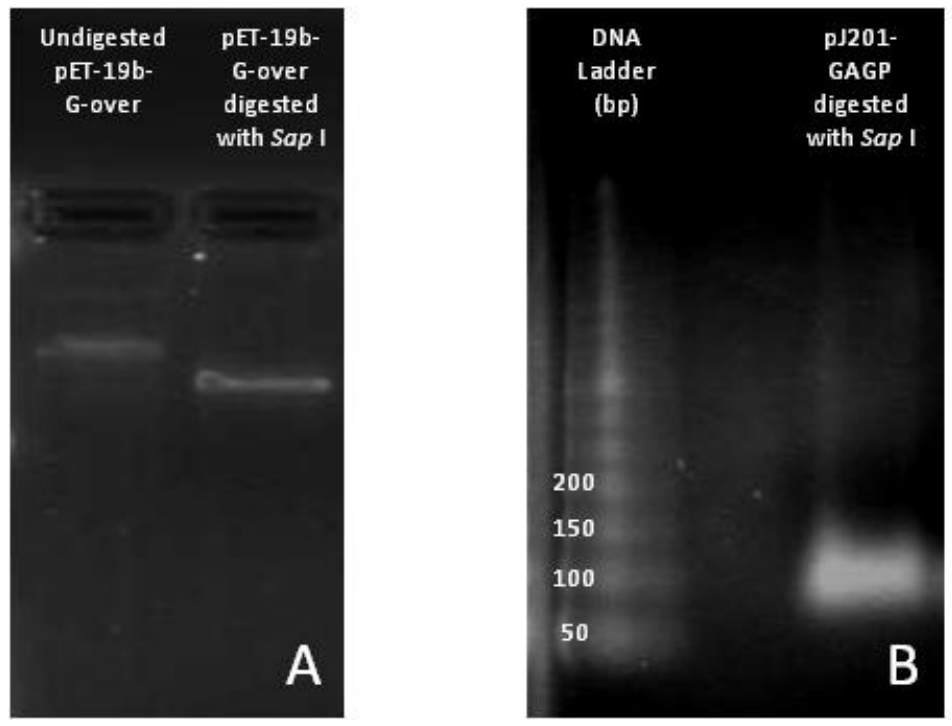

Figure 7 A) Successful Sap I digestion of pET-19b-G-over, and B) successful Sap I digestion of DNA coding for the (GAGPGP) $)_{12}$ peptide

The Sap I enzyme should have removed 55 bp from pET-19b-G-over. The gel picture in Figure 7a shows the difference between an undigested pET-19b-G-over sample and a digested sample. This difference demonstrates a successful Sap I digestion. The GAGP insert was expected be 72 bp, and in Figure 7b, a band appears on the 2\% agarose gel just below the 100 bp reference band showing a successful digestion of the DNA coding for (GAGPGP) $)_{12}$.

Lastly, the GAGP insert coding for the (GAGPGP) ${ }_{12}$ peptide was ligated into the pET-19b-Gover. Again, because both pieces of DNA were digested with Sap I, the sticky ends should match. Because Sap I was used to digest both ends of the insert and plasmid rather than two different restriction enzymes, the DNA can ligate together forming multiple (GAGPGP) ${ }_{12}$ coding regions that insert themselves into the plasmid. To confirm the ligation of the DNA coding for (GAGPGP $_{12}$ into pET-19b-G-over, restriction enzymes Nco I and Eco RI were used to cut around the modified portion of the plasmid, and the digest was run on an $2 \%$ agarose gel. The results from multiple ligated samples can be seen below in Figure 8. 


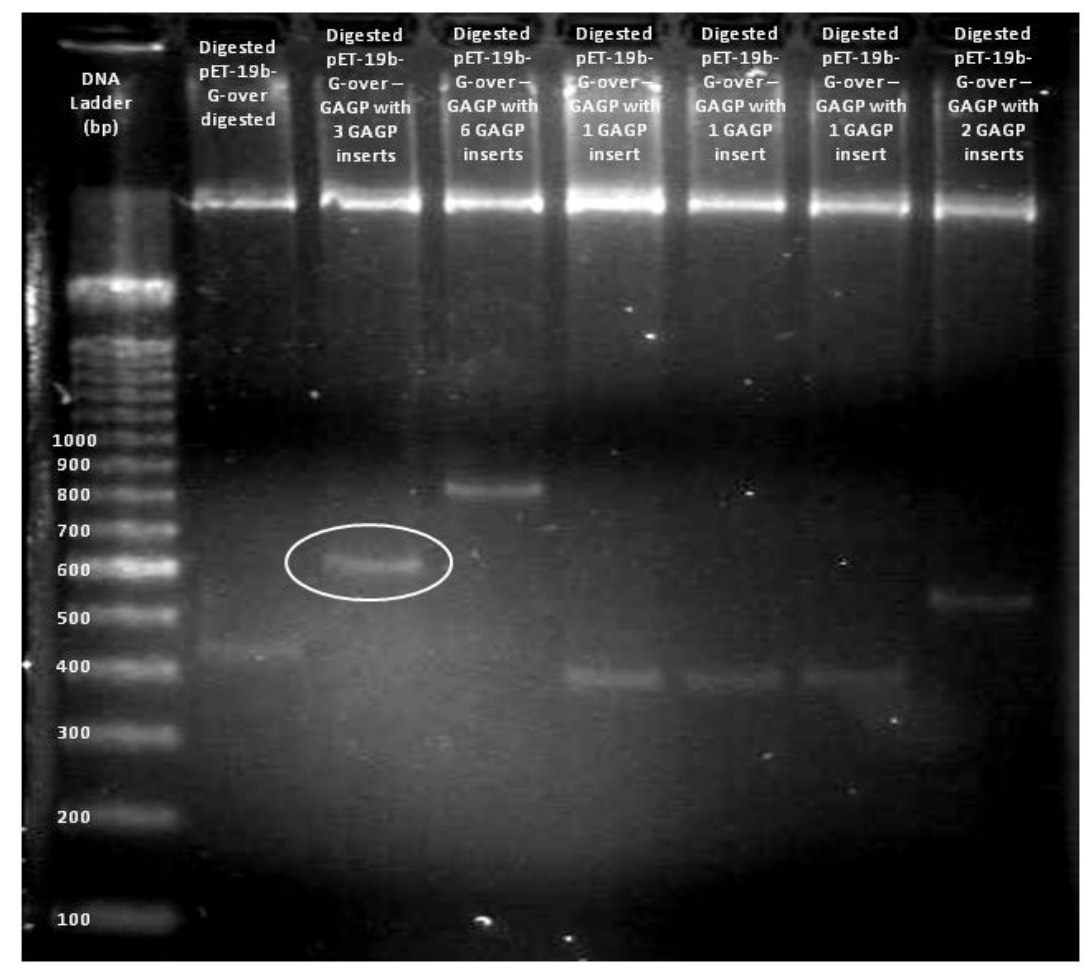

Figure 8 DNA coding for (GAGPGP) ${ }_{12}$ ligated into G-over/pET-19b

The bands from each digested sample can be compared to the base pair reference standard on the left-hand side of the gel. The lengths of the digested samples were estimated from the gel, and nucleotide sequencing at the Biology Genomics lab at WVU confirmed the sequence of all samples (see Appendix A). Through this recombinant DNA strategy, four lengths of the GAGP multimers (1, 2, 3, and 6) were successfully ligated into the pET-19b expression plasmid. The sample pET-19b with three inserts of DNA coding for a peptide with the sequence (GAGPGP) $)_{12}$ (circled in Figure 8) was chosen as the DNA insert to work with for all phase separation experiments. The DNA coding a peptide with the sequence (GAGPGP) ${ }_{12}$ was chosen because the molecular weight of the peptide was about $10 \mathrm{kDa}$ which was comparable to the molecular weights of synthetic polymers in house and the peptide was easily expressed by E. coli.

\subsection{Peptide Characterization}

The DNA coding for (GAGPGP) 12 was transformed into E. coli and the target protein was expressed. Once produced, the peptide was purified with using the His-tag on the peptide and NiNTA affinity chromatography. A $10 \mu \mathrm{L}$ aliquot from each column rinse and elution was collected and run on a 15\% SDS-PAGE gel (see Figure 9). 


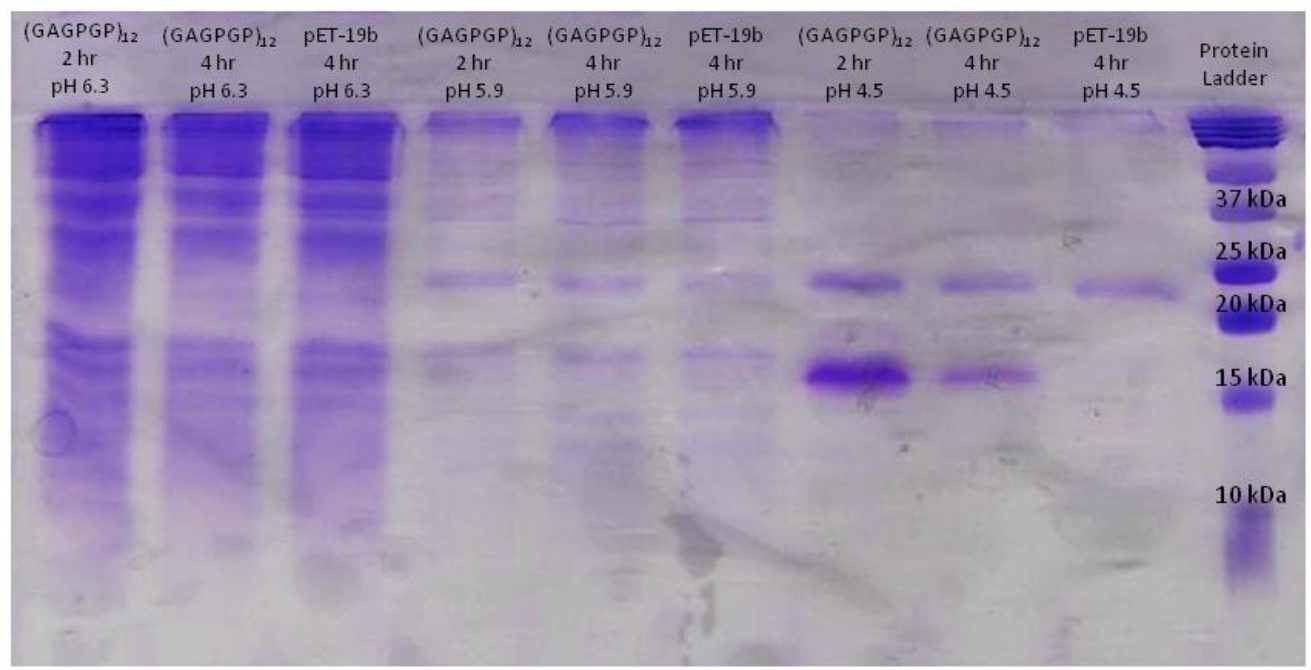

Figure 9 Purification profile of (GAGPGP) 12

The purification profile shown in Figure 9 shows the removal of the natural proteins produced by E. coli through successive decreases in $\mathrm{pH}$ from $\mathrm{pH} 6.3$ to 5.9. The target peptide was eluted with a solution at $\mathrm{pH} 4.5$ and the SDS-PAGE shows a band at a molecular weight of about $16 \mathrm{kDa}$. The gel in Figure 9 also shows the results of testing two different durations of expression time to optimize the amount of peptide produced. Additionally, a control sample of pET-19b without DNA coding for the (GAGPGP) $)_{12}$ peptide was expressed and purified along side of the samples to confirm the absence of the (GAGPGP) $)_{12}$ peptide in the control. The lighter band seen in both samples and the control around $21 \mathrm{kDa}$ was a natural protein expressed by E. coli called SlyD. SlyD has many histidines and nonspecifically binds the Ni-NTA column along with the target peptide. To remove this contaminate protein, a small concentration of imidazole was used in the purification and elution buffers. The results of this SDS-PAGE study indicate that the (GAGPGP) ${ }_{12}$ peptide could be accurately produced and purified from other proteins and peptides in the expression host $E$. coli.

On SDS-PAGE gels, the band of our target protein appears at a molecular weight of $\sim 16 \mathrm{kDa}$ (see Figure 9). This molecular weight was higher than expected for the (GAGPGP) $)_{12}$ molecule as nucleotide analysis indicates nucleotides coding for a peptide with a molecular weight of $7.8 \mathrm{kDa}$ (see Appendix A). It is predicted that because the peptide hydrophobic and electrophoresis is run in an aqueous environment, (GAGPGP) $)_{12}$ may be aggregating and running at double the actual molecular weight of the peptide. To further confirm that the band appearing at $16 \mathrm{kDa}$ is $(\text { GAGPGP })_{12}$, a Western Blot was run and the results shown in Figure 10. 


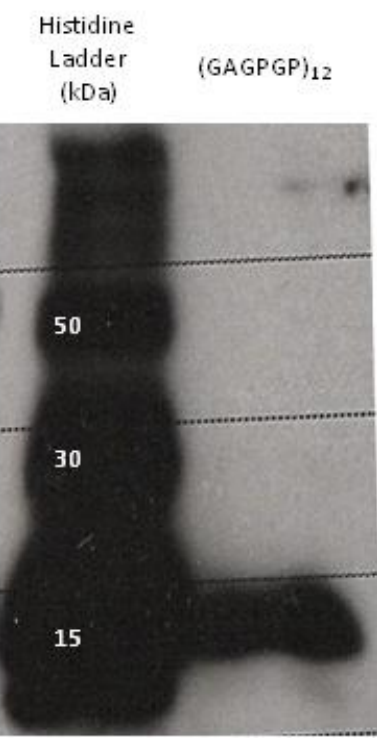

Figure 10 Western Blot analysis of (GAGPGP) $)_{12}$ peptide

The binding of the anti-His antibody to the band at $16 \mathrm{kDa}$ confirms the presence of a His-tag located at the beginning of the expressed (GAGPGP) ${ }_{12}$ peptide. Natural E. coli peptides of this molecular weight that might have been eluted at $\mathrm{pH} 4.5$ would not have enough histidine residues to bind the anti-His antibodies on a Western Blot. Furthermore, an amino acid analysis of the (GAGPGP) ${ }_{12}$ peptide eluted at $\mathrm{pH} 4.5$ was performed at the Proteomics Core at the University of California Davis (see Table 1).

Table 1 Amino acid analysis results of the (GAGPGP) 12 peptide

\begin{tabular}{|c|c|c|c|}
\hline $\begin{array}{c}\text { Amino } \\
\text { Acid }\end{array}$ & $\begin{array}{c}\text { Expected } \\
\text { Mole \% }\end{array}$ & $\begin{array}{c}\text { Actual } \\
\text { Mole \% }\end{array}$ & Deviation \\
\hline Asx & 1.087 & 1.423 & $0.336 \%$ \\
\hline Ser & 2.174 & 2.372 & $0.198 \%$ \\
\hline Pro & 26.087 & 26.561 & $0.474 \%$ \\
\hline Gly & 42.391 & 39.892 & $-2.499 \%$ \\
\hline Ala & 13.043 & 12.894 & $-0.149 \%$ \\
\hline Met & 1.087 & 1.107 & $0.020 \%$ \\
\hline Ile & 1.087 & 1.721 & $0.634 \%$ \\
\hline Tyr & 1.087 & 0.874 & $-0.212 \%$ \\
\hline His & 11.957 & 11.694 & $-0.262 \%$ \\
\hline
\end{tabular}

The results of the amino acid analysis of (GAGPGP) $)_{12}$ peptide shows less than a $2.5 \%$ deviation in all expected amino acids in the (GAGPGP) ${ }_{12}$ peptide. Together the results of the SDS-PAGE, 
Western Blot, and amino acid analysis characterization techniques ensure the (GAGPGP $)_{12}$ peptide was indeed the molecule that was designed to for the biological polymer studies planned for this research.

The (GAGPGP) 12 peptide was designed to have a random coil secondary structure in aqueous environments, and to determine the actual secondary structure of the peptide circular dichroic spectroscopy (CD) was utilized. A $0.5 \mathrm{mg} / \mathrm{mL}$ sample of (GAGPGP) $)_{12}$ in non-buffered water was run on the $\mathrm{CD}$, and the results of the $\mathrm{CD}$ analysis are shown below in Figure 11.

\section{$(\text { GAGPGP })_{12}$}

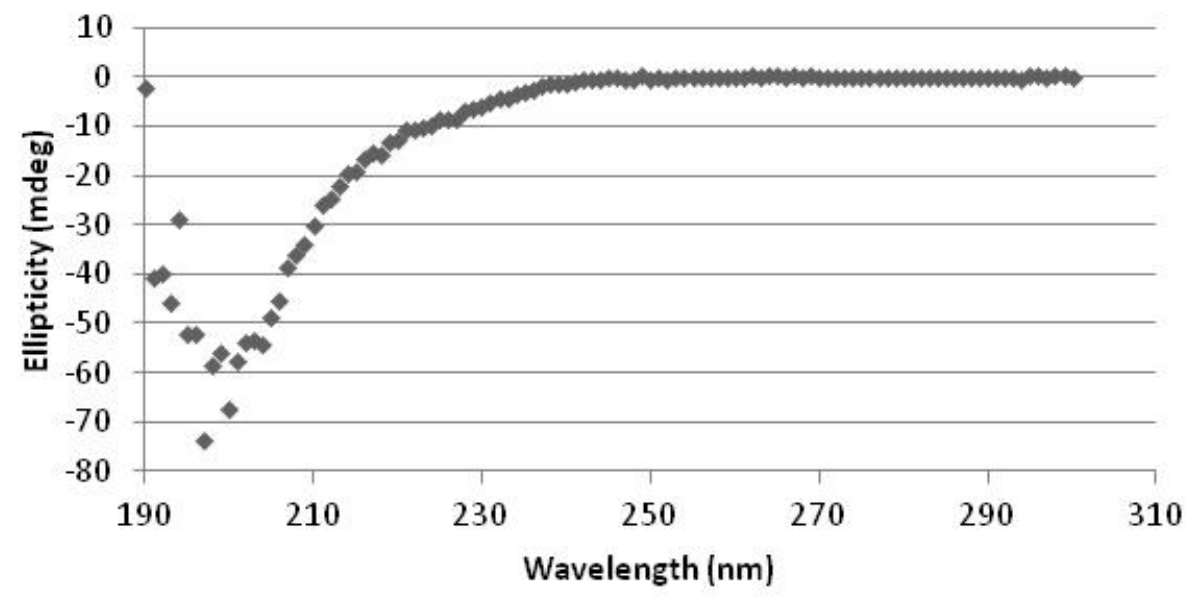

Figure $11 \mathrm{CD}$ evaluation of $0.5 \mathrm{mg} / \mathrm{mL}$ (GAGPGP) ${ }_{12}$ in non-buffered water

The single minimum observed at approximately $197 \mathrm{~nm}$ without an apparent maximum confirms a random coil secondary structure of the peptide. A random coil secondary structure indicates that the peptide does not adopt an $\alpha$-helix conformation or form $\beta$-sheets in aqueous solution, ensuring flexibility of the peptide molecule.

The sequence, molecular weight, and secondary structure of (GAGPGP) $)_{12}$ were confirmed by various analytical techniques and all confirmed that the peptide produced by the E.coli expression host was the intended peptide. To determine if the peptide was capable of forming a continuous solid state film, (GAGPGP) $)_{12}$ was dried onto silicon wafers and observed with SEM and AFM. The first sample of (GAGPGP) $)_{12}$ peptide was a $0.15 \mathrm{mg} / \mathrm{mL}$ solution of (GAGPGP) 12 in water was spotted onto a silicon wafer and allowed to dry overnight at $37^{\circ} \mathrm{C}$. An image from SEM analysis can be seen in Figure 12. 


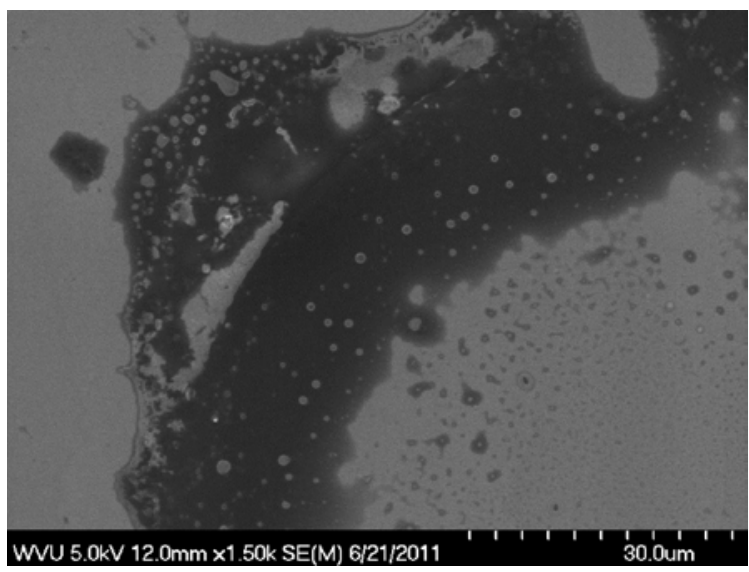

Figure 12 SEM image of a $2 \mathrm{mg} / \mathrm{mL}$ solution of (GAGPGP) $)_{12}$ in water dried onto Si

The image in Figure 12 shows the differences in contrast and film features between the edges and center of a droplet of (GAGPGP) $)_{12}$ dried on Si. Around the edges of the sample there is a dark background with light grey circular features that resemble flatten micelles or vesicles. In the center of the sample, there is a light grey background color with darker grey features. Some of these features are irregular in shape and within the irregular shapes there are appear to be circular shapes. To investigate the circular and irregular shaped features further, higher magnification images of both the edge of the sample (Figure 13a) and center (Figure 13b) of the same (GAGPGP) $)_{12}$ sample spotted onto Si.
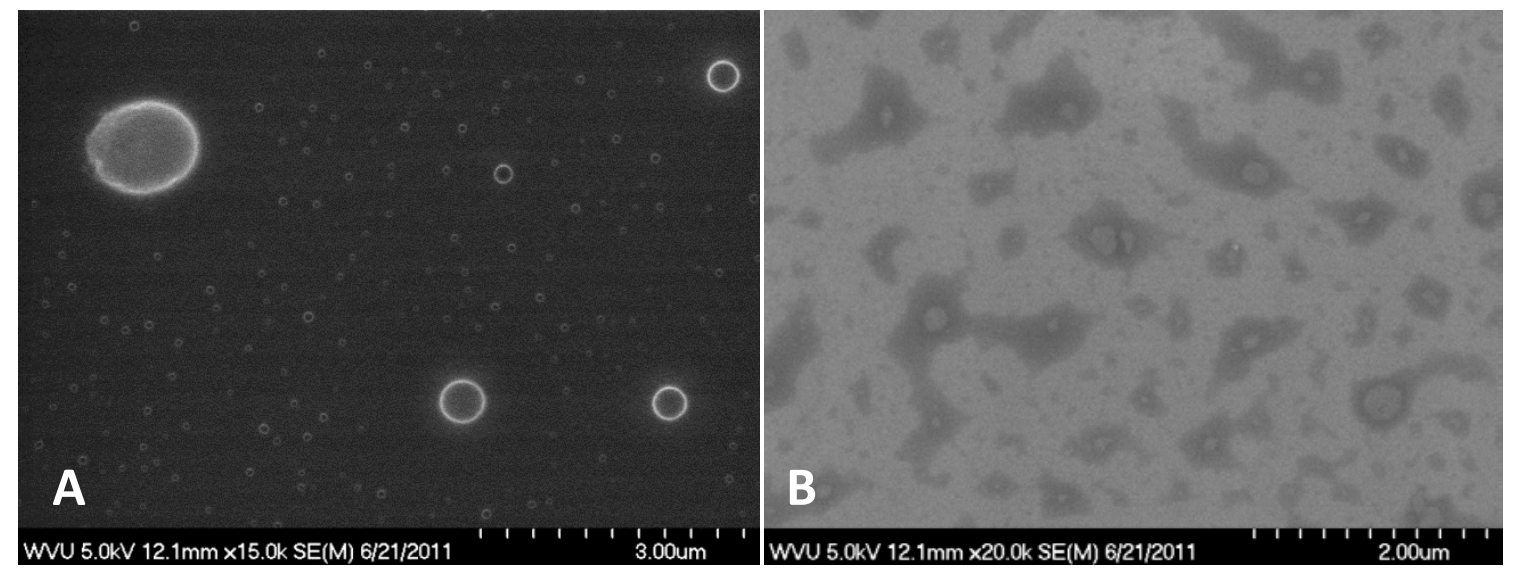

Figure 13 A) Detailed SEM image of (GAGPGP) $)_{12}$ taken at the edge of the sample and, B) Detailed SEM image of (GAGPGP) $)_{12}$ taken at the center of the sample

The circular-shaped features at the edge of the sample appear to be micelles or vesicles that formed in the liquid state of the sample and retained their shape after the water evaporated at the edge of the sample. The (GAGPGP) $)_{12}$ molecule was not intentionally designed to be amphiphillic and form micelles, but it is possible that the His-tag on the front of the peptide is acting as the 
hydrophilic end of the molecule, while the alanine residues throughout the rest of the molecule are acting as the hydrophobic end. According to the Kyte-Doolittle hydropathy scale histidine is very hydrophilic with a score of -3.2 on a scale of 4.6 to -4.6 where -4.6 is most hydrophilic. ${ }^{69}$ Alanine has a score of 1.8 making it a hydrophobic residue. Glycine is almost neutral at a score of 0.4 and proline is considered hydrophilic with a score of -1.6. Although it does not seem that an alanine placed every six residues throughout the peptide could cause much of a hydrophobic behavior, the results of the SDS-PAGE gel (see Figure 9) support the idea that the (GAGPGP) ${ }_{12}$ molecules prefer to aggregate in an aqueous environment. From SEM analysis it appears these aggregations may be self-assembled micelles. In the SEM image from the center of the sample multiple shades of grey can be observed. The reason for the differences in contrast is not clear, but it seems that micelles or vesicles are also present in this section of the sample. Although SEM is not the ideal method of determining height differences between features in a sample, it seems as though the circular-structures are within a matrix of the peptide.

While SEM analysis was useful for obtaining an overall 2D image of the sample, it is difficult to distinguish between different phases of a sample and heights of features within the sample. To achieve this type of phase analysis and topography analysis, tapping mode AFM was employed. A $2 \mathrm{mg} / \mathrm{mL}$ solution of (GAGPGP) ${ }_{12}$ in water was spotted onto a silicon wafer and allowed to dry overnight at room temperature. An image obtained by tapping mode AFM can be seen below in Figure 14.

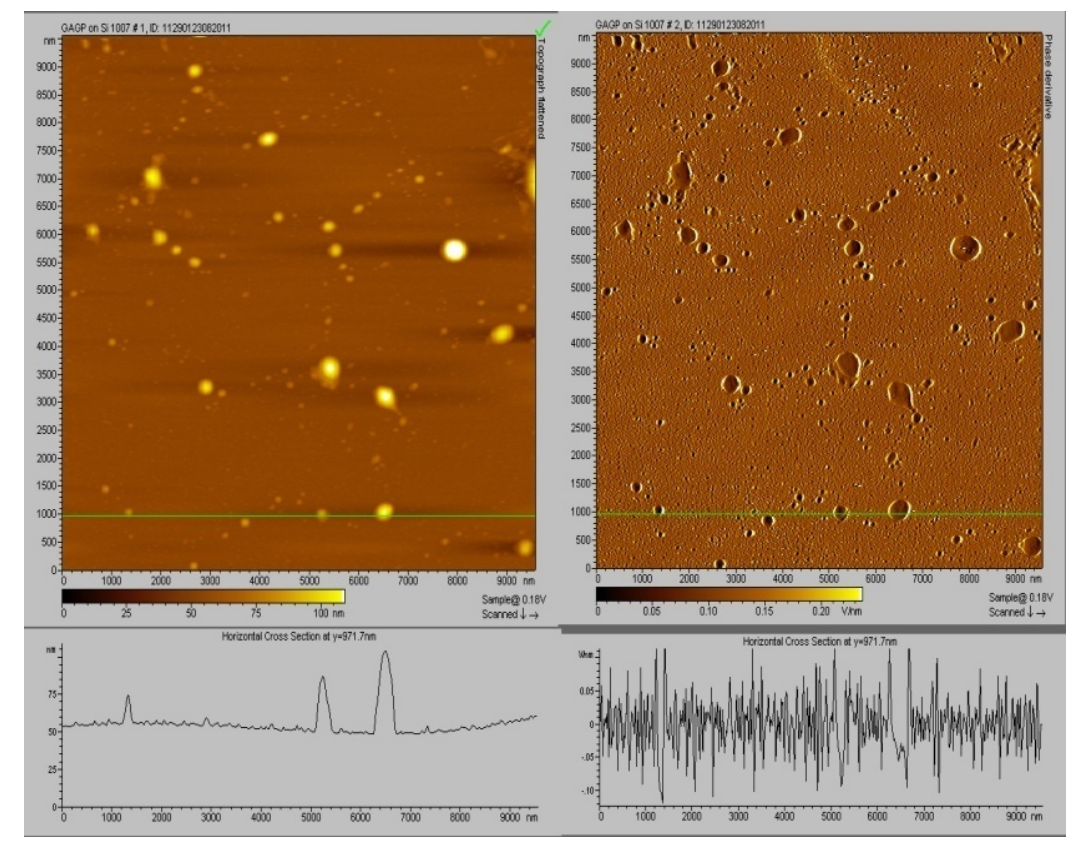

Figure 14 AFM topology (left) and phase (right) analysis of (GAGPGP) ${ }_{12}$ dried at room temperature on Si 
The topology image shows obvious height differences in the spherical assemblies compared to the background of the image, but there is no significant difference in contrast in the phase image. The lack of a change in the phase angle on the phase image indicates that the sample composition is continuous throughout the sample. The height differences observed in the spherical structures could indicate various sizes of micelles survived the overnight evaporation of solvent.

To further investigate the relationship between the circular-shaped and spherical-shaped morphologies versus the transition from liquid state to solid state, (GAGPGP) 12 samples were spin coated onto the silicon wafer resulting in a faster drying rate than simple evaporation. A $10 \mu \mathrm{L}$ volume of $0.15 \mathrm{mg} / \mathrm{mL}$ (GAGPGP) $)_{12}$ in water was spotted onto a silicon wafer and spun at 1200 rpms. SEM was used to visualize both the edge (Figure 15a) and center (Figure 15b) of the sample on Si.
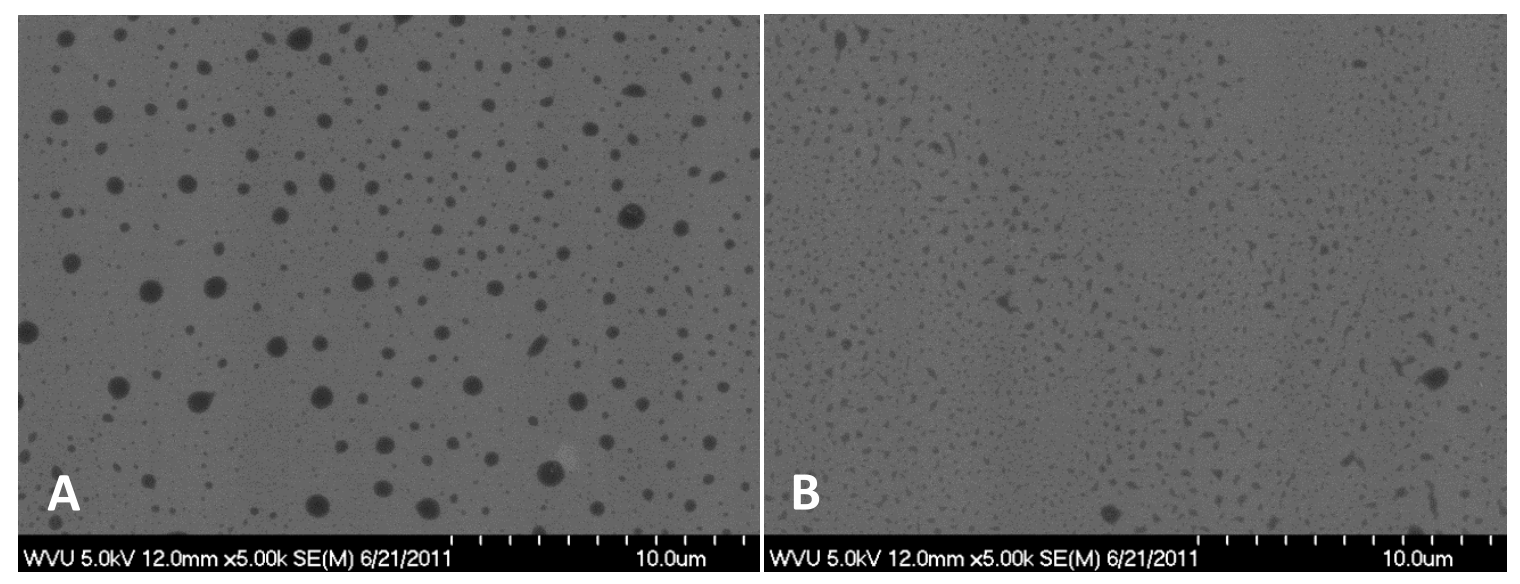

Figure 15 A) SEM image of spin coated (GAGPGP) ${ }_{12}$ on Si taken at the edge of the sample and, B) SEM image of spin coated (GAGPGP) $)_{12}$ on $\mathrm{Si}$ in the center of the sample

Similar to the evaporated sample of (GAGPGP) ${ }_{12}$, the spin coated sample also appears to have spherical-shaped and irregular-shaped features. Near the edge of the sample shown in Figure 15a, the majority of the shapes are circular, like in the evaporated sample. It appears that the circular shapes in this sample are holes within a matrix of peptide. It seems possible the micelles that may have formed in the liquid state were spread over the silicon wafer during spin coating, and then burst due to the faster drying rate creating holes. Also like the evaporated sample, an SEM image from the center of the spin coated sample show mainly irregular-shaped features (see Figure 15b). Both the reason for the formation of these irregular shapes and the multiple shades of grey that appear in the SEM image are unclear. Unlike the (GAGPGP) ${ }_{12}$ sample that simply evaporated, the entire spin coated sample has black features within a light grey background. 
Spherical-shaped and irregular-shaped features were found in every solid film of (GAGPGP $)_{12}$ observed by SEM or AFM. It was thought that (GAGPGP) $)_{12}$ must be undergoing some type of self-assembly process while in the liquid state and the assembled structures maintained their shape while drying. To observe the behavior of (GAGPGP) ${ }_{12}$ in the liquid state, $1 \mathrm{mg} / \mathrm{mL}$ samples were evaluate with dynamic light scattering (DLS). The percentage of number of particles at each hydrodynamic diameter is shown below in Figure 16.

\begin{tabular}{|c|c|c|c|c|c|}
\hline & & & Diam. (mm) & ¿ Number & Wicthlo (nm) \\
\hline Z-Aver aye (tl.nun: & 1030 & Peak 1: & 296.0 & 44.1 & 80.77 \\
\hline Pill: & 0.354 & Peak 2: & 924.0 & 55.9 & 382.0 \\
\hline Intercept: & 0.968 & Peak 3: & 0.000 & 0.0 & 0.000 \\
\hline
\end{tabular}

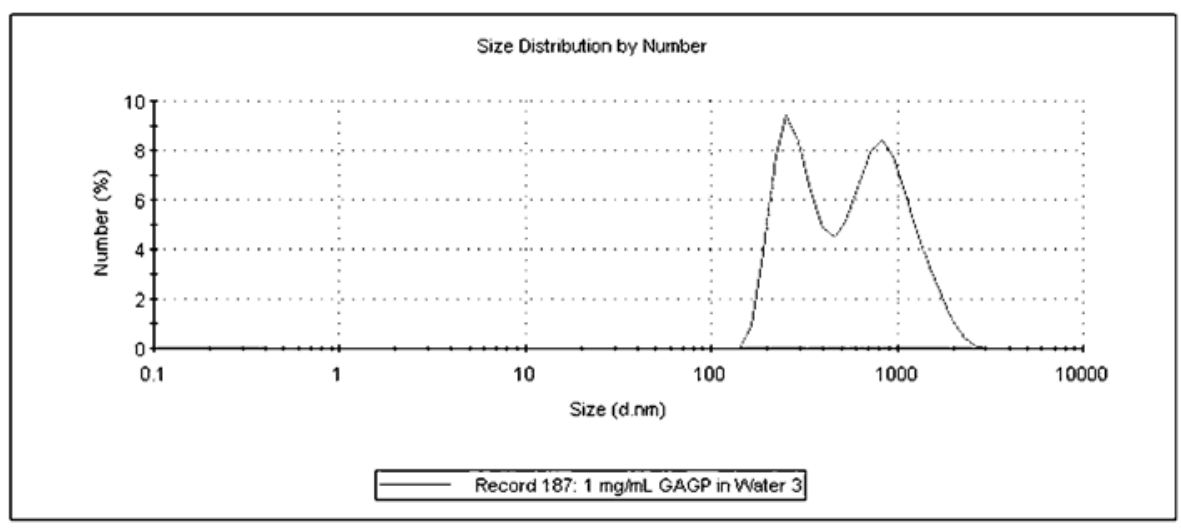

Figure 16 DLS results of a $1 \mathrm{mg} / \mathrm{mL}$ solution of (GAGPGP) $)_{12}$ in water

The DLS results confirm that aggregations of a various sizes are occurring when (GAGPGP) $)_{12}$ is in an aqueous environment. The size range of about $150 \mathrm{~nm}$ to $3000 \mathrm{~nm}$ agrees with the range of circular-shaped features observed in the SEM image of the edge of a (GAGPGP) ${ }_{12}$ sample (see Figure 13a). It is clear from the DLS results that the molecules of (GAGPGP) $)_{12}$ are aggregating in the liquid state into a very broad range of structures. If the structures were micelles, most often a narrow peak is documented at a small diameter size. ${ }^{70}$ The broad peaks are large diameters found from DLS analysis of (GAGPGP) ${ }_{12}$ suggest that the structures found in the films are vesicles.

TEM is another technique high utilized in the literature to evaluate phase separation in multicomponent polymer systems. To explore this option a $2 \mathrm{mg} / \mathrm{mL}$ solution of (GAGPGP) $)_{12}$ in water was spotted onto a carbon TEM grid and allowed to dry overnight at room temperature. Micrographs from the sample were obtained and can be found in Appendix B, but a continuous film could not be formed and maintained for solid state analysis. 
From the SEM and AFM solid phase analysis techniques, it appears that (GAGPGP) ${ }_{12}$ forms a mostly continuous peptide film on Si wafers. Circular-shaped or spherical-shaped features were found within all images taken of the (GAGPGP) ${ }_{12}$ films. DLS results suggest these spherical shaped features are micelles or vesicles forming in solution and most often flattening when dried. There are some instances of spherical shapes retaining their 3D structure when dried and this may be due to micelles-like aggregates forming during the drying process. Finally, no indications of multiple phase domains exist in the samples of (GAGPGP) ${ }_{12}$ dried onto a silicon wafer. To ensure a continuous film, as well as, the ease and simplicity of procedure, the method of spotting a solution onto the silicon wafer and drying at ambient temperature was used for all following sample preparations.

\subsection{Hybrid Synthetic Biological Polymer Blends}

\subsection{PNIPAM and GAGPGP Blend}

After thoroughly charactering (GAGPGP) ${ }_{12}$ films in the solid state, multiple synthetic polymers were blended with the (GAGPGP) 12 peptide to evaluate the behavior of multicomponent hybrid polymer systems. The synthetic polymer Poly(N-isopropylacrylamide) (PNIPAM) was blended with the (GAGPGP) $)_{12}$ peptide to explore the solid state behavior of a multicomponent hybrid polymer system. PNIPAM is water soluble at temperatures below $30^{\circ} \mathrm{C}$, but at higher temperatures the polymer molecules coacervate due to a lower critical solution temperature (LCST) of $31-33^{\circ} \mathrm{C}$ very similar to elastin-like-peptides (ELPs). ${ }^{71}$ The aim of this study was to combine this flexible random coil molecule with the slightly hydrophobic peptide (GAGPGP) $)_{12}$ in water below the LCST and determine if the differences in hydrophobicity was enough to drive phase separation in a solid film. If phase separation between (GAGPGP) 12 and PNIPAM was achieved, it may be an indication that phase separation between a peptides like ELP and $(\text { GAGPGP })_{12}$ was possible.

The hybrid polymer system was produced by combining (GAGPGP) $)_{12}$ and PNIPAM in water at $2 \mathrm{mg} / \mathrm{mL}$ total polymer concentration. Then the solution was drop casted onto silicon wafers and left to dry overnight at room temperature. The topology and phase image results of tapping mode AFM can be seen below in Figure 17. 


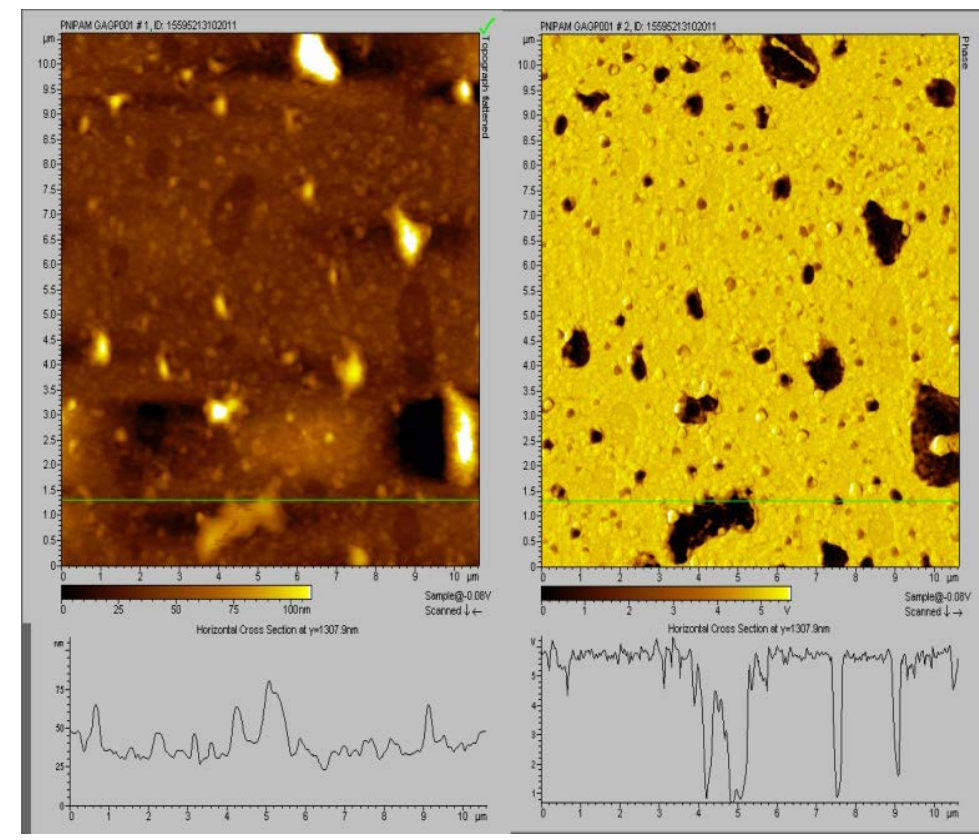

Figure 17 AFM topography (left) and phase (right) images of PNIPAM/(GAGPGP) ${ }_{12}$ blend dried on Si

The topography image in Figure 17 (left) show numerous spherical structures throughout the samples that appear to be smaller and more numerous than in previously studied (GAGPGP) $)_{12}$ samples. These spherical structures seem indicative of the globular structures that form when PNIPAM is dried into a film. Lu et al. published a studying in 2004 describing a surface roughness of about $5 \mathrm{~nm}$ due to globular structures that form during drying of PNIPAM-based polymers. ${ }^{72}$ Where the molecules of (GAGPGP) ${ }_{12}$ segregate when PNIPAM globules are formed in unclear. The topology image shows some large irregular-shaped features that could be large aggregates of (GAGPGP) $)_{12}$ sitting atop a film of PNIPAM. The phase image shows significant differences in the phase contrast, but these areas of large phase contrast also correspond to areas of large height differences. The contrast could be due to differences in composition or, as mentioned above in the introduction section addressing AFM, height is one many factors that can affect the phase angle displayed in the phase image of tapping mode AFM. It seems possible that the phase angle differences are an artifact of the height differences in those areas and not due to a change in composition of the material.

No further studies were performed with PNIPAM because of the strong tendency of PNIPAM to form globules on the surface of Si and possibility eject large aggregates of (GAGPGP) ${ }_{12}$ from the bulk of the material. Even when the temperature was kept below the LCST, the evaporation of the solvent seemed to cause globules to form. The effect of strong intermolecular associations formed 
within each PNIPAM molecule forming globules and how that affected phase separation with peptides in solid-state films was beyond the scope of this study.

\subsection{Poly(Acrylic Acid) and (GAGPGP) ${ }_{12}$ Blend}

The next synthetic polymer to be combined with (GAGPGP) ${ }_{12}$ was poly(acrylic acid) (PAA). PAA is a water soluble polymer composed a carbon backbone and carboxyl functional side chains. $^{73}$ This very hydrophilic polymer was combined with (GAGPGP) ${ }_{12}$ to determine if the difference in hydrophobicity between the macromolecules was enough to drive phase separation in a solid film. In addition, there has been no evidence of PAA forming any sort of globule-like structures in water, so this study was planned to eliminate the variable of intermolecular associations that were present in the PNIPAM study while investigating the effect of hydrophobicity. The peptide (GAGPGP) ${ }_{12}$ and PAA were combined at a 1:1 wt ratio in water at a $2 \mathrm{mg} / \mathrm{mL}$ concentration. The solution was dried on $\mathrm{Si}$ at room temperature overnight and analyzed using SEM (see Figure 18).

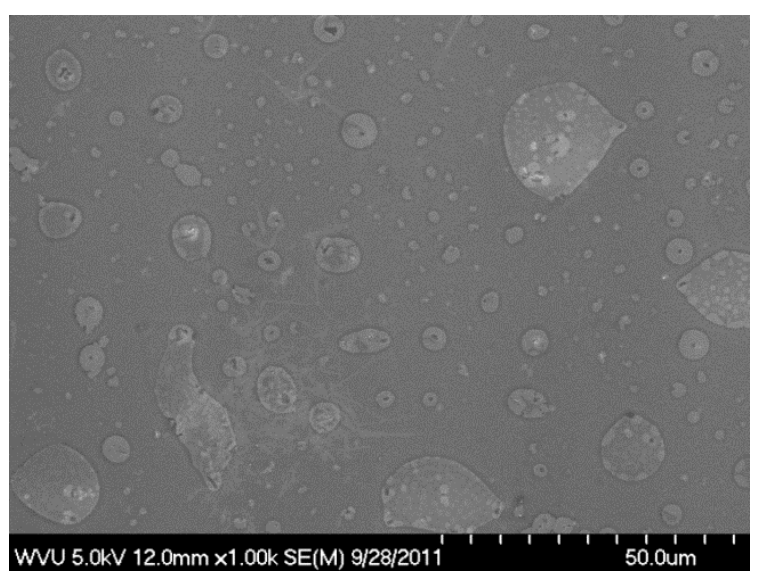

Figure 18 SEM image of dried solution of $2 \mathrm{mg} / \mathrm{mL}$ PAA/(GAGPGP) ${ }_{12}$ 1:1 wt ratio blend on Si 
The SEM image in Figure 18 shows large circular structures measuring $5 \mu \mathrm{m}$ in diameter and larger. Within the center and lining the perimeter of the large circular structures are light greycolored irregular-shaped features. It appears that there may be islands of one composition within a matrix of another composition, and within the islands is yet a third composition. To compare the composition of the island structures to the matrix AFM phase analysis was conducted on the same sample and the results shown below in Figure 19 (right).

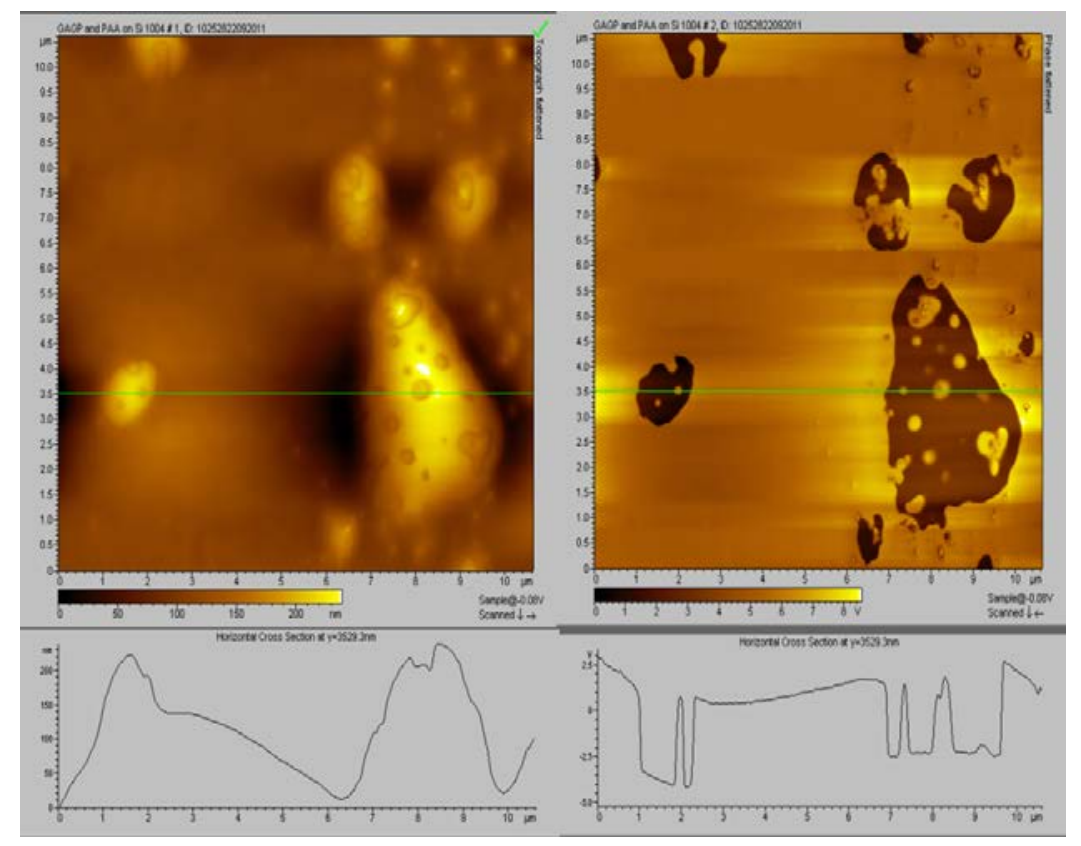

Figure 19 AFM topography image (left) and phase image (right) of dried droplet of $2 \mathrm{mg} / \mathrm{mL}$ PAA/(GAGPGP) ${ }_{12}$ $1: 1$ wt ratio blend on $\mathrm{Si}$

From the AFM topology image a difference in the height of the matrix and the height of the islands can be observed, and the phase image reveals there are large differences in the phase angle indicating the likelihood of two different compositions. For comparison, an AFM topographical and phase image of PAA alone on Si can be found in Appendix C. The blend structures resemble islands similar to those seen by Gutmann et al. when blending two strongly incompatible polymers of poly-styrene-stat-para-bromo-styrene copolymer each containing a different mole fraction of para-bromo-styrene. ${ }^{5}$ The Gutmann group spin coated their sample onto silicon wafers from a toluene solvent. In the published study, Gutmann et al. conclude that the blend composition and blend compatibility of their samples had a correlation to the phase separated morphologies revealed by AFM in their thin films. Furthermore, it seems like the matrix may be the (GAGPGP) ${ }_{12}$ and the island composed of PAA. PAA is hygroscopic in nature and most likely softens with some humidity in the ambient environmental conditions. ${ }^{74}$ The 
softening of the material leads to a more attractive force with the tip in tapping mode AFM this effect results in a dark phase. ${ }^{75}$ The islands of dark phase material within a matrix of lighter phase material suggests that there are island of PAA within a matrix of (GAGPGP) ${ }_{12}$. The smaller light phase areas within the island may also be (GAGPGP) $)_{12}$ that trapped within PAA when the water was evaporating from the sample. This idea is also supported by the AFM topology image showing the areas of dark phase being taller in height versus the areas of light phase material. The very distinct contrast shown in the AFM phase images suggests that the polymers are immiscible and possibly phase separating when drying at room temperature on a silicon wafer.

To test the effect of varying drying conditions on a PAA/(GAGPGP) $)_{12}$ blend film, a $2 \mathrm{mg} / \mathrm{mL}$ sample of 1:1 wt\% PAA/(GAGPGP) $)_{12}$ blend was spin-coated onto a silicon wafer and dried at room temperature overnight. When analyzed with AFM, a continuous film was achieved, but no significant features were found within the film to report. Similarly, a $2 \mathrm{mg} / \mathrm{mL}$ sample of $1: 1 \mathrm{wt} \%$ PAA/(GAGPGP $)_{12}$ blend was spotted onto a silicon wafer and dried overnight at $90^{\circ} \mathrm{C}$. Again, a continuous film was made, but the topography and phase images were not significantly different than the results found from drying the sample at room temperature. AFM results from the spincoated PAA/(GAGPGP) $)_{12}$ blend sample and the PAA/(GAGPGP) $)_{12}$ blend sample dried at $90^{\circ} \mathrm{C}$ overnight can be found in Appendix D.

Without published examples of peptide interaction parameters with other peptides or polymers, establishing a theoretical degree of incompatibility is difficult for the blend of PAA/(GAGPGP) ${ }_{12}$. However, characterization of (GAGPGP) $)_{12}$ has shown that the peptide prefers to aggregate in aqueous environments and may be slightly hydrophobic, while PAA is very hydrophilic. The samples were prepared in water so the difference in hydrophobicity between the (GAGPGP) $)_{12}$ peptide and PAA has the potential to lead to aggregated domains. PAA and (GAGPGP) 12 are only blended and not covalently attached, so it seems possible that the hydrophobic peptide prefers to coat the native silicon oxide surface of the silicon wafer while PAA segregates to shrinking areas of water while the sample is drying. ${ }^{76}$ The areas of water become smaller and smaller during evaporation until the dried sample shows a thin coating of (GAGPGP) $)_{12}$ on the Si and aggregates of PAA where the water last evaporated.

The effect of varying the ratio of (GAGPGP) $)_{12}$ to PAA was also explored. A $2 \mathrm{mg} / \mathrm{mL}$ sample with the composition of 9:1 wt\% PAA/(GAGPGP) $)_{12}$ polymer blend in water was spotted onto a silicon wafer and allowed to dry overnight at room temperature. AFM analysis was conducted on the dried samples and the result can be found in Appendix E. Both the AFM topography and 
phase image showed large circular structures within a continuous film. A much smaller difference in phase contrast can be observed from the 9:1 wt\% PAA/(GAGPGP) $)_{12}$ blend film, compared to the phase image of a 1:1 wt\% PAA/(GAGPGP) $)_{12}$ blend film.

To further explore the possibility of phase separation between the PAA and (GAGPGP) 12 a 1:1 wt ratio blend of a PAA/(GAGPGP) $)_{12}$ was examined using DSC. A (GAGPGP) 12 sample, a PAA sample taken straight from the manufacturer's bottle, a drop cast PAA sample, and PAA/(GAGPGP $)_{12}$ sample were run on the DSC instrument on four different days. The resulting thermograms were compiled together and shown below in Figure 20.

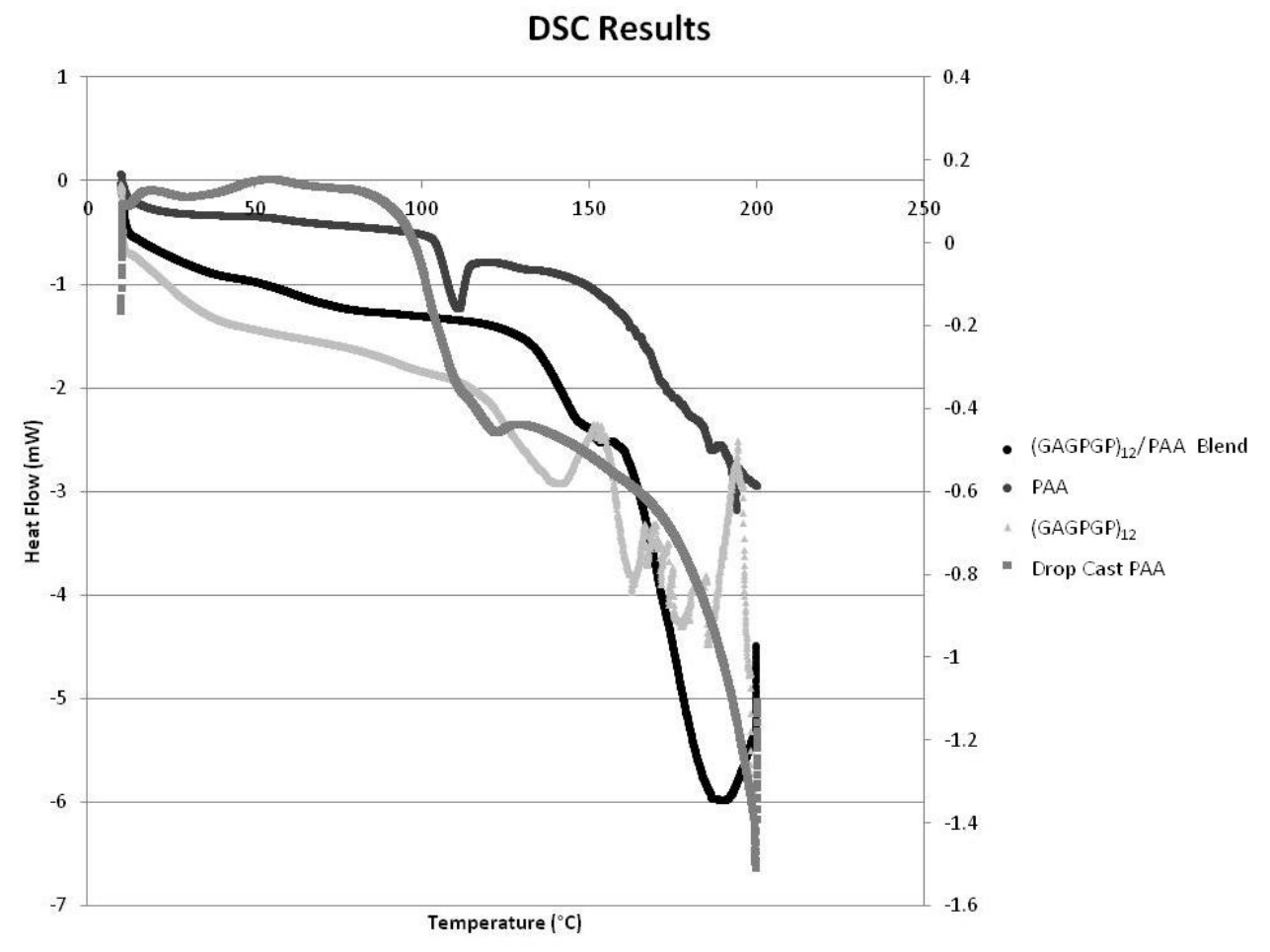

Figure 20 DSC results of (GAGPGP) ${ }_{12}$, PAA, drop cast PAA, and the PAA/(GAGPGP) ${ }_{12}$ blend

The thermograms from both drop cast and bulk PAA samples show a minimum around $110^{\circ} \mathrm{C}$ which agrees with values reported in the literature. ${ }^{77}$ The (GAGPGP) $)_{12}$ sample shows a change in slope around $30^{\circ} \mathrm{C}$, and then evidence of the peptide beginning to degrade around $140^{\circ} \mathrm{C}$. If there is phase separation in two synthetic polymers, each of the polymers' distinct glass transition temperatures will be apparent in the blend. If the polymers are miscible, then one glass transition temperature will be observed. In the results from the blended PAA/(GAGPGP) ${ }_{12}$ sample the distinct dip at PAA's glass transition temperature of about $110^{\circ} \mathrm{C}$ is absent. This absence could in indicate miscibility between PAA and (GAGPGP) $)_{12}$. The blend sample also shows a large 
decrease in heat flow around $145^{\circ} \mathrm{C}$ which is most likely due to the degradation of the peptide. Overall, the DSC results of the PAA/(GAGPGP $)_{12}$ blend support neither miscibility nor phase separation.

Another method used to investigate the possible phase separation of blended PAA and (GAGPGP $)_{12}$ was the ability or inability to organize nanoparticles into one of the distinct phases. Nickel nanoparticles were produced and added to a PAA/(GAGPGP) $)_{12}$ blend sample to test for any preferential binding of the nanoparticles to the His-tag of the (GAGPGP) ${ }_{12}$ peptide. Nickel was chosen as the nanoparticle material because of binding complexes formed between the amino acid, histidine, and the metal nickel in a high $\mathrm{pH}$ environment. As mentioned above in the design and purification of the (GAGPGP) $)_{12}$ peptide, the biological polymer used in this multicomponent blend contains a ten residue long histidine his-tag at N-terminal of the molecule. A $2 \mathrm{mg} / \mathrm{mL}$ solution of PAA/(GAGPGP) $)_{12}$ 1:1 wt ratio blend was evaporated onto a silicon wafer overnight at room temperature. A solution of nickel nanoparticles in water titrated with $\mathrm{NaOH}$ to be $\mathrm{pH} 10$ was spotted on top of the dried PAA/(GAGPGP $)_{12}$ solution. The sample was dried at room temperature overnight and the results of SEM analysis shown in Figure 21.

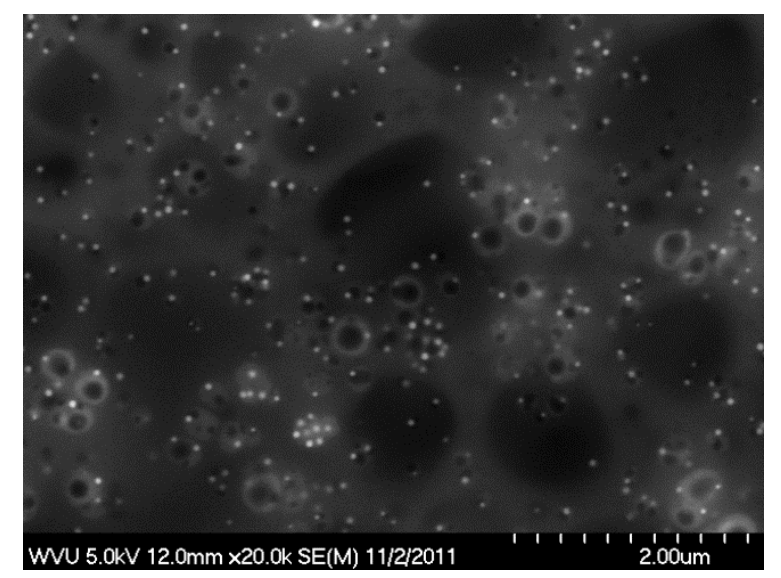

Figure 21 SEM image of a PAA/(GAGPGP) ${ }_{12}$ blend film on Si with Ni nanoparticles

From the SEM images alone it appears that the nanoparticles are well-dispersed throughout the material, but there are no distinct phase domains visible with the electron microscopy technique. Homogeneous dispersion of the nanoparticles could indication miscibility between the two polymers. However, there are some hazy dark regions within the SEM image that appear to be lacking nanoparticles which could indicate phase separation and nanoparticle binding preference (an SEM image of Ni nanoparticles dispersed in a control film of only (GAGPGP) ${ }_{12}$ can be found in Appendix F). It is also possible that the addition of metal nanoparticles into the polymer blend disrupts the self-assembly of phase separation between the two polymers; however, literature on 
the inclusion of nanoparticles into phase-separated polymer systems indicates nanoparticles will be excluded from the polymer matrix, rather than disrupt the morphology. ${ }^{55,78}$

Overall, the phase image obtained by tapping mode AFM indicate that phase separation between a blend of PAA and (GAGPGP) $)_{12}$ is probable. Comparison between the AFM phase results of this research and published phase images from phase separated polymeric blends appear very similar also indicating the likelihood of phase separation. However, inconclusive DSC results and the seemingly well-dispersed nanoparticles could mean that PAA and (GAGPGP) $)_{12}$ are miscible.

\subsection{Peptide-Peptide Biological Polymer Blends and Block Copolymers}

\subsection{Poly(Glutamic Acid) and (GAGPGP) 12}

In the hybrid blend samples, a film of blended PNIPAM/(GAGPGP) $)_{12}$ resulted in the formation of globular structures and phase separation was inconclusive, but the results of a PAA/(GAGPGP) 12 blend resulted in the possibility of separate phase domains when evaporated from water onto Si. The next step was to evaluate the ability of purely biological multicomponent polymer systems to phase separate in the solid state. A $10 \mathrm{kDa}$ peptide composed of a chain of glutamic acids called poly(glutamic acid) (polyE) was blended with (GAGPGP) ${ }_{12}$. PolyE was chosen as the first peptide to work with because the side chains of glutamic acid have carboxylic acid functional groups which are comparable to the carboxylic acid side chains of PAA. PolyE is also hydrophilic like PAA and when blended with (GAGPGP) $)_{12}$ maybe behave the same. The aim of this blend was to replicate the results of a hybrid polymer blend with a purely biological polymer blend. PolyE and (GAGPGP) 12 were blended in water at a 1:1 wt ratio (resulting in about a 1:1 molar ratio) and spotted onto a Si wafer. The film was then analyzed by tapping mode AFM and the results shown below in Figure 22. 


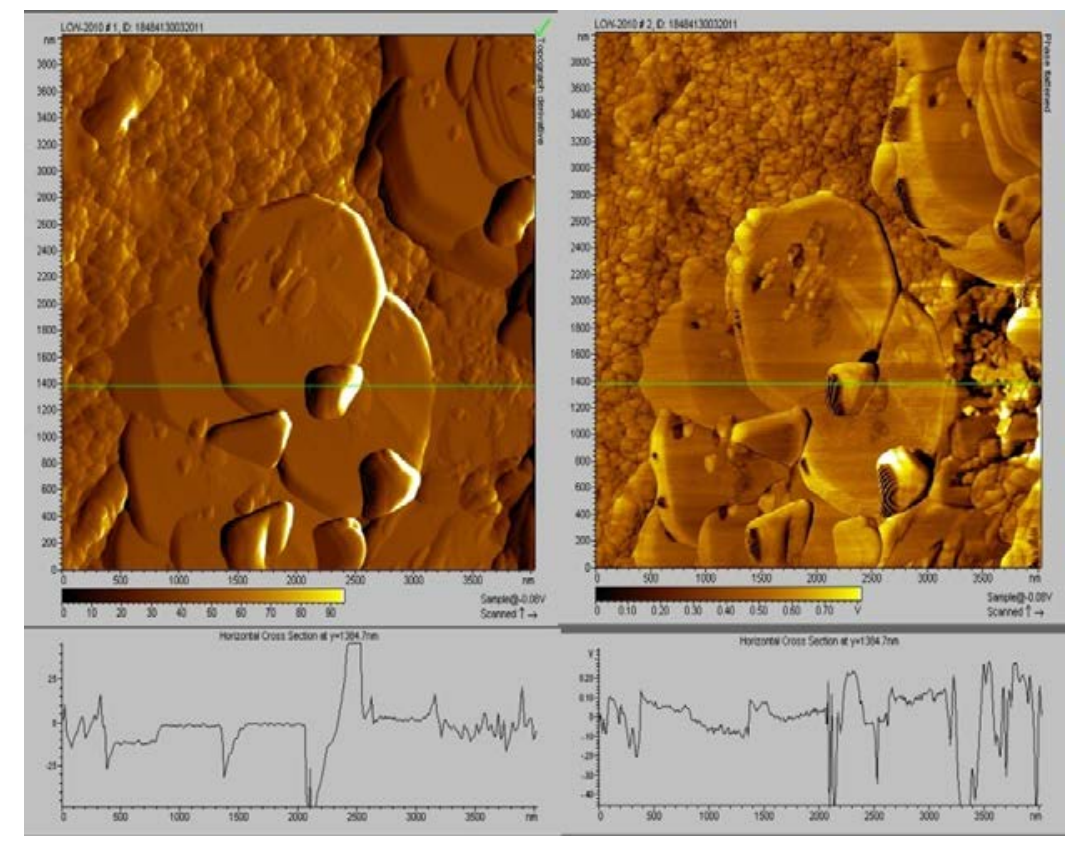

Figure 22 AFM topography (left) and phase (right) images of polyE/(GAGPGP) ${ }_{12}$ blend

When analyzed with the AFM, both the topography image and the phase image show a continuous film with flatten spherical or plateau structures (see Figure 22). If the circular structures are flatten self-assembled micelles or vesicles the possibility of phase separation in the solid state seems possible. However, there is no indication of differences in phase angle in the phase image obtained by the AFM. It is possible that the lack in phase contrast is due to there not being enough difference between the (GAGPGP) $)_{12}$ molecules and the polyE molecules. If the peptides are similar enough that there is almost no change in phase angle felt by the AFM probe, then there may not be enough difference in the molecules to drive phase separation. Or the lack of phase contrast could be because the two peptides are miscible. Overall, there was no difference in contrast of the phase images obtained from the blended polyE/(GAGPGP) ${ }_{12}$ system. The multicomponent biological polymer system of polyE and (GAGPGP) ${ }_{12}$ showed no signs of phase separation with AFM analysis.

\subsection{VA2 Peptide and (GAGPGP) ${ }_{12}$ Blend and Copolymer}

Although the SEM and AFM topography images showed evidence of macromolecule selfassembly, the previous attempt to document evidence of phase separation in a PAA/(GAGPGP) ${ }_{12}$ blend film multiple phase domains were not confirmed with tapping mode AFM phase imaging. There is a chance that the lack of phase contrast during phase imaging is due to lack of difference in the stiffness, work involved in adhesion, or damping between the two peptides. To address this issue a hydrophilic peptide with varying negatively charged side chains was used at the next 
blended peptide. Unlike the polyE peptide which contained only glutamic acid residues, the VA2 peptide contains both glutamic acid and aspartic acid amino acids. VA2 has a molecular weight similar to (GAGPGP) $)_{12}$ at $7.9 \mathrm{kDa}$ peptide and was designed by a previous graduate student. The DNA and amino acid sequence of this peptide can be seen in Figure 23.

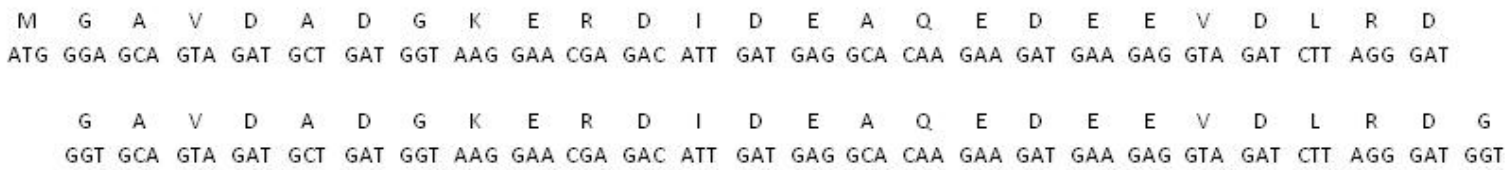

Figure 23 DNA and amino acid sequence of VA2 peptide

While side chain of glutamic acid has a $\mathrm{pK}_{\mathrm{a}}$ value of 4.3, the side chain of aspartic acid has a $\mathrm{pK}_{\mathrm{a}}$ value of 3.9. ${ }^{66}$ The lower $\mathrm{pK}_{\mathrm{a}}$ values of aspartic acid means the functional group acts as a stronger acid than glutamic acid. The aim of this study was to determine if the increase in acidic strength of the peptide would affect the stiffness, work involved in adhesion, or dampening of the tapping mode AFM probe enough to cause a difference in phase angle between VA2 and (GAGPGP) ${ }_{12}$. VA2 was blended with the (GAGPGP) $)_{12}$ peptide at a 1:1 $\mathrm{wt} \%$ ratio in water. The solution was then spotted onto a silicon wafer and allowed to dry overnight at room temperature. The sample was then analyzed with tapping mode AFM and the results are shown in Figure 24.

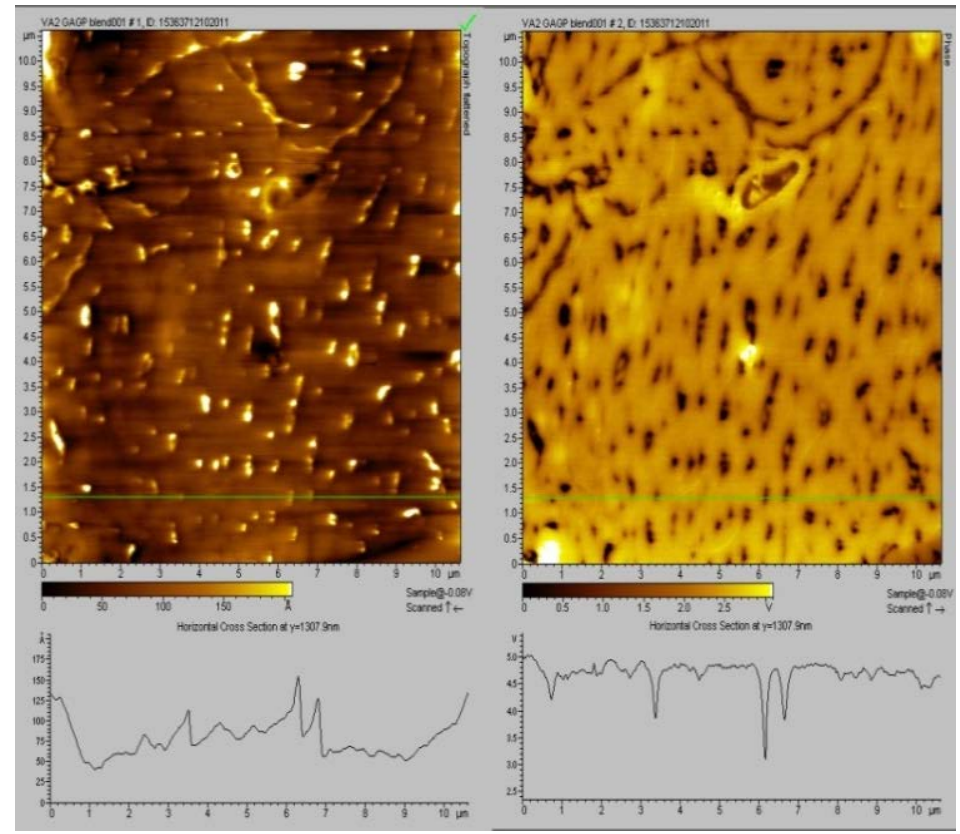

Figure 24 AFM topography (left) and phase (right) image of VA2/(GAGPGP) ${ }_{12}$ blend

The AFM topography image shows what appears to be a continuous film with small regular height changes. The many peaks protruding from the film are about range from about 10 to $15 \mathrm{~nm}$ 
high and are irregular in shape. The phase image displays significant differences in the phase angle between the background polymer matrix and the protrusions. It appears that there may be small islands of one phase domain within a continuous matrix of another phase domain. Although height differences can contribute to changes in phase angle, the height differences found in the VA2/(GAGPGP) $)_{12}$ blend are minimal compared to the height difference found in the AFM topography image obtained of (GAGPGP) ${ }_{12}$ (refer to Figure 14). In the films of only (GAGPGP) $)_{12}$ topography difference of about $50 \mathrm{~nm}$ show very little contrast in the phase image, while height difference of $15 \mathrm{~nm}$ in the VA2/(GAGPGP) $)_{12}$ blend show drastic differences in contrast of the phase image.

The results of the tapping mode AFM analysis of a VA2/(GAGPGP) ${ }_{12}$ blend indicate that phase separation could be occurring in the solid state films produced on silicon wafers. Similar to the PAA/(GAGPGP $)_{12}$ to further investigate the phase separation possibility, Ni nanoparticles were incorporated into the films to observe if the nanoparticles preferred distinct regions of the film. Because both peptides were originally produced with a His-tag for purification purposes, the Histag was removed from VA2 and then a 1:1 wt\% ratio of VA2 to (GAGPGP) 12 was combined in water to produce a $2 \mathrm{mg} / \mathrm{mL}$ solution of VA2/(GAGPGP) ${ }_{12}$ blend. The blend was spotted onto a silicon wafer and allowed to dry overnight at room temperature. Next, a fresh solution of $\mathrm{Ni}$ nanoparticles was prepared. The nanoparticles were titrated to $\mathrm{pH} 10$ with $\mathrm{NaOH}$ and the solution was spotted on top of the VA2/(GAGPGP) $)_{12}$ spot. SEM imaging was used to document the location of the nanoparticles within the film. The SEM results can be seen in Figure 25.

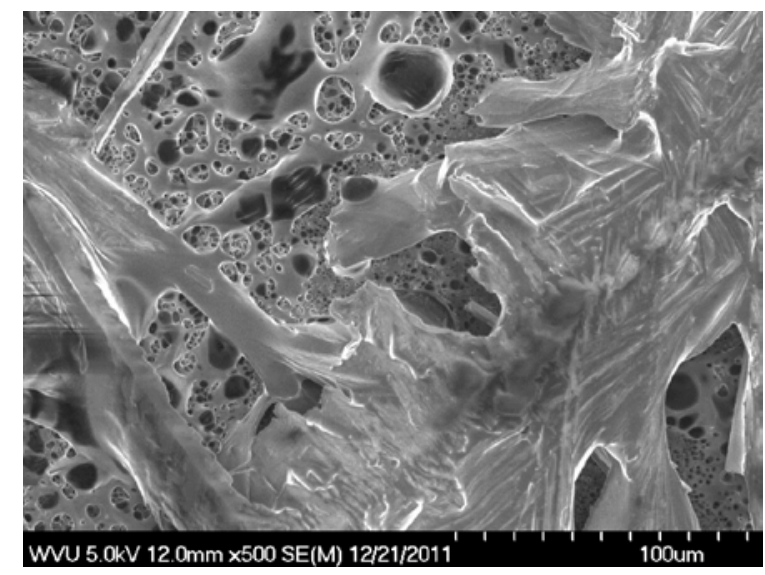

Figure 25 SEM image of a VA2/(GAGPGP) ${ }_{12}$ blend film with Ni nanoparticles

A very complex film was formed by the VA2/(GAGPGP) ${ }_{12}$ blend with Ni nanoparticles on Si. No nanoparticles were visible by SEM. It is possible that the high $\mathrm{pH}$ used with the nanoparticles neutralized some of the acidic side chains of the charged amino acids in VA2. The neutralized 
functional groups then led to a much different over morphology of the VA2/(GAGPGP) $)_{12}$ blend. The VA2/(GAGPGP) $)_{12}$ at high $\mathrm{pH}$ seems to result in a network morphology. The network morphology can also be an indication of phase separation, but the sample observed in SEM is too rough to analyze with AFM.

Blends have been used throughout this study because producing the blended samples is much easier than producing block copolymers of each multicomponent polymer system. Because of the promising AFM results seen in Figure 24 though, a VA2-(GAGPGP) ${ }_{12}$ block copolymer was produced and analyzed for phase separation. A condensation reaction was used to couple amine groups within the peptides to carboxylic acid functional groups. Due to the number of carboxylic acid side chains in VA2, the coupling reaction most likely results in a brush structured molecules, though no characterization technique was employed to confirm this in an actual sample. Once the molecules were coupled, a $2 \mathrm{mg} / \mathrm{mL}$ solution in water was produced and spotted onto a silicon wafer. Tapping mode AFM was used to observe the both the topography and phase angle of the film (see Figure 26 below).

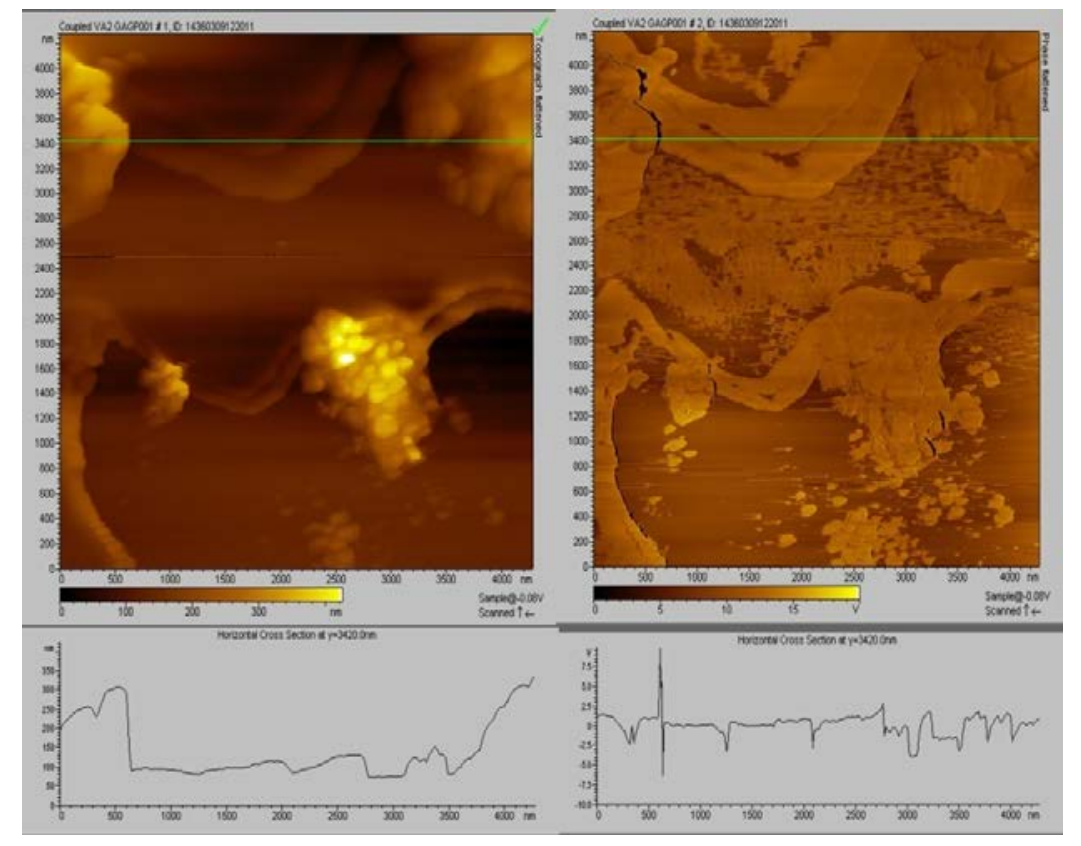

Figure 26 AFM topography (left) and phase (right) image of VA2-(GAGPGP) ${ }_{12}$ block copolymer

The AFM topography image shows a varied terrain of aggregates in the VA2-(GAGPGP) ${ }_{12}$ block copolymer film. The large aggregates shown in the image could be due to an incomplete coupling reaction or a change in the assembled microstructure due to the change in molecular structure of 
the molecules. The phase image does not show any significant differences in contrast indicating that the VA2-(GAGPGP) ${ }_{12}$ does not undergo phase separation in a film on Si.

Overall, a blend of VA2 and (GAGPGP) 12 appeared to phase separate when the topology and phase angle were analyzed by tapping mode AFM, but when a solution of Ni nanoparticles at high $\mathrm{pH}$ was added to the film, the morphology changed drastically and no indications of phase separation or nanoparticle organization could be found. The two peptides were coupled together to make a block copolymer and also analyzed for topography and phase angle with AFM, but again the morphology was drastically different than the structures found in the first blended sample. The charged amino acids included in the VA2 sequence most likely are contributing to the drastic change in microstructure when the solution of nanoparticles at high $\mathrm{pH}$ was added. Furthermore, a VA2-(GAGPGP) ${ }_{12}$ block copolymer resulted in a multicomponent polymer system that appears to be miscible from AFM tapping mode phase analysis.

\subsection{ELP Peptide and (GAGPGP) 12 Blend}

In the polyE/(GAGPGP) $)_{12}$ blend flat circular-shaped plateaus were observed possibly indicating self-assembly, but no phase contrast could be detected in the phase images taken with tapping mode AFM. The VA2/(GAGPGP) $)_{12}$ blend seemed to show phase separation, but once nanoparticles at a high $\mathrm{pH}$ were added to the film, the morphology of the film changed drastically. To increase the difference between the two biological polymers in a purely biological multicomponent polymer blend and to eliminate some of the charged functionally groups, the $(\text { GAGPGP })_{12}$ peptide was combined with a peptide that changes hydrophobicity with temperature. The peptide used in this study was ELP peptide. The sequence of the ELP peptide consists of hydrophobic domains of proline-glycine-valine-glycine-valine-alanine, and hydrophilic domains commonly used for crosslinking filled with lysine. According the KyteDoolittle hydrophathy scale, valine is the second most hydrophobic amino acid with a value of 4.2 on a scale of -4.5 to 4.5 with 4.5 being the most hydrophobic. ${ }^{69}$ Lysine has a value of -3.9 and is the second most hydrophilic amino acid on the scale. The presence of two valine residues within the repeating hexapeptide sequence results in a significantly hydrophobic portion of the peptide, while the presence of lysine produces a hydrophilic portion of the peptide. These alternating domains help the macromolecule to self-assemble in aqueous solutions with a low LCST of about $37^{\circ} \mathrm{C}$. ${ }^{79}$ The readiness to self-assemble may help with self-assembly of phase separation of an ELP/(GAGPGP) $)_{12}$ blend in the solid state of a film. The ELP peptide was blended with (GAGPGP) $)_{12}$ in water and drop casted onto silicon wafers to check for indications of phase separation. SEM images of two different areas within the ELP/(GAGPGP) ${ }_{12}$ blend film 
are shown below in Figure 27. SEM images of ELP alone on a silicon wafer can be found in Appendix G.
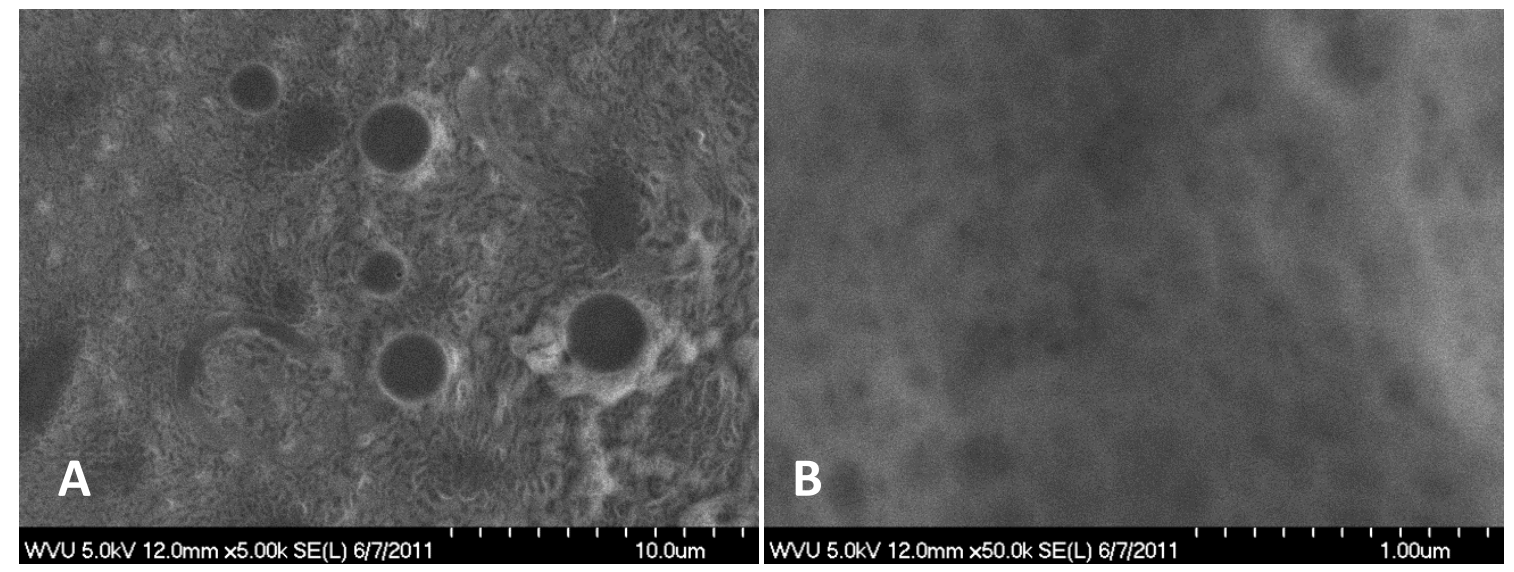

Figure 27 A) SEM image of the overall network morphology within an ELP/(GAGPGP) ${ }_{12}$ blend film, and B) SEM image of the details of the network morphology in an ELP/(GAGPGP) $)_{12}$ blend film

Very distinct circular assemblies are seen in the ELP/(GAGPGP) 12 blend samples and there appears to be a continuous film constructed of a network of very thin strands. Although spherical features have been observed in pervious (GAGPGP) ${ }_{12}$ samples, ELP peptides are also known to form micelles. ${ }^{80}$ Whether the circular structures are due to (GAGPGP) $)_{12}$ self-assembly or ELP self-assembly, it seems as if there is an assembly processing happening in the liquid state and remains throughout the drying process into the solid film. The appearance of a network in the film could be an indication of phase separation and is most likely due to the alternating hydrophilic and hydrophobic domains of ELP. The hydrophobic domains prefer to assemble into micelles but the macroscopic movement is limited by the hydrophilic linker created a tricontinuous structure called a gyroid phase structure. ${ }^{2}$ An example of this porous network assembly has been documented in the phase separated polymers acrylated poly(e-caprolactone) and N-vinylpyrrolidone by Liao et al. in $2007 .^{81}$

Tapping mode AFM was used next to determine if phase separation could be confirm through phase imaging, The same sample of a 1:1 wt ratio ELP/(GAGPGP) ${ }_{12}$ blend in water spotted onto Si was used for the AFM analysis. The results topographical imaging (left) and phase imaging (right) can be seen in Figure 28 below. 


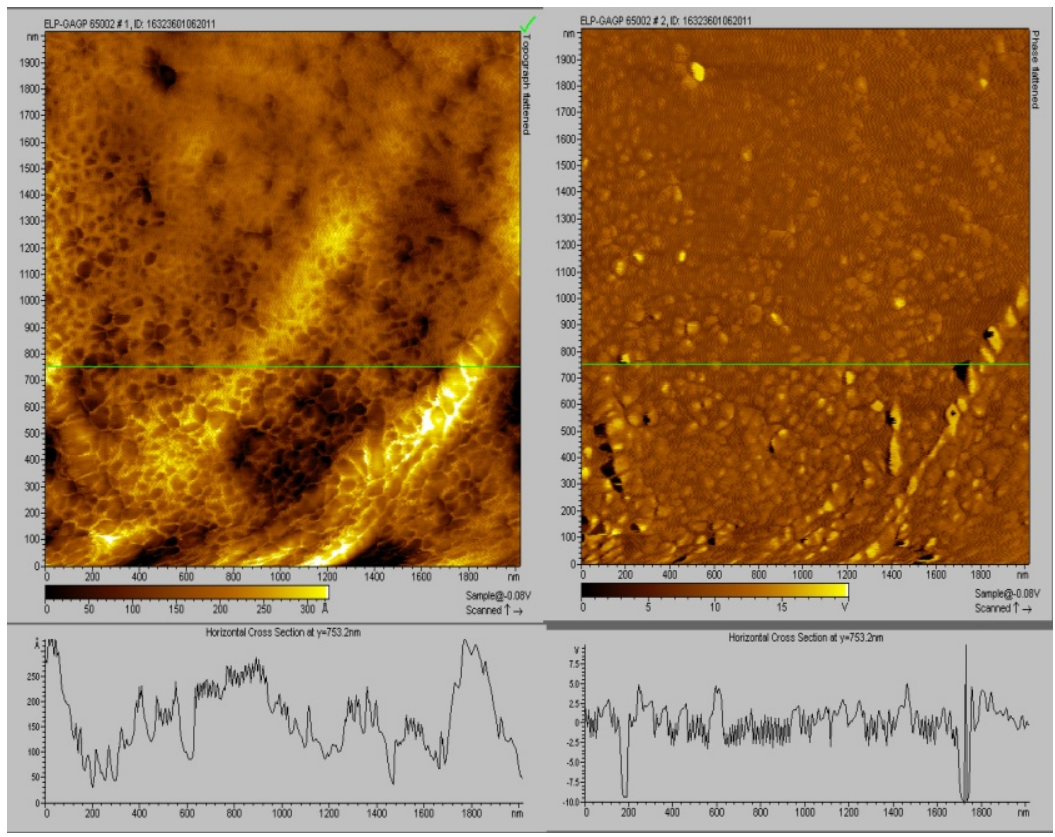

Figure 28 AFM topography (left) and phase (right) images of ELP/(GAGPGP) $)_{12}$ blend on Si

The large circular structures were not documented with tapping mode AFM, but topographical imaging confirms a network morphology in the ELP/(GAGPGP) ${ }_{12}$ blend on $\mathrm{Si}$, but there is no significant contrast in the phase image. The topography image supports the idea that there is separation of phase domains with in a blend of ELP and (GAGPGP) ${ }_{12}$, but the tapping mode phase images cannot confirm any separated phases. The lack of contrast in the phase image could again be the result of a lack of sensitivity in the probe to distinguish between ELP-rich domains and (GAGPGP) $)_{12}$ rich domains.

A $2 \mathrm{mg} / \mathrm{mL}$ solution of ELP/(GAGPGP) $)_{12}$ blend in water was spin-coated onto silicon and dried at room temperature to investigate the phase behavior of a spin-coated drying method. AFM analysis found spheres, but no significant phase contrast could be detected (see Appendix H). Also, because ELP is temperature sensitive, a blend of ELP and (GAGPGP) 12 was spotted onto a silicon wafer and dried at $65^{\circ} \mathrm{C}$ overnight. Crystallization occurred within the film and no significant phase image findings were made. AFM and SEM results can be found in Appendix I.

Overall, a phase separated-like network morphology was observed with both SEM and AFM imaging of a ELP/(GAGPGP) $)_{12}$ blend on $\mathrm{Si}$, but tapping mode AFM did not distinguish two distinct phase domains in the sample. This could indicate that tapping mode AFM is not a suitable method for determining phase separation in biological polymers, or that the network structure observed was the effect of ELP macromolecules only and the (GAGPGP) ${ }_{12}$ macromolecules were homogenously woven within the network film. 


\section{Chapter 4 Conclusions and Future Directions}

\subsection{Conclusions}

This research investigated the ability of biological polymers to phase separate in the solid state when part of a synthetic biological hybrid system or as a purely biological polymer system. Recombinant DNA techniques and an E. coli expression host were employed to accurately and precisely produce a $7.8 \mathrm{kDa}$ random coil peptide referred to as (GAGPGP) ${ }_{12}$. The molecular weight, sequence, and secondary structure were confirmed by SDS-PAGE, Western Blot, amino acid analysis, and circular dichroic spectroscopy.

Examination into biological hybrid multicomponent polymer systems began with blending $(\text { GAGPGP })_{12}$ with the temperature sensitive polymer PNIPAM. AFM phase analysis of PNIPAM/(GAGPGP) $)_{12}$ blend film showed a large contrast in phase angle, but the topography image indicted the presence of very prominent globular structures that are characteristic of PNIPAM. It was determined that the formation of globular structures could be interfering with a phase separation self-assembly process. Next, (GAGPGP) 12 was blended with the very hydrophilic polymer PAA. The results from SEM micrographs, tapping mode AFM phase images, and DSC thermograms of a PAA and (GAGPGP) $)_{12}$ blend film suggest that phase separated domains may be present in thin films. The films were exposed to nickel nanoparticles to investigate whether preferential binding to the peptide could organize nanoparticles in a biological polymer composite material. The nickel nanoparticles appeared well-dispersed throughout the composite material, but there was no evidence of organization within specific phase domains of the film.

To examine purely biological polymer systems a peptide closely resembling PAA was blended with (GAGPGP) ${ }_{12}$ and dried onto Si to produce a film. Analysis with tapping mode AFM phase angle analysis resulted in no distinguishable phases in the polyE/(GAGPGP) 12 blend. Likewise, promising topography images of a ELP peptide and (GAGPGP) ${ }_{12}$ blend were found from SEM and AFM analysis, but no differences in phase angle could be documented. (GAGPGP) ${ }_{12}$ was finally blended with a highly charged peptide called VA2 and examined for phase separation. The AFM topography image showed what appeared to be small regular-shaped islands within a matrix of polymer. The tapping mode AFM phase image confirmed that the islands had a different phase angle than the background matrix of the film. This phase contrast indicates possible phase separation in the blend. When, a solution of $\mathrm{Ni}$ nanoparticles at high $\mathrm{pH}$ was added to the film drastically different film morphology was the result. A condensation coupling reaction was 
employed to produce a block copolymer of VA2 and (GAGPGP) ${ }_{12}$, but when the block copolymer was dried into a film on Si no phase angle differences could be found.

Overall, the results of this research indicate that phase separation is possible in biological multicomponent polymer systems. Hopefully this work can serve as a starting point for the additional time and effort needed to optimize the multicomponent systems and to characterize the parameters involved in phase separation of peptides. The significance of phase separated biological polymers is yet to be determined, but the current needs in fields of biosensors, coatings, and biomedical materials suggest that impact will be considerable.

\subsection{Future Directions}

Some of the difficulties encountered with characterizing the biological films could be addressed in the future by finding a way to optimize the parameters used when obtaining the phase images during tapping mode AFM analysis. Alternatively, future work could include finding a more sensitive characterization technique to distinguish between phase domains of peptides. The nanoparticle polymer composite films in this study were designed to rely on the association of nickel with the histidine residues found in the His-tag of the (GAGPGP) $)_{12}$ peptide. In the further studies instead of using the Ni-histidine binding affinity, metal nanoparticles could be incorporated into films of peptides without His-tags to explore whether the functional groups within the peptides would attract the nanoparticles.

Additionally, the behavior of these multicomponent polymer systems in solution could be studied for the application of drug delivery. Evidence of micelles or vesicles was present in the solid state of many of the samples indicating the blended or coupled polymer systems have the ability to self-assembly in solution. A preliminary study into the influence of poly(ethylene glycol) (PEG) on the self-assembly behavior of (GAGPGP) $)_{12}$ molecules was conducted. Using the same condensation coupling method used to covalently attached VA2 to (GAGPGP) 12 , linear diblock copolymers of PEG and (GAGPGP) ${ }_{12}$ were produced. PEG was attached to the amine terminal of $(\text { GAGPGP })_{12}$, the carboxylic acid terminal of (GAGPGP) ${ }_{12}$, and to both ends of the (GAGPGP $)_{12}$ molecule. Samples at a concentration of $0.5 \mathrm{mg} / \mathrm{mL}$ were prepared in non-buffered water and analyzed with CD to determine the secondary structure (see Figure 29). 


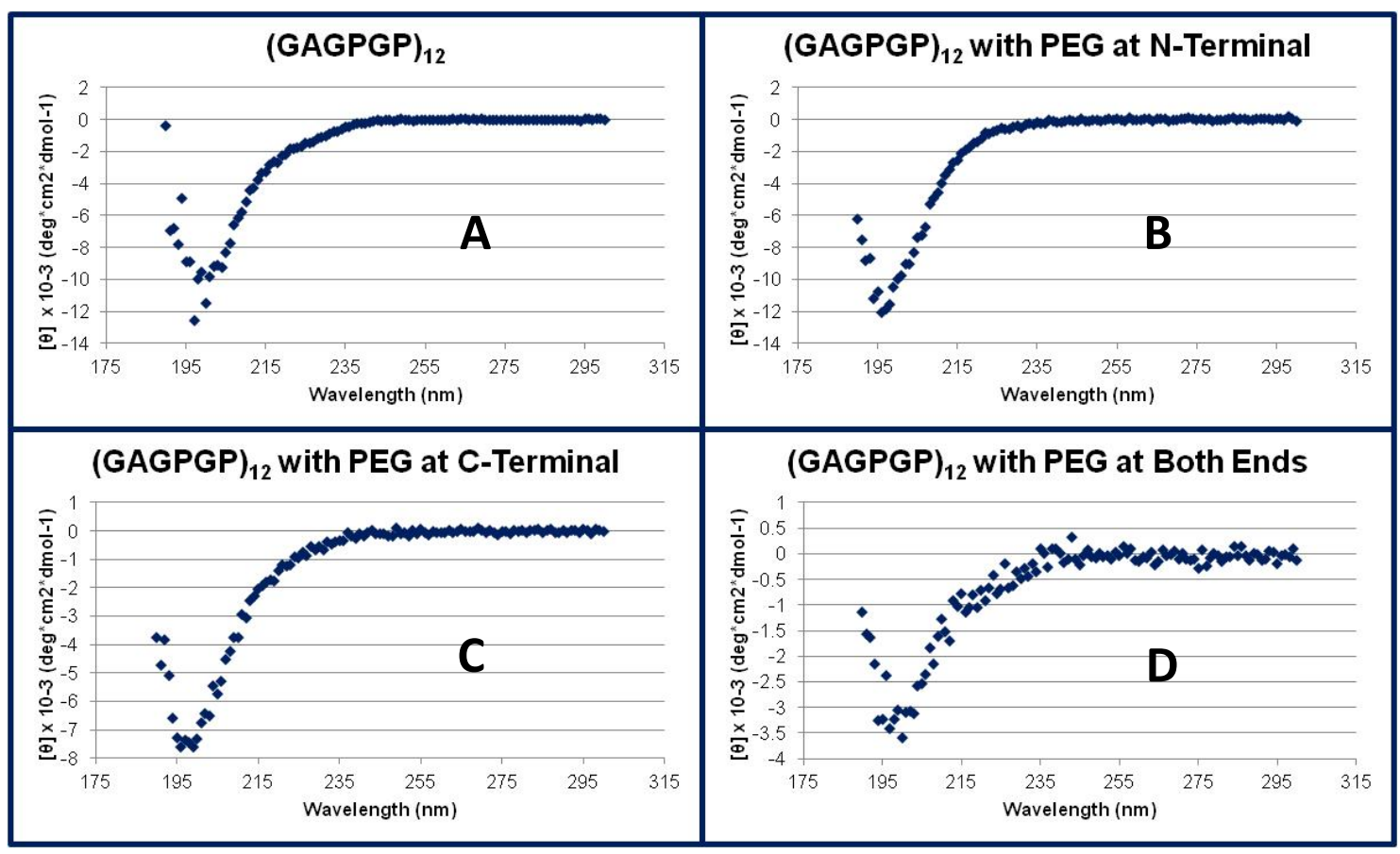

Figure 29 CD data comparing A) the peptide (GAGPGP) ${ }_{12}$ alone to the block copolymers: B) PEG-(GAGPGP) ${ }_{12}$, C) (GAGPGP) ${ }_{12}$-PEG, and D) PEG-(GAGPGP) ${ }_{12}$-PEG

The results of (GAGPGP) $)_{12}$ alone and (GAGPGP) $)_{12}$ with PEG attached to the N-terminal of the peptide look very similar. Though, when PEG is attached to the C-terminal of (GAGPGP) ${ }_{12}$ the minimum at about $197 \mathrm{~nm}$ decreases slightly and when PEG is attached to both ends of (GAGPGP $)_{12}$, the minimum decreases significantly. The slight difference seen between the samples is most likely due the His-tag acting as a spacer between the peptide and PEG. When PEG is attached to the N-terminal, there is a His-tag located between the peptide and PEG, so any influence PEG might have o the secondary structure is minimized. On the other two block copolymers PEG has the ability to slightly affect the secondary structure.

Preliminary DLS analysis was performed on $2 \mathrm{mg} / \mathrm{mL}$ samples of the peptide alone and of each block copolymer in water to study the self-assembly behavior of the macromolecules in solution. Three runs were performed on each sample and the mean number results of the experiment shown below in Table 2. 
Table 2 DLS results of (GAGPGP) ${ }_{12}$ and the hybrid block copolymers in water

\begin{tabular}{|l|c|}
\multicolumn{1}{|c|}{ Sample } & $\begin{array}{c}\text { Hydrodynamic Mean } \\
\text { Diameter (nim) }\end{array}$ \\
\hline${\text { (GA GPGP })_{12}}^{(\text {GA GPGP })_{12} \text { with PEG at C-Terminal }}$ & 455.4 \\
\hline$(\text { GA GPGP })_{12}$ with PEG at N-Terminal & 134.5 \\
\hline$(\text { GA GPGP })_{12}$ at Both Terminals & 142.3 \\
\hline
\end{tabular}

The preliminary DLS results measuring mean number hydrodynamic diameter indicate that the covalent attachment of PEG to the (GAGPGP) $)_{12}$ peptides does have an impact on the selfassembly behavior in water. When PEG is attached to either end of the peptide the macromolecules seem to form micelles with a diameter of about $140 \mathrm{~nm}$. The comparable diameters support the idea that there is a discrete number of block copolymer molecules that assemble into a micelle/vesicle to shield the slightly hydrophobic peptide block core with the very hydrophilic PEG block. Switching the PEG to the opposite end of the macromolecule doesn't affect the diameter because the ratio of PEG to (GAGPGP) ${ }_{12}$ remains the same, and the length of the PEG block and the (GAGPGP) $)_{12}$ block remain the same. Therefore, the number of molecules needed to shield the hydrophobic block core remains about the same. On the other hand, when adding PEG to both terminals of the (GAGPGP) ${ }_{12}$ peptide, the hydrodynamic diameter decreases. This is most likely due to the fact that the ratio of PEG block to (GAGPGP) ${ }_{12}$ block has changed. The hydrophobic peptide block core has the flexibility to fold and expose the two hydrophilic PEG ends to the aqueous environment. With two blocks of PEG for every one block of (GAGPGP)12, fewer block copolymer macromolecules are needed to shield the hydrophobic core. The decrease in the number of molecules results in a smaller core and a smaller overall hydrodynamic diameter of the micelle.

This idea could be explored much further by changing the length and ratio of the blocks used and comparing the results to the results shown above. Then, the encapsulation of hydrophobic small molecule drugs, siRNA, or nanoparticles could be tested and characterized. Using micelles as a drug delivery method is a growing field of interest with significant applications. With future research on (GAGPGP) ${ }_{12}$ or peptides in general in the form of a block copolymers, noteworthy contributions could made to this field. 


\section{References}

1. Atorngitjawat, P., Klein, R. J., McDermott, A. G., Masser, K. A., Painter, P. C. \& Runt, J. (2009). Dynamics of concentrated solutions of low molecular weight phenolics and poly(2-vinylpyridine): Role of intermolecular hydrogen bonding. Polymer 50, 24242435.

2. $\quad$ Bates, F. S. (1991). Polymer-Polymer Phase Behavior. Science 251, 898-905.

3. Binder, K. (1999). Phase Transitions of Polymer Blends and Block Copolymer Melts in Thin Films Polymers in Confined Environments (Granick, S., Binder, K., de Gennes, P. G., Giannelis, E., Grest, G., Hervet, H., Krishnamoorti, R., Léger, L., Manias, E., Raphaël, E. \& Wang, S. Q., eds.), Vol. 138, pp. 1-89. Springer Berlin / Heidelberg.

4. $\quad$ Eastwood, E., Viswanathan, S., O'Brien, C. P., Kumar, D. \& Dadmun, M. D. (2005). Methods to improve the properties of polymer mixtures: optimizing intermolecular interactions and compatibilization. Polymer 46, 3957-3970.

5. Gutmann, J. S., Muller-Buschbaum, P. \& Stamm, M. (1999). Complex pattern formation by phase separation of polymer blends in thin films. Faraday Discussions 112, 285-297.

6. Menelle, A., Russell, T. P., Anastasiadis, S. H., Satija, S. K. \& Majkrzak, C. F. (1992). Ordering of thin diblock copolymer films. Physical Review Letters 68, 67-70.

7. Fréchet, J. M. J. (1994). Functional Polymers and Dendrimers: Reactivity, Molecular Architecture, and Interfacial Energy. Science 263, 1710-1715.

8. Green, P. F. \& Limary, R. (2001). Block copolymer thin films: pattern formation and phase behavior. Advances in Colloid and Interface Science 94, 53-81.

9. Painter, P. C. \& Coleman, M. M. (1994). Fundamentals of Polymer Science: An Introductory Text, Technomic Publishing Company, Inc., Lancaster, PA.

10. Paul, D. R. \& Barlow, J. W. (1984). A binary interaction model for miscibility of copolymers in blends. Polymer 25, 487-494.

11. Anastasiadis, S. H., Gancarz, I. \& Koberstein, J. T. (1988). Interfacial tension of immiscible polymer blends: temperature and molecular weight dependence. Macromolecules 21, 2980-2987.

12. Roe, R.-J. \& Zin, W.-C. (1980). Determination of the Polymer-Polymer Interaction Parameter for the Polystyrene-Polybutadiene Pair. Macromolecules 13, 1221-1228.

13. Robeson, L. M. (2007). Polymer Blends: A Comprehensive Review, Hanser Gardner Publications, Inc., Cincinnati.

14. Krause, S. (1986). Polymer-polymer miscibility. Pure \& Applied Chemistry 58, $1553-$ 1560 .

15. Kato, A., Nishioka, M., Takahashi, Y., Suda, T., Sawabe, H., Isoda, A., Drozdova, O., Hasegawa, T., Izumi, T., Nagata, K., Hikasa, S., Iwabuki, H. \& Asano, A. (2010). Phase separation and mechanical properties of polyketone/polyamide polymer alloys. Journal of Applied Polymer Science 116, 3056-3069. 
16. Raghavan, D., VanLandingham, M., Gu, X. \& Nguyen, T. (2000). Characterization of Heterogeneous Regions in Polymer Systems Using Tapping Mode and Force Mode Atomic Force Microscopy. Langmuir 16, 9448-9459.

17. Behrend, O. P. \& Odoni, L. (1999). Phase imaging: Deep or superficial? Applied Physics Letters 75, 2551.

18. Meaurio, E., Zuza, E. \& Sarasua, J. R. (2005). Miscibility and specific interactions in blends of poly(L-lactide) with poly(vinylphenol). Macromolecules 38, 1207-1215.

19. Fredrickson, G. H. \& Bates, F. S. (1996). Dynamics of Block Copolymers: Theory and Experiment. Annual Review of Materials Science 26, 501-550.

20. Freed, K. F. \& Dudowicz, J. (2005). Influence of monomer molecular structure on the miscibility of polymer blends. In Phase Behavior of Polymer Blends (Freed, K., ed.), Vol. 183, pp. 63-126. Springer-Verlag Berlin, Berlin.

21. Karim, A., Douglas, J. F., Sung, L. P. \& Ermi, B. D. (2002). Self-Assembly by Phase Separation in Polymer Thin Films. In Encyclopedia of Materials: Science and Technology (Buschow, K. H. J., Cahn, R. W., Flemings, M. C., Ilschner, B., Kramer, E. J. \& Mahajan, S., eds.), pp. 8319-8322. Elservier Science Ltd, Gaithersburg, MD.

22. Xue, L., Zhang, J. \& Han, Y. (2011). Phase separation induced ordered patterns in thin polymer blend films. Progress in Polymer Science.

23. Yan, D. R., Huang, H. Y., He, T. B. \& Zhang, F. J. (2011). Coupling of Microphase Separation and Dewetting in Weakly Segregated Diblock Co-polymer Ultrathin Films. Langmuir 27, 11973-11980.

24. Cozzens, D., Luk, A., Ojha, U., Ruths, M. \& Faust, R. (2011). Surface Characterization and Protein Interactions of Segmented Polyisobutylene-Based Thermoplastic Polyurethanes. Langmuir 27, 14160-14168.

25. Meier, R., Ruderer, M. A., Diethert, A., Kaune, G., Körstgens, V., Roth, S. V. \& MüllerBuschbaum, P. (2011). Influence of Film Thickness on the Phase Separation Mechanism in Ultrathin Conducting Polymer Blend Films. The Journal of Physical Chemistry B 115, 2899-2909.

26. Hou, L., Wang, E., Bergqvist, J., Andersson, B. V., Wang, Z., Müller, C., CampoyQuiles, M., Andersson, M. R., Zhang, F. \& Inganäs, O. (2011). Lateral Phase Separation Gradients in Spin-Coated Thin Films of High-Performance Polymer:Fullerene Photovoltaic Blends. Advanced Functional Materials 21, 3169-3175.

27. Peumans, P., Uchida, S. \& Forrest, S. R. (2003). Efficient bulk heterojunction photovoltaic cells using small-molecular-weight organic thin films. Nature 425, 158-162.

28. Klok, H.-A. (2005). Biological-synthetic hybrid block copolymers: Combining the best from two worlds. Journal of Polymer Science Part A: Polymer Chemistry 43, 1-17.

29. Krishnaji, S. T., Huang, W., Rabotyagova, O., Kharlampieva, E., Choi, I., Tsukruk, V. V., Naik, R., Cebe, P. \& Kaplan, D. L. (2011). Thin Film Assembly of Spider Silk-like Block Copolymers. Langmuir 27, 1000-1008. 
30. Rabotyagova, O. S., Cebe, P. \& Kaplan, D. L. (2011). Protein-Based Block Copolymers. Biomacromolecules 12, 269-289.

31. Gauthier, M. A. \& Klok, H.-A. (2008). Peptide/protein-polymer conjugates: synthetic strategies and design concepts. Chemical Communications, 2591-2611.

32. Gazit, E. (2007). Self-assembled peptide nanostructures: the design of molecular building blocks and their technological utilization. Chemical Society Reviews 36, 1263-1269.

33. Nagapudi, K., Brinkman, W. T., Leisen, J., Thomas, B. S., Wright, E. R., Haller, C., Wu, X., Apkarian, R. P., Conticello, V. P. \& Chaikof, E. L. (2004). Protein-Based Thermoplastic Elastomers. Macromolecules 38, 345-354.

34. Shlyk-Kerner, O., Samish, I., Kaftan, D., Holland, N., Maruthi Sai, P. S., Kless, H. \& Scherz, A. (2006). Protein flexibility acclimatizes photosynthetic energy conversion to the ambient temperature. Nature 442, 827-830.

35. Merrifield, R. B. (1963). Solid Phase Peptide Synthesis. I. The Synthesis of a Tetrapeptide. Journal of the American Chemical Society 85, 2149-2154.

36. Goeden-Wood, N. L., Conticello, V. P., Muller, S. J. \& Keasling, J. D. (2002). Improved assembly of multimeric genes for the biosynthetic production of protein polymers. Biomacromolecules 3, 874-879.

37. McMillan, R. A., Lee, T. A. T. \& Conticello, V. P. (1999). Rapid assembly of synthetic genes encoding protein polymers. Macromolecules 32, 3643-3648.

38. Carlsen, A. \& Lecommandoux, S. (2009). Self-assembly of polypeptide-based block copolymer amphiphiles. Current Opinion in Colloid \& Interface Science 14, 329-339.

39. Deming, T. J. (1997). Facile synthesis of block copolypeptides of defined architecture. Nature 390, 386-389.

40. Shibayama, M. \& Osaka, N. (2010). Pressure- and Temperature-Induced Phase Separation Transition in Homopolymer, Block Copolymer, and Protein in Water. Macromolecular Symposia 291-292, 115-121.

41. Klok, H.-A. \& Lecommandoux, S. (2007). Solid-State Structure, Organization and Properties of Peptide-Synthetic Hybrid Block Copolymers. ChemInform 38, no-no.

42. Heredia, K. L. \& Maynard, H. D. (2007). Synthesis of protein-polymer conjugates. Organic \& Biomolecular Chemistry 5, 45-53.

43. Perly, B., Douy, A. \& Gallot, B. (1976). Block Copolymers Polybutadiene-Poly(BenzylL-Glutamate) and Polybutadiene-Poly(N5-Hydroxypropylglutamine) Preparation and Structural Study by X-Ray and Electron Microscopy. Makromolekulare ChemieMacromolecular Chemistry and Physics 177, 2569-2589.

44. Rathore, O. \& Sogah, D. Y. (2001). Nanostructure Formation through $\beta$-Sheet SelfAssembly in Silk-Based Materials. Macromolecules 34, 1477-1486. 
45. Vandermeulen, G. W. M., Kim, K. T., Wang, Z. \& Manners, I. (2006). Metallopolymer-Peptide Conjugates: Synthesis and Self-Assembly of Polyferrocenylsilane Graft and Block Copolymers Containing a $\beta$-Sheet Forming GlyAla-Gly-Ala Tetrapeptide Segment. Biomacromolecules 7, 1005-1010.

46. Wiradharma, N., Tong, Y. W. \& Yang, Y. Y. (2010). Design and Evaluation of Peptide Amphiphiles with Different Hydrophobic Blocks for Simultaneous Delivery of Drugs and Genes. Macromolecular Rapid Communications 31, 1212-1217.

47. Chécot, F., Rodríguez-Hernández, J., Gnanou, Y. \& Lecommandoux, S. (2006).

Responsive micelles and vesicles based on polypeptide diblock copolymers. Polymers for Advanced Technologies 17, 782-785.

48. Rabotyagova, O. S., Cebe, P. \& Kaplan, D. L. (2009). Self-Assembly of Genetically Engineered Spider Silk Block Copolymers. Biomacromolecules 10, 229-236.

49. Niwa, T., Kato, A., Tanaka, M. \& Kinoshita, T. (2007). Formation of MicrophaseSeparated Structure in a Triblock Copolypeptide LB Film. SEN'I GAKKAISHI 63, 49-51.

50. Minich, E. A., Nowak, A. P., Deming, T. J. \& Pochan, D. J. (2004). Rod-rod and rod-coil self-assembly and phase behavior of polypeptide diblock copolymers. Polymer 45, 19511957.

51. Shenhar, R., Norsten, T. B. \& Rotello, V. M. (2005). Polymer-Mediated Nanoparticle Assembly: Structural Control and Applications. Advanced Materials 17, 657-669.

52. Balazs, A. C., Emrick, T. \& Russell, T. P. (2006). Nanoparticle Polymer Composites: Where Two Small Worlds Meet. Science 314, 1107-1110.

53. Rosset, S., Niklaus, M., Dubois, P. \& Shea, H. R. (2009). Metal Ion Implantation for the Fabrication of Stretchable Electrodes on Elastomers. Advanced Functional Materials 19, 470-478.

54. Lee, J. Y., Shou, Z. \& Balazs, A. C. (2003). Modeling the Self-Assembly of CopolymerNanoparticle Mixtures Confined between Solid Surfaces. Physical Review Letters 91, 136103.

55. Lin, Y., Boker, A., He, J., Sill, K., Xiang, H., Abetz, C., Li, X., Wang, J., Emrick, T., Long, S., Wang, Q., Balazs, A. \& Russell, T. P. (2005). Self-directed self-assembly of nanoparticle/copolymer mixtures. Nature 434, 55-59.

56. Kim, B. J., Bang, J., Hawker, C. J. \& Kramer, E. J. (2006). Effect of Areal Chain Density on the Location of Polymer-Modified Gold Nanoparticles in a Block Copolymer Template. Macromolecules 39, 4108-4114.

57. McMillan, R. A., Paavola, C. D., Howard, J., Chan, S. L., Zaluzec, N. J. \& Trent, J. D. (2002). Ordered nanoparticle arrays formed on engineered chaperonin protein templates. Nat Mater 1, 247-252.

58. Shindel, M. M., Mumm, D. R. \& Wang, S.-W. (2010). Biotemplating of Metallic Nanoparticle Arrays Through Site-Specific Electrostatic Adsorption on Streptavidin Crystals. Langmuir 26, 11103-11112. 
59. Cui, Y., Kim, S. N., Jones, S. E., Wissler, L. L., Naik, R. R. \& McAlpine, M. C. (2010). Chemical Functionalization of Graphene Enabled by Phage Displayed Peptides. Nano Letters 10, 4559-4565.

60. Xue, L. \& Han, Y. (2011). Pattern formation by dewetting of polymer thin film. Progress in Polymer Science 36, 269-293.

61. Baba, A. R., Gowda, D. C. \& Sankar, K. U. (2005). Elastic protein-based polymers a step towards plasticity: Thermal stability of Glu-containing co-polypeptides as analyzed by differential scanning calorimetry. International Journal of Peptide Research and Therapeutics 11, 185-193.

62. Farmer, R. S., Argust, L. M., Sharp, J. D. \& Kiick, K. L. (2006). Conformational behavior of alanine-rich helical protein polymers with varied functional group density. Abstracts of Papers of the American Chemical Society 231, 1.

63. Petka, W. A., Harden, J. L., McGrath, K. P., Wirtz, D. \& Tirrell, D. A. (1998). Reversible hydrogels from self-assembling artificial proteins. Science 281, 389-392.

64. Aluru, V. K. (2010). Ferric Iron Nanoparticle Formation Mediated By Negatively Charged Polypeptides. 1490209, West Virginia University.

65. EMD Chemicals Group, N. (2012). pET-19b DNA Vector Map. Merck KGaA, Darmstadt, Germany.

66. Voet, D., Voet, J. G. \& Pratt, C. W. (2008). Fundamentals of Biochemistry. 3rd edit, Wiley \& Sons, Inc.

67. Ausubel, F. M., Brent, R., Kingston, R. E., Moore, D. D., Seidman, J. G., Smith, J. A. \& Struhl, K., Eds. (2002). Short Protocols in Molecular Biology. 5th edit. Vol. 2: John Wiley \& Sons, Inc.

68. Sidhaye, D. S., Bala, T., Srinath, S., Srikanth, H., Poddar, P., Sastry, M. \& Prasad, B. L. V. (2009). Preparation of Nearly Monodisperse Nickel Nanoparticles by a Facile Solution Based Methodology and Their Ordered Assemblies. The Journal of Physical Chemistry C 113, 3426-3429.

69. Kyte, J. \& Doolittle, R. F. (1982). A Simple Method for Displaying the Hydropathic Character of a Protein. Journal of Molecular Biology 157, 105-132.

70. Owen, T., Pynn, R., Martinez, J. S. \& Butler, A. (2005). Micelle-to-Vesicle Transition of an Iron-Chelating Microbial Surfactant, Marinobactin E. Langmuir 21, 12109-12114.

71. Fujishige, S., Kubota, K. \& Ando, I. (1989). Phase transition of aqueous solutions of poly(N-isopropylacrylamide) and poly(N-isopropylmethacrylamide). The Journal of Physical Chemistry 93, 3311-3313.

72. Lu, C., Wei, F., Wu, N., Zhao, X., Luo, C. \& Cao, W. (2004). Micropatterned selfassembled film based on temperature-responsive poly( $\mathrm{N}$-isopropylacrylamide-co-acrylic acid). Journal of Colloid and Interface Science 277, 172-175.

73. Aldrich, S. Poly(acrylic acid) Product Detail. 
74. Sprenger, M., Walheim, S., Budkowski, A. \& Steiner, U. (2003). Hierarchic Structure Formation in Binary and Ternary Polymer Blends. Interface Science 11, 225-235.

75. Dong, R. \& Yu, L. E. (2003). Investigation of Surface Changes of Nanoparticles Using TM-AFM Phase Imaging. Environmental Science \& Technology 37, 2813-2819.

76. Morita, M., Ohmi, T., Hasegawa, E., Kawakami, M. \& Ohwada, M. (1990). Growth of native oxide on a silicon surface. Journal of Applied Physics 68, 1272.

77. Maurer, J. J., Eustace, D. J. \& Ratcliffe, C. T. (1987). THERMAL CHARACTERIZATION OF POLY(ACRYLIC ACID). Macromolecules 20, 196-202.

78. Papalia, J. M. (2007). Self-ordering of spherical nanoparticles in a block copolymer system. 3247683, University of Delaware.

79. Osborne, J. L., Farmer, R. \& Woodhouse, K. A. (2008). Self-assembled elastin-like polypeptide particles. Acta Biomaterialia 4, 49-57.

80. Dash, B. C., Mahor, S., Carroll, O., Mathew, A., Wang, W., Woodhouse, K. A. \& Pandit, A. (2011). Tunable elastin-like polypeptide hollow sphere as a high payload and controlled delivery gene depot. Journal of Controlled Release 152, 382-392.

81. Liao, L., Zhang, C. \& Gong, S. (2007). Synthesis and characterization of amphiphilic polymer networks based on acrylated poly( $\epsilon$-caprolactone) and $\mathrm{N}$-vinylpyrrolidone. Journal of Applied Polymer Science 105, 2712-2716. 


\section{Appendix A: Nucleotide Analysis of the DNA coding for (GAGPGP) 12}
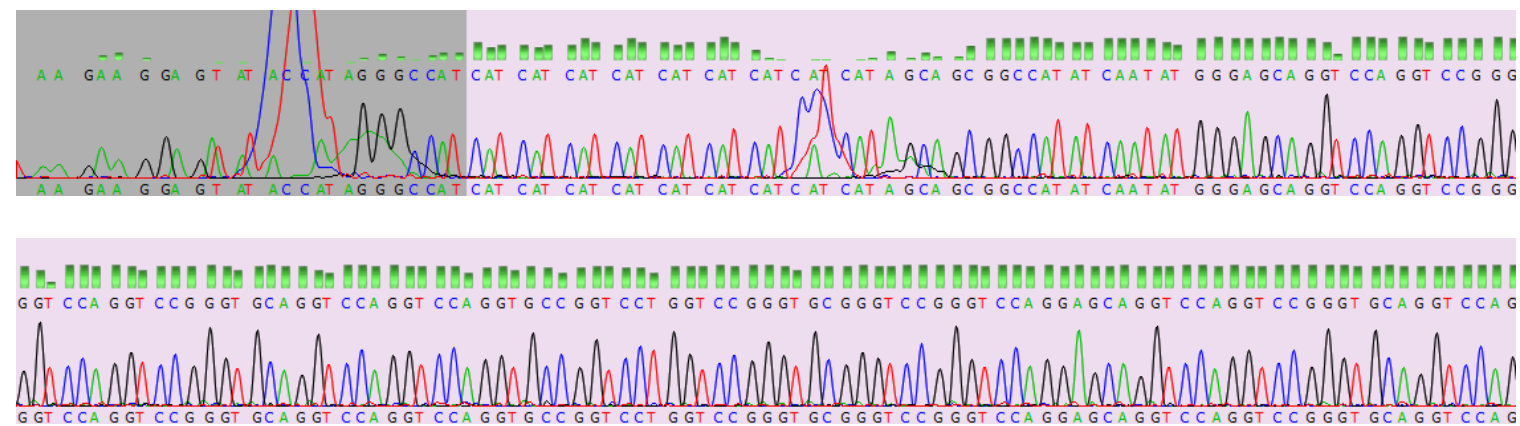

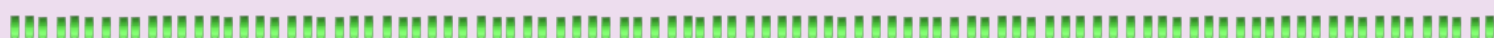

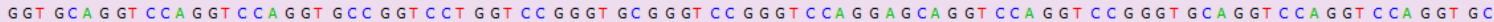
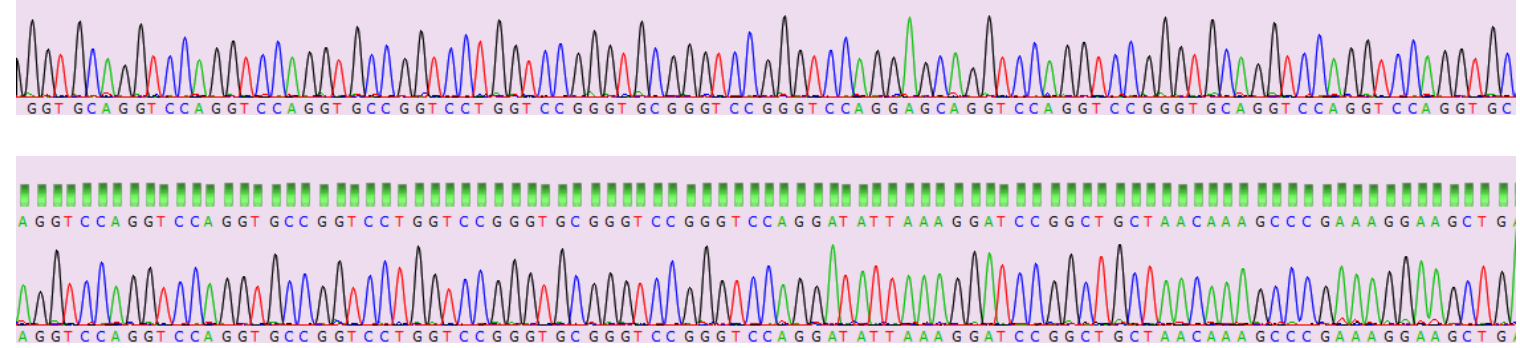

Figure A1 Nucleotide analysis results of the DNA coding for (GAPGPGP) 12 


\section{Appendix B: TEM images of (GAGPGP) 12}
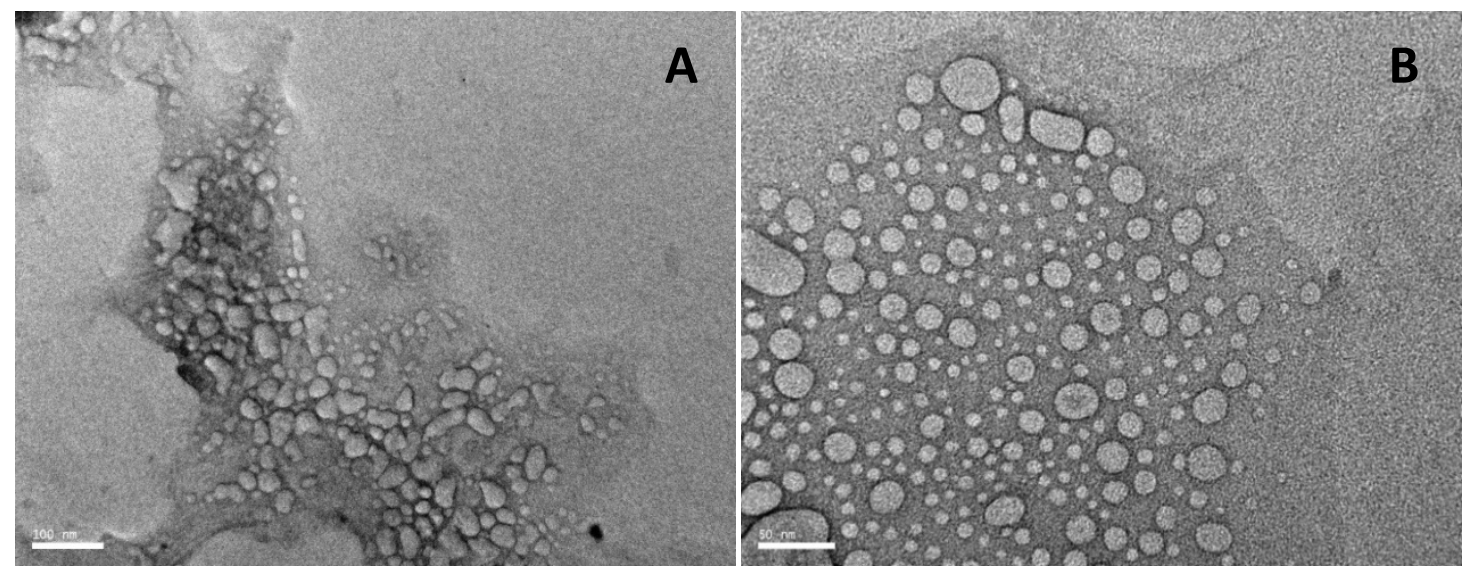

Figure B1 A) TEM micrograph a sample of (GAGPGP) ${ }_{12}$ dried on a carbon TEM grid, and B) a closer TEM image of the (GAGPGP) $)_{12}$ sample 


\section{Appendix C: SEM and AFM Images of PAA Alone on Si}

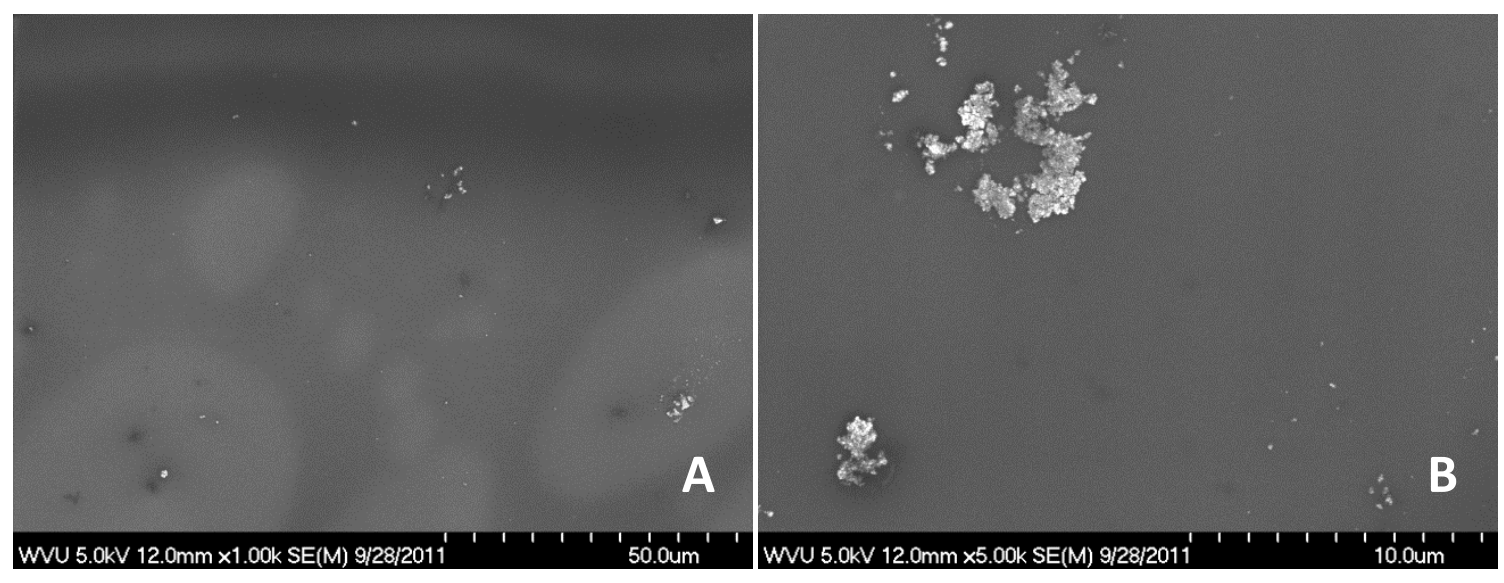

Figure C1 A) An SEM image of PAA dried on Si, and B) a closer image of aggregates observed during SEM analysis of PAA on Si

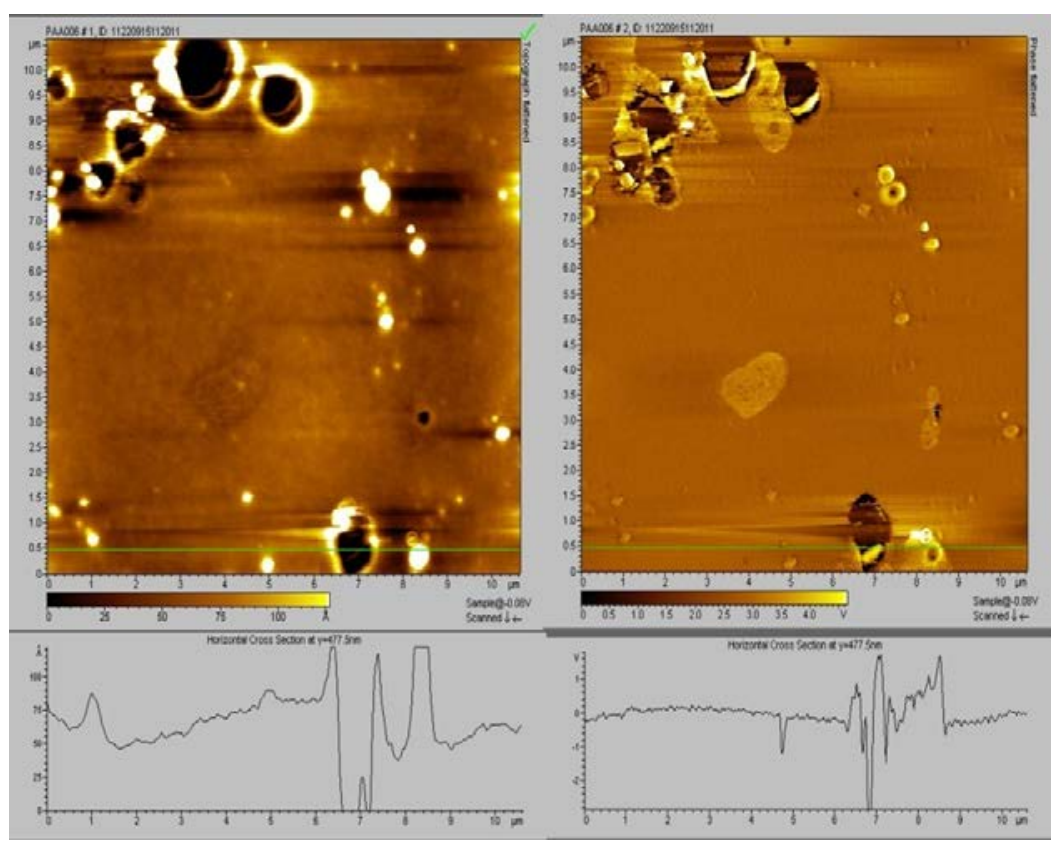

Figure C2 AFM topology (left) and phase (right) image of a film of PAA on Si 


\section{Appendix D: Spin-Coated and $90^{\circ} \mathrm{C}$ Drying Temperature PAA/(GAGPGP $)_{12}$ Blend Samples}

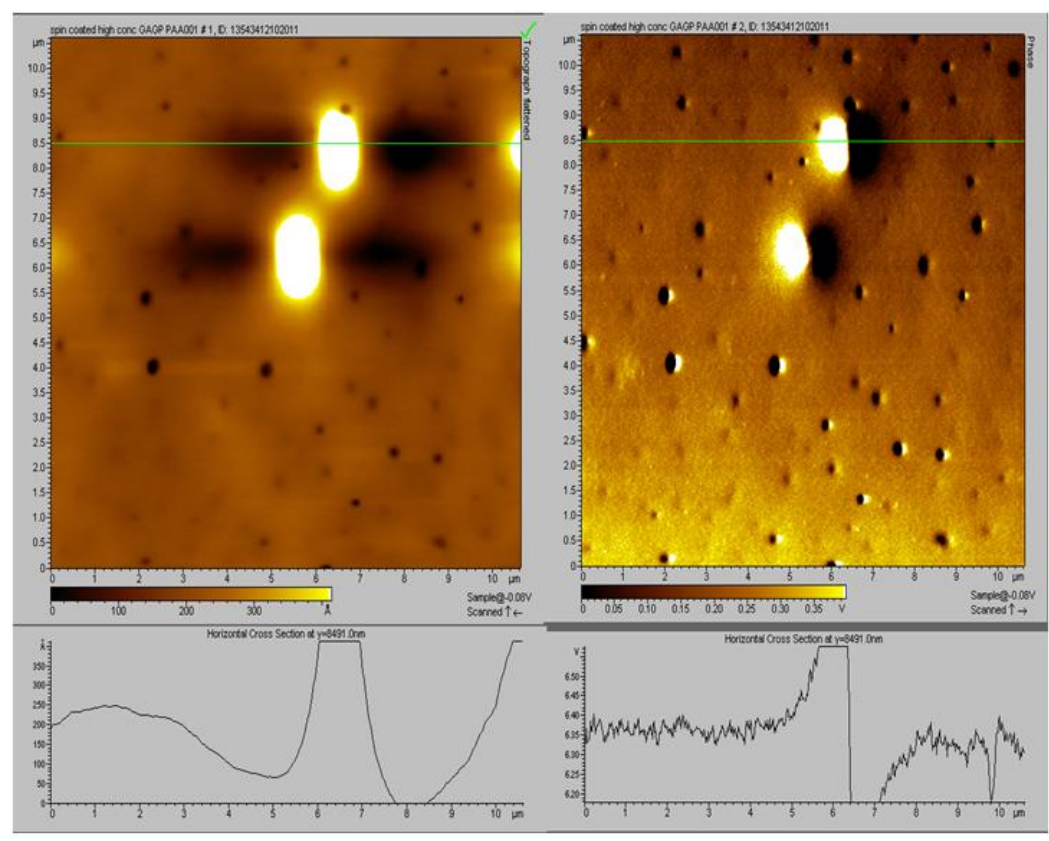

Figure D1. AFM topography (left) and phase (right) image of a $2 \mathrm{mg} / \mathrm{mL}$ sample of a 1:1 wt\% PAA/(GAGPGP) ${ }_{12}$ blend spin-coated onto $\mathrm{Si}$

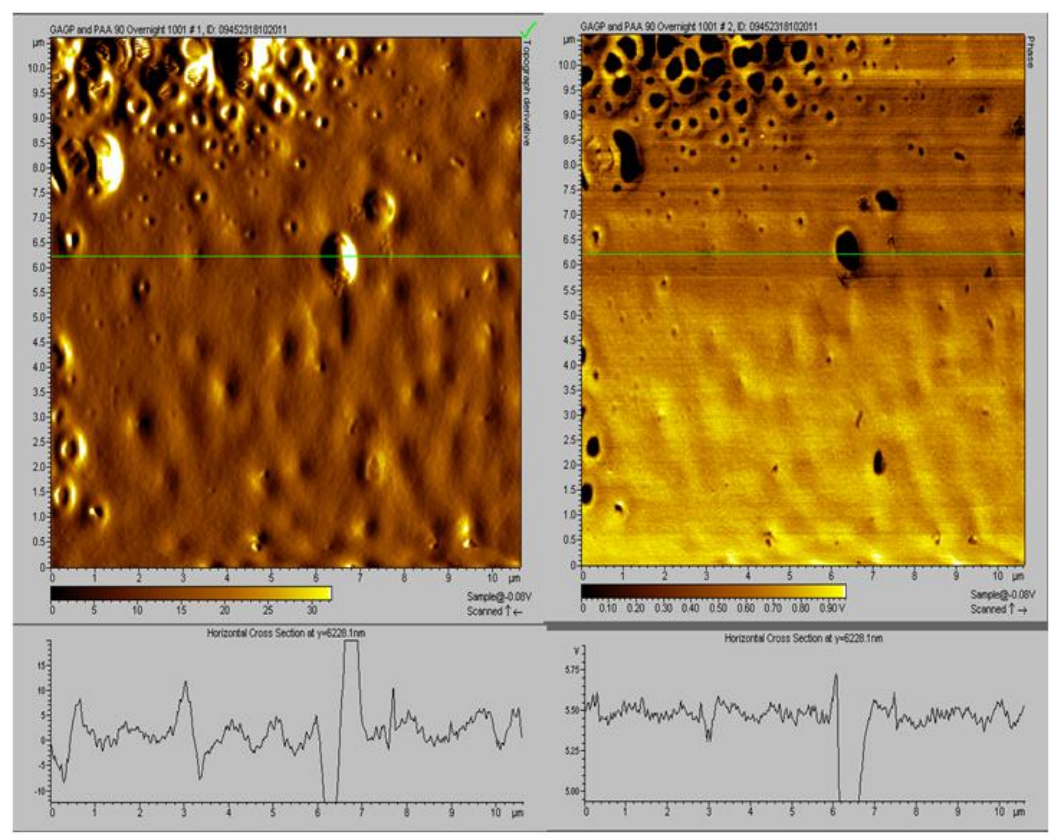

Figure D2 AFM topography (left) and phase (right) analysis of a $2 \mathrm{mg} / \mathrm{mL}$ sample of 1:1 wt\% PAA/(GAGPGP) 12 blend spotted onto $\mathrm{Si}$ and dried at $90^{\circ} \mathrm{C}$ overnight 


\section{Appendix E: AFM analysis of a 9:1 wt\% PAA/(GAGPGP) $)_{12}$ Blend}

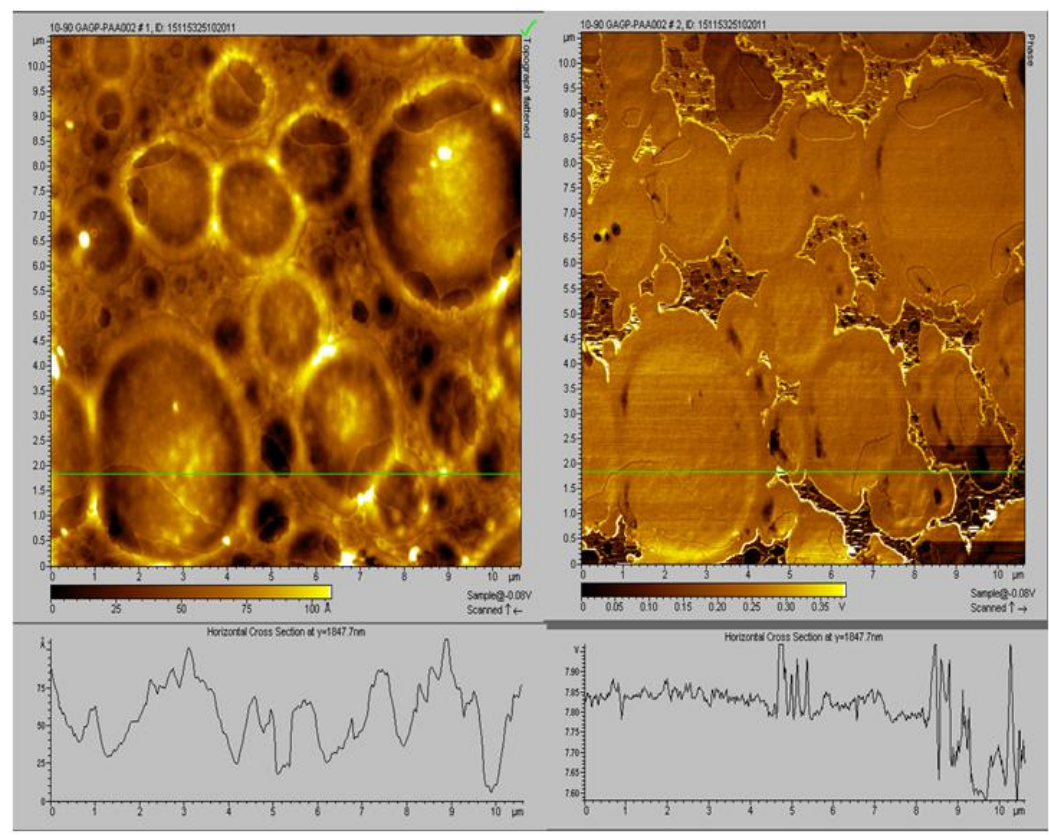

Figure E1 AFM topography (left) and phase (right) image of a 9:1 wt $\%$ PAA/(GAGPGP) ${ }_{12}$ blend sample dried on $\mathrm{Si}$

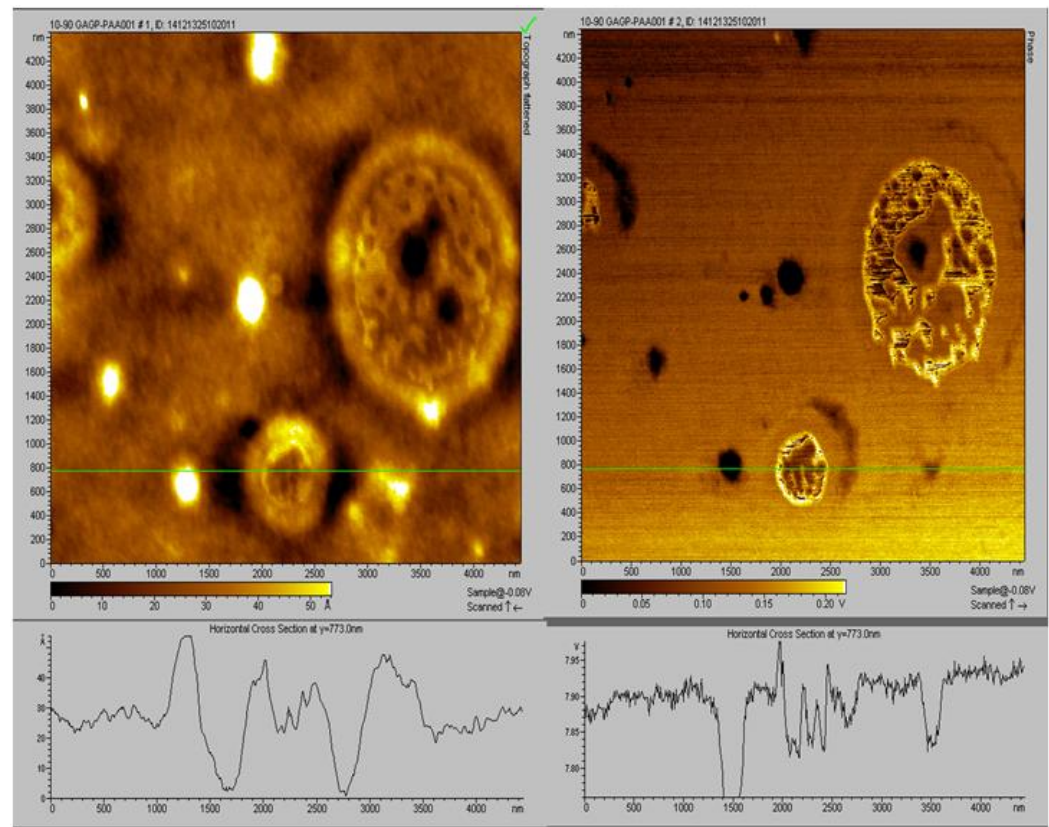

Figure E2 AFM topography (left) and phase (right) image of another section of the 9:1 wt\% PAA/(GAGPGP) ${ }_{12}$ blend sample dried on $\mathrm{Si}$ 


\section{Appendix F: SEM Images of Ni Nanoparticles in (GAGPGP) ${ }_{12}$ Films}

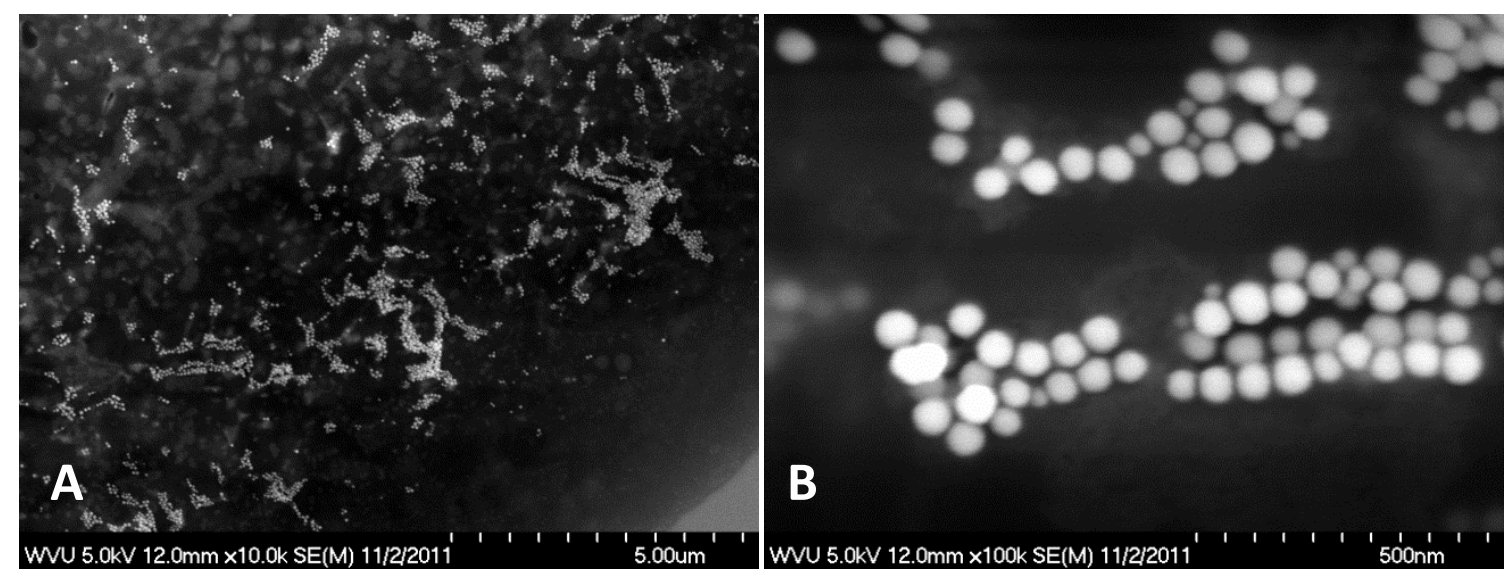

Figure F1 A) An overall SEM image of Ni nanoparticles within a (GAGPGP) ${ }_{12}$ film, and B) and detailed image of the nanoparticles within the a dried (GAGPGP) ${ }_{12}$ film 


\section{Appendix G: SEM Images of ELP Alone on Si}

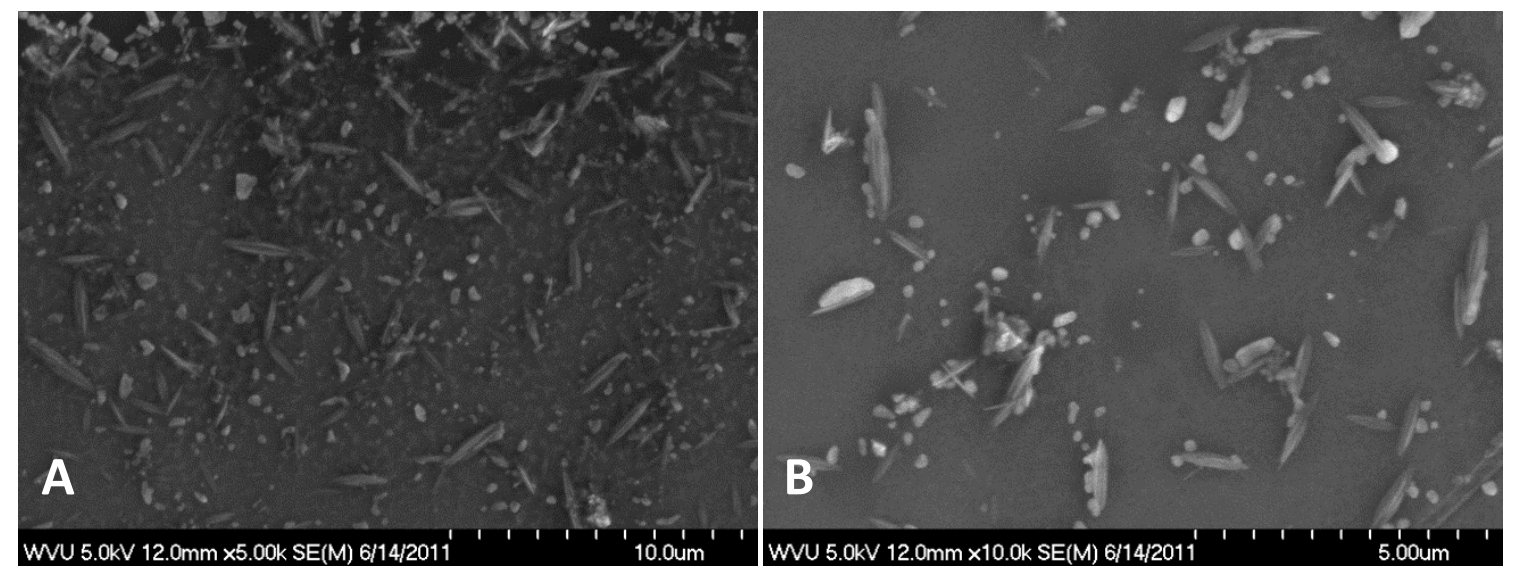

Figure G1 A) An overall SEM image of the ELP aggregates found in a film of ELP on Si, and B) a closer SEM of the ELP aggregates formed after drying ELP on $\mathrm{Si}$ 


\section{Appendix H: Spin-Coated ELP/(GAGPGP) $)_{12}$ Blend on Si}

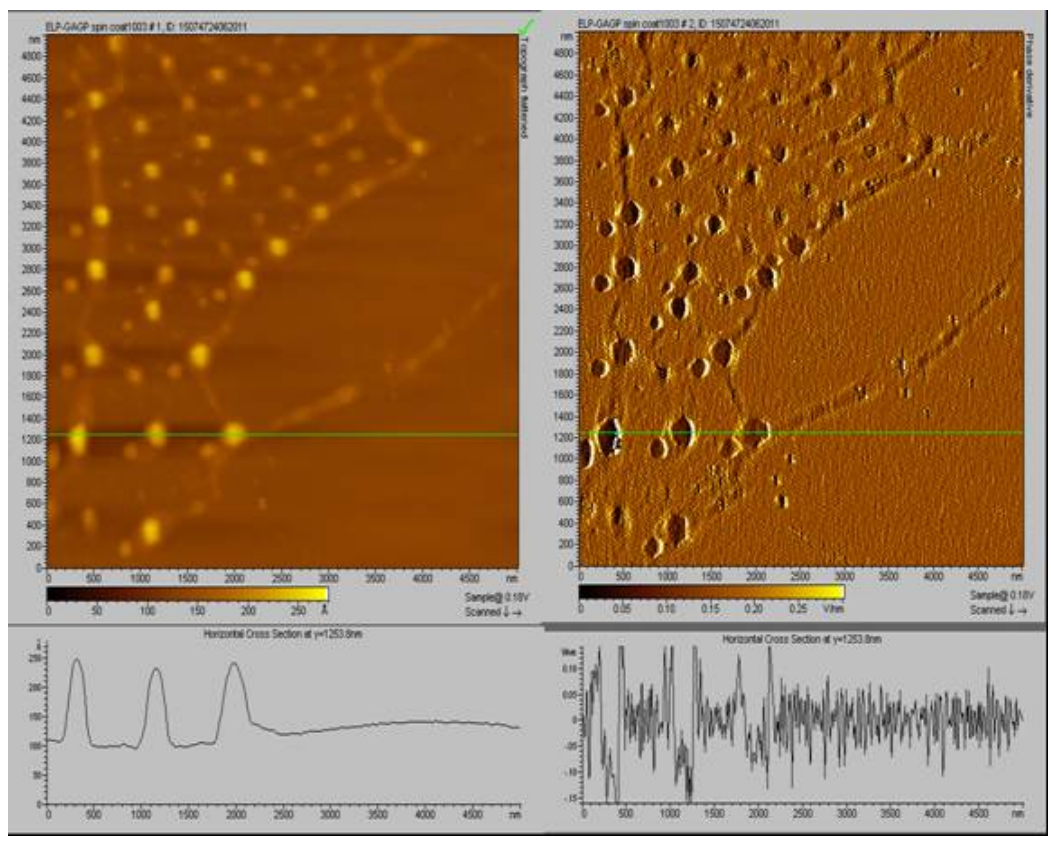

Figure H1. AFM topography (left) and phase (right) analysis of spin-coated ELP/(GAGPGP) ${ }_{12}$ blend film 


\section{Appendix I: ELP/(GAGPGP) $)_{12}$ Blend Dried at $65^{\circ} \mathrm{C}$}

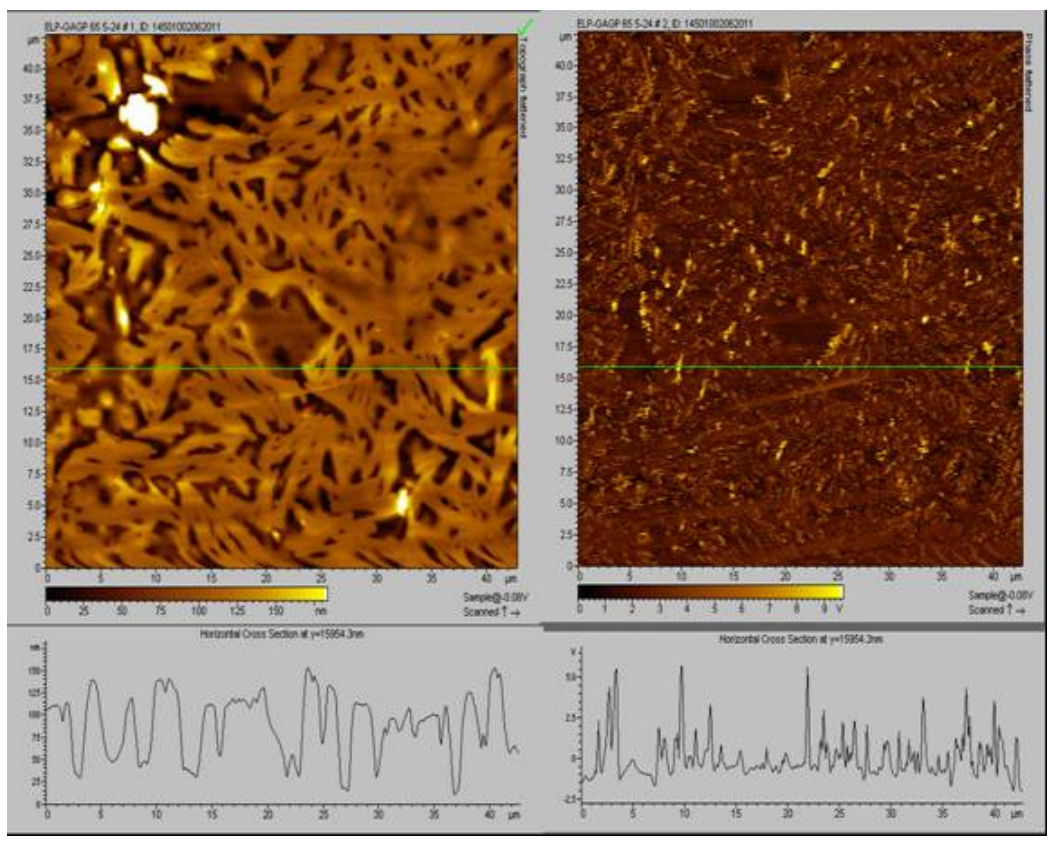

Figure I1. AFM topography (left) and phase (right) image of an ELP/(GAGPGP) ${ }_{12}$ blend dried at $65^{\circ} \mathrm{C}$
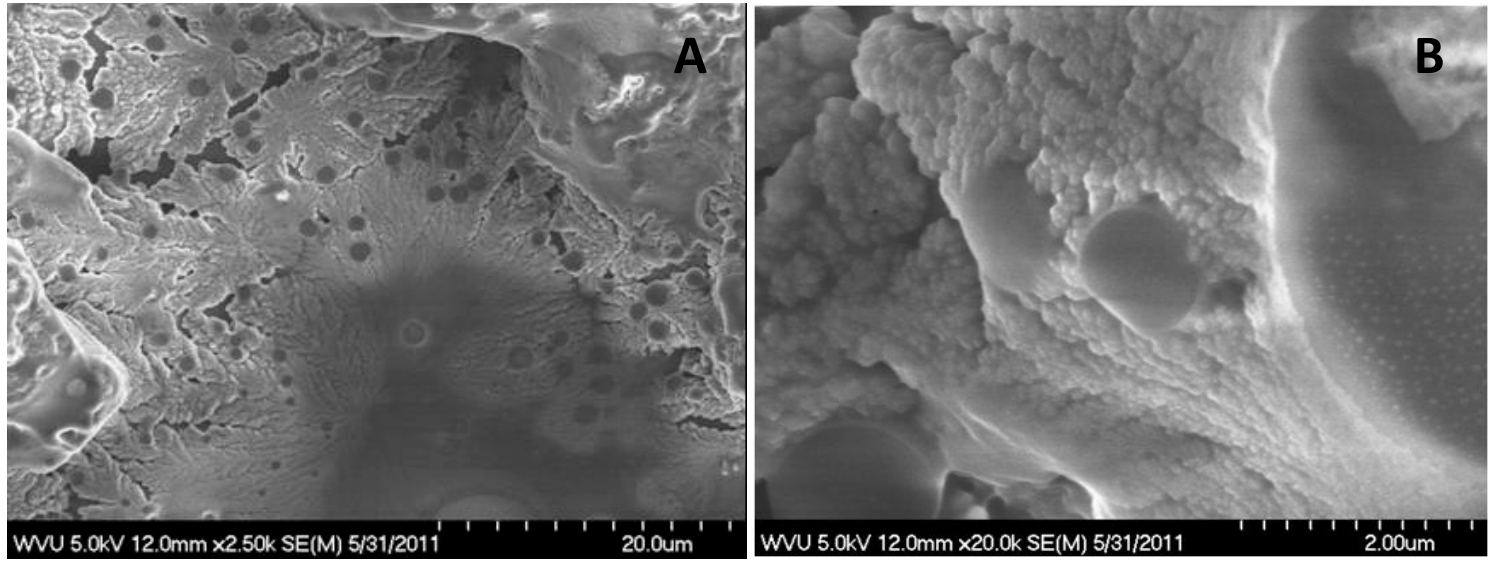

Figure I2. A) Overall SEM image of ELP/(GAGPGP $)_{12}$ blend dried at $65^{\circ} \mathrm{C}$ and B) a more detailed SEM image of the morphology found in ELP/(GAGPGP) $)_{12}$ blend dried at $65^{\circ} \mathrm{C}$ 


\section{Appendix J: Figure Reprint Permission}

\section{THE AMERICAN ASSOCIATION FOR THE ADVANCEMENT OF SCIENCE LICENSE TERMS AND CONDITIONS}

Jan 29, 2012

This is a License Agreement between Jaclyn Kokx ("You") and The American Association for the Advancement of Science ("The American Association for the Advancement of Science") provided by Copyright Clearance Center ("CCC"). The license consists of your order details, the terms and conditions provided by The American Association for the Advancement of Science, and the payment terms and conditions.

\section{All payments must be made in full to CCC. For payment instructions, please see information listed at the bottom of this form.}

License Number: 2838471422268

License date: Jan 29, 2012

Licensed content publisher: The American Association for the Advancement of Science

Licensed content publication: Science

Licensed content title: Polymer-Polymer Phase Behavior

Licensed content author: FRANK S. BATES

Licensed content date: Feb 22, 1991

Volume number: 251

Issue number: 4996

Type of Use: Thesis / Dissertation

Requestor type: Other Individual

Format: Print and electronic

Portion: Figure

Number of figures/tables: 2

Order reference number: Title of your thesis / dissertation

A Phase Separation Study of Biological Polymers in Solid State Films 
Expected completion date: May 2012

Estimated size(pages): 65

Total: 0.00 USD

Terms and Conditions: American Association for the Advancement of Science TERMS AND CONDITIONS

Regarding your request, we are pleased to grant you non-exclusive, non-transferable permission, to republish the AAAS material identified above in your work identified above, subject to the terms and conditions herein. We must be contacted for permission for any uses other than those specifically identified in your request above.

The following credit line must be printed along with the AAAS material: "From [Full Reference Citation]. Reprinted with permission from AAAS."

All required credit lines and notices must be visible any time a user accesses any part of the AAAS material and must appear on any printed copies and authorized user might make.

This permission does not apply to figures / photos / artwork or any other content or materials included in your work that are credited to non-AAAS sources. If the requested material is sourced to or references nonAAAS sources, you must obtain authorization from that source as well before using that material. You agree to hold harmless and indemnify AAAS against any claims arising from your use of any content in your work that is credited to non-AAAS sources.

If the AAAS material covered by this permission was published in Science during the years 1974 - 1994, you must also obtain permission from the author, who may grant or withhold permission, and who may or may not charge a fee if permission is granted. See original article for author's address. This condition does not apply to news articles.

The AAAS material may not be modified or altered except that figures and tables may be modified with permission from the author. Author permission for any such changes must be secured prior to your use.

Whenever possible, we ask that electronic uses of the AAAS material permitted herein include a hyperlink to the original work on AAAS's website (hyperlink may be embedded in the reference citation).

AAAS material reproduced in your work identified herein must not account for more than $30 \%$ of the total contents of that work.

AAAS must publish the full paper prior to use of any text.

AAAS material must not imply any endorsement by the American Association for the Advancement of Science.

This permission is not valid for the use of the AAAS and/or Science logos.

AAAS makes no representations or warranties as to the accuracy of any information contained in the AAAS material covered by this permission, including any warranties of merchantability or fitness for a particular purpose. 
If permission fees for this use are waived, please note that AAAS reserves the right to charge for reproduction of this material in the future.

Permission is not valid unless payment is received within sixty (60) days of the issuance of this permission. If payment is not received within this time period then all rights granted herein shall be revoked and this permission will be considered null and void.

In the event of breach of any of the terms and conditions herein or any of CCC's Billing and Payment terms and conditions, all rights granted herein shall be revoked and this permission will be considered null and void.

AAAS reserves the right to terminate this permission and all rights granted herein at its discretion, for any purpose, at any time. In the event that AAAS elects to terminate this permission, you will have no further right to publish, publicly perform, publicly display, distribute or otherwise use any matter in which the AAAS content had been included, and all fees paid hereunder shall be fully refunded to you. Notification of termination will be sent to the contact information as supplied by you during the request process and termination shall be immediate upon sending the notice. Neither AAAS nor CCC shall be liable for any costs, expenses, or damages you may incur as a result of the termination of this permission, beyond the refund noted above.

This Permission may not be amended except by written document signed by both parties.

The terms above are applicable to all permissions granted for the use of AAAS material. Below you will find additional conditions that apply to your particular type of use.

\section{FOR A THESIS OR DISSERTATION}

If you are using figure(s)/table(s), permission is granted for use in print and electronic versions of your dissertation or thesis. A full text article may be used in print versions only of a dissertation or thesis.

Permission covers the distribution of your dissertation or thesis on demand by ProQuest / UMI, provided the AAAS material covered by this permission remains in situ.

If you are an Original Author on the AAAS article being reproduced, please refer to your License to Publish for rules on reproducing your paper in a dissertation or thesis. 